NBER WORKING PAPER SERIES

\title{
DELAYED CREATIVE DESTRUCTION: HOW UNCERTAINTY SHAPES CORPORATE ASSETS
}

\author{
Murillo Campello \\ Gaurav Kankanhalli \\ Hyunseob Kim \\ Working Paper 28971 \\ http://www.nber.org/papers/w28971 \\ NATIONAL BUREAU OF ECONOMIC RESEARCH \\ 1050 Massachusetts Avenue \\ Cambridge, MA 02138 \\ June 2021
}

We are grateful to Kevin Aretz, Nick Bloom, Alex Fakos, Huseyin Gulen (discussant), Charlie Hadlock, Candace Jens, Andrea Lanteri (discussant), Howard Kung, Roni Michaely, Roberto Pinto (discussant), Frederik Schlingemann as well as conference and seminar participants at the 2020 ASU Sonoran Winter Finance Conference, Auburn University, Baylor University, 2019 Bristol Corporate Finance Conference, Cornell University, Federal Reserve Bank of Chicago, 2020 ITAM Finance Conference, Michigan State University, Seoul National University, University of Illinois at Urbana-Champaign, University of Notre Dame, and 2020 WFA for helpful comments, David Jordan and Darren Liew at Clarksons Research for data support, Byung-Ryul Ahn at Hyundai Samho Heavy Industries for helpful discussions on the shipping industry. This research was funded in part by the Cornell Center for the Social Sciences and Smith Family Business Initiative at Cornell University. Heewon Ahn, Ikchan An, Penghao Chen, Eric Kim, Jason Lee, Phillip Lee, Boyao Li, Youngjun Song, and George Sun provided excellent research assistance. All errors are our own. The views expressed herein are those of the authors and do not necessarily reflect the views of the National Bureau of Economic Research.

NBER working papers are circulated for discussion and comment purposes. They have not been peer-reviewed or been subject to the review by the NBER Board of Directors that accompanies official NBER publications.

(C) 2021 by Murillo Campello, Gaurav Kankanhalli, and Hyunseob Kim. All rights reserved. Short sections of text, not to exceed two paragraphs, may be quoted without explicit permission provided that full credit, including $\odot$ notice, is given to the source. 
Delayed Creative Destruction: How Uncertainty Shapes Corporate Assets

Murillo Campello, Gaurav Kankanhalli, and Hyunseob Kim

NBER Working Paper No. 28971

June 2021

JEL No. D22,D25,G31

\begin{abstract}
$\underline{\text { ABSTRACT }}$
We show how uncertainty shapes the asset allocation, composition, productivity, and value of capital-intensive firms. We do so using detailed, near-universal data on shipping firms' new orders, secondary-market transactions, and demolition of ships. Firms curtail both the acquisition and disposal of vessels in response to heightened uncertainty. The mechanism operates primarily through cuts in new ship orders and demolition of older ships - decisions that are costlier to reverse vis-à-vis deals in the used ship market. These dynamics are more pronounced when secondary ship markets are illiquid, as firms face stronger incentives to delay their decisions. The rise of Somali pirate attacks in 2009-2011 is used as a shock to well-defined shipping sectors to corroborate our findings. Critically, uncertainty prompts firms to concentrate their fleets into narrower, less productive portfolios, leading to value losses. Our work is novel in showing that uncertainty hampers "creative destruction," slowing both the adoption of innovation embodied in new capital and the disposal of old capital.
\end{abstract}

Murillo Campello

Johnson Graduate School of Management Cornell University

114 East Avenue

369 Sage Hall

Ithaca, NY 14853-6201

and NBER

campello@cornell.edu

Gaurav Kankanhalli

Joseph M. Katz Graduate School of Business

University of Pittsburgh

226 Mervis Hall

Pittsburgh, PA 15260

gkankanhalli@katz.pitt.edu
Hyunseob Kim

Cornell University

Johnson Graduate School of Management

325 Sage Hall

114 East Avenue

Ithaca, NY 14853

United States

hk722@ cornell.edu 


\section{Introduction}

Recent macroeconomic models emphasize the role of asset allocation in shaping the effect of uncertainty on aggregate productivity and economic growth (see, e.g., Bloom (2009) and Bloom et al. (2018)). This body of research stresses that investigating the link between uncertainty and firms' capital adjustment decisions at a micro-level is key to identifying the dynamics at work. In a similar fashion, vintage capital models emphasize the importance of firm investment in new, efficient assets in fostering productivity (Solow (1960) and Hsieh (2001)). In this paper, we show how uncertainty affects corporate asset allocation, composition, productivity, and value through the lens of firms' decisions to invest and disinvest. We do so in the context of the shipping industry, which accounts for over $80 \%$ of the global trade volume. In this industry, investment and disinvestment decisions (buying, selling, and demolishing ships) are discrete, well-defined, and fully documented. The industry's singularly most important capital input, the ship vessel, is actively traded in worldwide markets.

Our study uses ship-level data over the 2006-2019 period from Clarksons Research (the "Clarksons data”), a leading maritime research firm. The Clarksons data cover the near-universe of shipping vessels in the global market, encompassing both public and private firms across one hundred countries. The data are unique in allowing us to measure three distinct, but related, concepts: asset allocation, asset composition, and asset productivity. On the dimension of firm-level "asset allocation," the Clarksons data contain detailed information on the four key margins along which shipping firms can alter their asset base; namely, new ship orders, secondary market purchases and sales (including data on resale prices), and demolition (including data on scrap values). Regarding "asset composition," the database records individual ships with identifiers linked to owner firms, allowing us to track the evolution of shipping firms' asset portfolios (fleets) over time. The data also contain measures of "asset productivity," such as ship age, dead-weight tonnage, and engine revolutions per minute. Using the ownership and transactions data, we can measure the liquidity of the secondary market for ships at a detailed level, which we demonstrate is a key factor modulating the effects of uncertainty on firms' asset-level decisions. The database further allows us to infer the specific maritime routes that different ships cover, enabling us to develop well-identified test strategies.

To guide our analysis, we develop a simple real-options framework delineating the link between uncertainty and firms' decisions to alter their asset portfolio through investment in and disinvestment of ships. We do so considering the liquidity of ships in the secondary market. As is standard, the model predicts a negative relation between uncertainty and both investment and disinvestment activities. The model additionally shows that these dynamics are stronger when decisions are costlier to reverse. ${ }^{1}$ In particular, it shows how a liquid secondary market modulates the negative uncertainty-

\footnotetext{
${ }^{1}$ The costly reversibility arises from two primary sources: secondary asset market illiquidity (Gavazza (2011)) and the sunk costs of investing or disinvesting (Hackbarth and Johnson (2015)).
} 
investment (-disinvestment) relation, as liquidity makes it easier for firms to undo their investment (disinvestment) decisions by selling (buying) used ships. Importantly, because new ship orders and demolitions entail high fixed costs, our model predicts that firms will exhibit a more pronounced response to uncertainty along these two decision margins, relative to decisions involving the straight up purchase or sale of ships in secondary markets. ${ }^{2}$ This asset misallocation problem highlighted by our model is new to the literature. It implies that uncertainty hinders "creative destruction:" it retards firms' acquisition of new, technologically-advanced capital and disposal of old, obsolete capital.

We begin our empirical analysis by showing how uncertainty broadly shapes shipping firms' investment (disinvestment) decisions. We first measure investment (disinvestment) using the total number of ships a firm purchases (sells) in the secondary market and orders new (demolishes). Our specifications incorporate forward-looking measures of a shipping firm's expected investment opportunities in each of the subsectors in which it operates using forward freight agreement prices ("first moment"). ${ }^{3}$ We operationalize the concept of business uncertainty faced by a shipping firm ("second moment") using the average equity option-implied volatility of firms in each of the subsectors the firm operates in. Our empirical results show a negative relation between uncertainty and both investment and disinvestment. The economic magnitudes are significant: for the average firm, a one-standard-deviation increase in our measure of subsector uncertainty is associated with a decline in investment rates that is $15 \%$ of the baseline average. ${ }^{4}$ This magnitude is comparable to that of the first moment effect: a one-standard-deviation increase in returns to subsectoral forward freight agreements is associated with an increase in investment of $9 \%$ relative to the baseline.

Critically, we show that asset liquidity plays a central role in modulating the impact of uncertainty on investment. Our estimates imply that when secondary markets are at the $5^{\text {th }}$ percentile of liquidity, investment declines by $97 \%$ of the baseline in response to a one-standard-deviation increase in uncertainty - investment comes to a halt. Conversely, when resale markets are at the $95^{\text {th }}$ percentile of liquidity, uncertainty does not affect investment. Also new to the literature, we show that the negative effect of uncertainty on disinvestment is large: a one-standard-deviation increase in uncertainty is associated with a decline in disinvestment of the order of $36 \%$ of the baseline rate; that magnitude rises to $57 \%$ when asset liquidity is at the $5^{\text {th }}$ percentile.

To shed granular, new light on the role that uncertainty plays in capital allocation, we then decompose investment and disinvestment into new ship orders, used ship purchases, ship demoli-

\footnotetext{
${ }^{2}$ Relative to used ship purchase, new ship orders incur additional fixed costs due to time-to-build, customization, and financing frictions. Demolition incurs several added costs relative to straight sale, including search costs when replacing a demolished ship (the same ship cannot be later reacquired and reintegrated into the fleet) and the value loss through disassembling a ship. Very few components of demolished ships find alternative end-uses (Stopford (2009)).

${ }^{3}$ Derivatives on shipping rate indexes, such as the Baltic Dry Index (BDI), trade on the Baltic Exchange, and we obtain their prices from Bloomberg. Kellogg (2014) uses a similar proxy for expected investment opportunities in the oil industry.

${ }^{4} \mathrm{~A}$ back-of-the-envelope calculation implies that this decline translates into 268 fewer ship purchases (new and used) in aggregate per year $(=15 \% \times 1787$ ships invested in a year), or a $\$ 12$ billion drop in investment measured in dollar terms.
} 
tions, and used ship sales; alternatives that, as we discuss below, entail different sunk costs and thus different degrees of irreversibility. In this analysis, it is particularly important to focus on the dimension of ship age as it serves as a convenient proxy for a wide range of technological advances in the shipping industry. ${ }^{5}$ Consistent with irreversibility being higher for new-vintage capital investments, we find that the negative relation between uncertainty and investment is almost entirely driven by new ship orders. In stark contrast, used ship purchases are largely unaffected by uncertainty. Analogously, among the two margins of disinvestment, the negative effect of uncertainty is driven in large part by ship demolitions, with ship sales playing a marginal role.

We provide more causal evidence for the link between uncertainty and firm investment and disinvestment using a quasi-experimental test design. In particular, we examine shipping firms' responses to a measurable increase in uncertainty caused by the escalation in Somali pirate attacks between 2009 and 2011. As we discuss below, that local piracy activity introduced uncertainty in certain shipping routes by increasing the likelihood of both very negative (being attacked) and very positive (higher profits given reduced competition) outcomes. Our discontinuity-based strategy relies on pre-determined size limitations on vessels that can physically pass through the Suez Canal to identify ships that are likely to be exposed to the heightened risk of Somali pirates and others that are similar in size and type of service (e.g., tankers) but unlikely affected. ${ }^{6}$ In a matched-sample difference-in-differences test, we find that firms significantly reduced both their investment in ships (particularly new orders) and disinvestment of ships (particularly demolitions) belonging to the affected group, relative to the control group, during that period of heightened uncertainty.

We next study the implications of the impact of uncertainty on firms' asset allocation for their productivity. We show that the negative effect of uncertainty on investment is more pronounced for the purchase of high-productivity ships (those that are newer, carry bigger loads, and have more efficient engines). At the same time, firms cut back more on demolishing their less productive ships (older, smaller, with less efficient engines). Our analysis demonstrates that uncertainty adversely affects the overall productivity of shipping firms' asset base by disproportionately reducing investment in new technology and more productive equipment, as well as the disposal of outdated, unproductive assets.

We supplement our base (firm-by-subsector level) analyses with a host of firm-level tests in order to characterize the economic implications of the decisions documented above for firms' asset base composition and value. We first show that firms reduce their exposure across different markets when uncertainty is high: they consolidate their ship holdings into fewer subsectors in response to

\footnotetext{
${ }^{5}$ Regulatory standards in the shipping industry, notably regarding safety, efficiency, and environmental impact, have evolved rapidly in recent years (see Stopford (2009) for a detailed timeline). Accordingly, the technological frontier in the industry has advanced to keep pace with these shifts in standards. New-vintage ships must conform to evolving standards, hence must embody the latest technological innovations.

${ }^{6}$ Evidence of the importance of this route for the global economy as well as its fragility to extraneous factors were made explicit by the large-scale disruption caused by an incident involving a single ship, the Ever Given. See The Wall Street Journal, March 24, 2021, “Suez Canal Is Blocked by Container Ship Causing Huge Traffic Jam."
} 
increased uncertainty; and the average productivity of assets kept in their portfolios is reduced. Finally, we show that increases in uncertainty trigger lower equity valuations for firms operating in less liquid ship resale markets. This reduction in firm value stems from the fact that those firms' capital allocation decisions are most affected by higher uncertainty - they show the greatest reductions in investment (particularly in new and highly-productive assets) and disinvestment (particularly the demolition of least-productive assets) rates. In other words, the capital misallocation problem we identify in this paper has measurable value consequences for firms. Altogether, our results show that high uncertainty, combined with low asset liquidity, has a particularly deleterious effect on the efficiency of firms' asset mix.

Our paper contributes to the literature on the effect of uncertainty on economic activity on several fronts. Despite a growing theoretical literature that emphasizes the importance of capital reallocation in shaping the effect of uncertainty on economic efficiency (Bloom (2009) and Bloom et al. (2018)), existing empirical papers have primarily looked at overall effects of uncertainty on output growth (Baker and Bloom (2013)) and firm investment levels (Julio and Yook (2012), Gulen and Ion (2015), Jens (2017), and Campello et al. (2021)). Relatively little attention has been paid to testing predictions regarding the allocation and composition of capital at a micro (asset) level. This is partly due to the lack of information on asset ownership, transactions, valuation, vintage, and productivity from standard data sources. Our paper is the first to study how uncertainty simultaneously affects a number of connected issues, including firm asset allocation, composition, productivity, and value. We do so along separate, well-identified margins of corporate investment and disinvestment. On this front, our paper's new findings highlight the negative effect of uncertainty on disinvestment, a key aspect of capital allocation and productivity that has been neglected by previous research. We also contribute to research in the area by developing measures of asset liquidity that vary across asset types and over time, contemplating it as a key mechanism underlying the effects we document. ${ }^{7}$

Our paper is also related to the theoretical (e.g., Benhabib and Rustichini (1991) and Hsieh (2001)) and empirical (Benmelech and Bergman (2011) and Ma et al. (2020)) literature on vintage capital. Prior theoretical work posits that investing in new capital while scrapping old one ("creative destruction") leads to higher productivity and economic growth. Our paper is the first to show micro-level evidence that uncertainty adversely affects productivity by hampering the adoption of technological progress embodied in newer-vintage capital. In doing so, we shed light on a novel dimension of uncertainty's deleterious impacts not only on the quantity of investment, but also on the nature of assets firms invest in and dispose of.

The remainder of the paper proceeds as follows. Section 2 presents our conceptual framework and associated testable implications. Section 3 describes our data, variable construction, and empirical testing approach. Section 4 presents the results from our main analysis on the relation

\footnotetext{
${ }^{7}$ Kim and Kung (2017) show additional evidence on liquidity modulating the uncertainty-investment relation.
} 
between uncertainty, asset liquidity, and firms' capital allocation decisions. Section 5 discusses the implications of uncertainty for firm asset productivity. Section 6 presents firm-level analysis of asset composition, while Section 7 considers firm value implications. Section 8 presents a series of robustness checks of our findings. Section 9 concludes.

\section{Conceptual Framework}

We develop a simple theoretical framework to guide our empirical analysis of the impact of uncertainty on the capital allocation decisions of shipping firms. The model is particularly useful for framing our contribution to the literature as it considers the moderating influence of liquidity in the secondary market for ships. In it, we characterize increases in uncertainty using the concept of mean-preserving spread (MPS). ${ }^{8}$

\subsection{Set Up}

\subsubsection{The Firm and the Ship Market}

The firm is endowed with ships $\omega_{\mathbf{t}} \in \mathbb{R}_{+}^{8}$ across eight "subsectors" at time $t$. Subsectors correspond to four size categories of the two largest sectors of the shipping industry: dry bulk carrier ships ("bulkers") and tanker ships ("tankers"). ${ }^{9}$ The representative firm is a price-taker in the market for ships. We begin by characterizing three price processes corresponding to the three sets of capital allocation decisions the firm can take: (1) trade (buy or sell) a used ship in the secondary market, (2) order a new ship in the primary market, and (3) demolish a ship.

\section{Trading Used Ships}

Let $\mathbf{p}_{\mathbf{t}}$ be the vector of the secondary market prices of ships in each subsector, with $\mathbf{p}_{\mathbf{t}}=\left(p_{1 t}, \ldots, p_{8 t}\right)^{\prime}$, where:

$$
p_{i t}=\lambda_{i}\left(N_{i t}\right) \times \text { Seller }_{i t}+\gamma_{i t}^{\alpha_{i}}
$$

$i=1, \ldots, 8$ indexes the shipping subsectors, $N_{i t}$ represents the number of ships in subsector $i$ at time $t$, and $\gamma_{i t}$ captures productivity, or the cash flow generated by a ship in subsector $i$ at time $t$ (defined shortly in Section 2.1.2). The elasticity parameter, $\alpha_{i}$, is positive. The function $\lambda(\cdot)$ is increasing in $N$ and can be interpreted as the probability of successfully finding a trading counterparty. ${ }^{10}$ Seller $_{i t}$ takes the value of $1(-1)$ if the transacting party is a seller (buyer).

\footnotetext{
${ }^{8} \mathrm{An}$ uncertainty-increasing MPS only requires that a zero-mean, non-degenerate random variable is added to the outcome distribution. This approach allows us to derive results that hold with generality, while remaining agnostic about the functional forms governing the distribution and moments of the outcomes (see also Lee and Shin (2000)).

${ }^{9}$ See Section 3.1 for more details on the classification of ships into industry sectors and subsectors.

${ }^{10} \mathrm{We}$ assume that $\lambda(\cdot)$ is differentiable for $N>0$ and $\lambda^{\prime}(\cdot)>0$.
} 


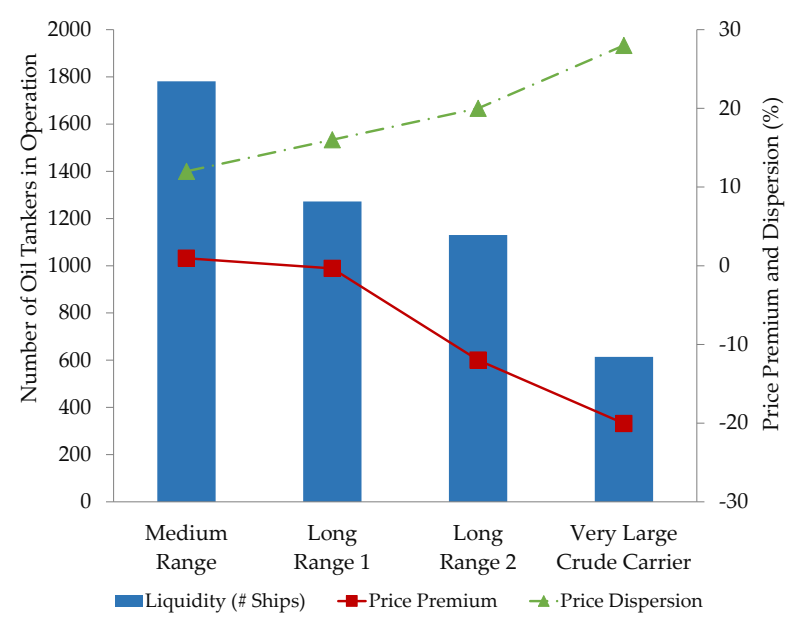

Figure 1. Asset Liquidity, Resale Price Premium, and Price Dispersion. This figure shows the average liquidity of secondary ship market, measured by the number of ships in each subsector of Oil Tankers (blue vertical bars, primary Y-axis), average percentage resale price premium (red connected squares, secondary Y-axis), and resale price dispersion (green connected triangles, secondary Y-axis). Resale price dispersion is defined as the mean absolute deviation of resale prices divided by the mean resale price.

The intuition for modeling the price is straightforward and found in prior literature (see, e.g., Gavazza (2011)). As $N$ increases, the ship's secondary market price increases from a seller's perspective (decreases from a buyer's perspective) due to improvement in liquidity driven by reduced search costs, holding $\gamma$ constant. The use of $N$, or the stock of ships, as a measure of secondary market liquidity is motivated by the idea that search frictions between buyers and sellers are smaller in "thicker" (more populated) asset resale markets. Likewise, holding liquidity $N$ constant, higher productivity $\gamma$ is associated with higher resale prices. A plausible micro-foundation for Eq. (1) is that the "premium" charged by a market maker (e.g., a ship broker) is proportional to the likelihood of finding a match between a potential buyer and seller in a given time window, assuming buyer and seller arrivals are driven by a Poisson process whose arrival rate increases with $N$. The pricing equation thus captures both the "fundamental" value of the ship and a "liquidity" premium associated with the ease with which the transacting party successfully finds a potential counterparty.

In Figure 1 we provide evidence supporting our choice of $N$ as a proxy for liquidity in Eq. (1) using data on the resale market for tankers. The figure shows a positive cross-sectional association between the number of ships $N$ (blue vertical bars) and resale price premium (red solid line), defined as the difference between the resale and purchase prices of a ship, divided by the purchase price. This positive relation is consistent with our model in that the theoretical counterpart to the resale price premium from a seller's perspective, $(p-q) / q$, is increasing in $N$ due to reduced search costs. ${ }^{11}$ Figure 1 also reveals a negative association between $N$ and the dispersion of resale prices

\footnotetext{
${ }^{11}$ From a buyer's perspective, high $N$ reduces the price paid by reducing search costs, such as the time to find a seller. In the above expression, $q$ is the new ship purchase price, which we define next in Eq. (2).
} 


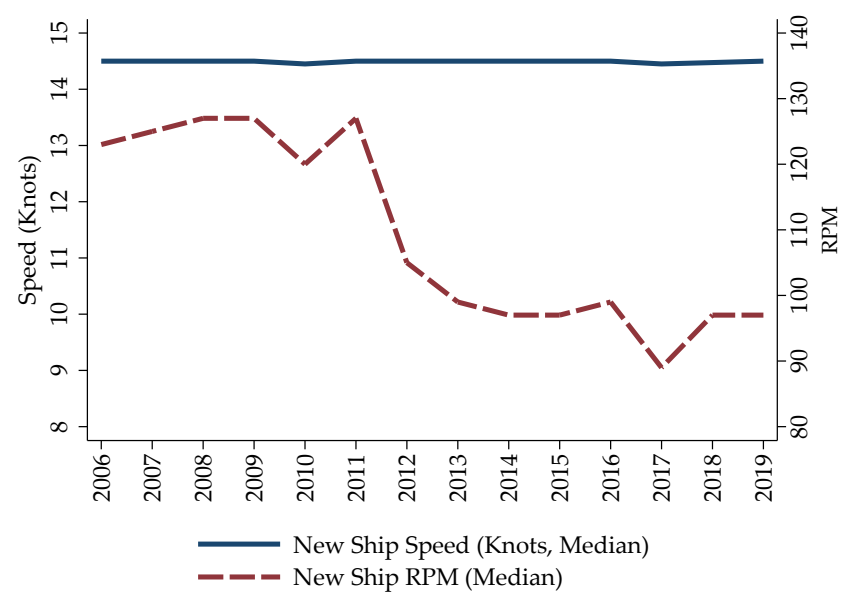

Figure 2. Speed and RPM of New Ships. This figure shows the median speed (in knots, primary Y-axis) and engine revolutions per minute (secondary Y-axis) for new ships ordered in each year in our sample period.

(green dashed line), implying that improved liquidity that arises from lower search costs reduces variability in resale prices (see also Gavazza (2011)).

\section{Ordering New Ships}

If the firm orders a new ship, the primary market price is denoted by $\mathbf{q}_{\mathbf{t}}=\left(q_{1 t}, \ldots, q_{8 t}\right)^{\prime}$, where:

$$
q_{i t}=F+\tilde{\gamma}_{i t}^{\alpha_{i}}
$$

The price at which a firm may order a new ship differs from the price at which it buys a ship in the secondary market along three dimensions. ${ }^{12}$ First, the new ship order price may be independent of $N$, the stock of existing ships. Second, the firm incurs fixed costs, $F>0$, when ordering a new ship. The fixed costs arise from time-to-build (often up to three years), customization, and financing frictions, among others. ${ }^{13}$ Third, new ships are likely more productive than ships purchased in the secondary market (i.e., $\widetilde{\gamma}_{i t}=\widetilde{\delta}_{i} \gamma_{i t}, \widetilde{\delta}_{i} \geq 1$ ). Our model allows the price of a new ship to be higher or lower than the price of a used ship according to the relative magnitudes of fixed costs $(F)$, secondary market liquidity $(N)$, and productivity differential $(\widetilde{\delta})$.

We utilize our data to show evidence of the notion that newly ordered ships embody significant technological advances in Figure 2. The figure shows that while the speed of new ships ordered in each year has remained constant between 2006 and 2019, the engine RPM has declined by over $20 \%$ over the same period. Our data encapsulate information about the ongoing trend towards more

\footnotetext{
${ }^{12}$ Our modeling of the new ship price assumes a competitive shipbuilding sector (i.e., aggregate supply is elastic). Naturally, this assumption may not hold in some subsectors due to capacity adjustment costs at shipyards.

${ }^{13}$ See Chapter 15 of Stopford (2009) for discussion on the fixed costs associated with ordering new ships, as well as demolishing existing ships. Rampini (2019) provides theoretical and empirical support for financing frictions affecting the decision to purchase new (relative to used) durable assets. When uncertainty is high, the fixed costs of new orders may be higher because high uncertainty leads shipyards to delay capacity expansion, increasing time-to-build.
} 
fuel-efficient - thus, more productive - engines, a key technological development in the field of maritime engineering. ${ }^{14}$

\section{Demolishing Ships}

The final course of action the firm can implement is to demolish a ship in its fleet, receiving the scrap value in return. Scrap values are given by $\mathbf{r}_{\mathbf{t}}=\left(r_{1 t}, \ldots, r_{8 t}\right)^{\prime}$, where:

$$
r_{i t}=G+\widehat{\gamma}_{i t}^{\alpha_{i}} .
$$

The scrap value a firm receives when demolishing a ship differs from the price at which it sells a ship in the secondary market along three dimensions. First, the demolition value is independent of $N$, but instead determined by supply and demand in the broader scrap metal market (which encompasses assets other than ships). ${ }^{15}$ Second, the firm incurs fixed costs $G<0$ when demolishing a ship. The fixed costs arise from environmental costs and legal exposures, as well as the loss in value from disassembling a ship into its raw materials. ${ }^{16}$ Third, demolished ships are likely less productive than ships sold in the secondary market (i.e., $\widehat{\gamma}_{i t}=\widehat{\delta}_{i} \gamma_{i t}, \widehat{\delta}_{i} \leq 1$ ). The scrap value of a used ship may be higher or lower than the secondary market price of a comparable used ship depending on the relative magnitudes of associated fixed costs $(G)$, secondary market liquidity $(N)$, and productivity differential $(\widehat{\delta})$.

\subsubsection{The Firm Investment Problem}

The firm operates for three periods, $t=0,1$, and 2. The cash flow from each ship at each time $t$ is given by $\pi_{\mathbf{t}} \circ \omega_{\mathbf{t}}$, where $\pi_{i t}=\gamma_{i} V_{t}+\epsilon_{i t}$. The source of sectoral uncertainty is represented by $V_{t}$, whose distribution can be characterized as an MPS with degree $x$; i.e., $V_{t} \sim H(\cdot, x)$. Thus, the total cash flow of the firm is $\pi_{\mathbf{t}} \cdot \omega_{\mathbf{t}}$. The firm's endowment vector, $\omega_{\mathbf{t}}$, evolves over time. At $t=2$, its endowment is $\omega_{2}=\omega_{1}+\mathbf{i}_{1}-\mathbf{d}_{1}$, where $\mathbf{i}_{1}=\mathbf{n}_{1}+\mathbf{u}_{1}$ is the vector of new and used ships purchased (investment), and $\mathbf{d}_{\mathbf{1}}=\mathbf{s}_{\mathbf{1}}+\mathbf{d e}_{\mathbf{1}}$ is the vector of ships sold and demolished (disinvestment) at $t=1$. The firm's investment set is limited at $\mathbf{I}=\mathbf{N}+\mathbf{U}$. Its disinvestment set is naturally limited by its endowment of ships. ${ }^{17}$

The firm makes investment and disinvestment decisions as follows. If the firm makes no new investment at $t-1$, then its income is $\pi_{\mathbf{t}} \cdot \omega_{\mathbf{t}}$ in $t$. If it invests, then its income is $-\mathbf{n}_{\mathbf{t}-1} \cdot \mathbf{q}_{\mathbf{t}}-\mathbf{u}_{\mathbf{t}-1} \cdot \mathbf{p}_{\mathbf{t}}+\pi_{\mathbf{t}} \cdot\left(\omega_{\mathbf{t}}+\right.$ $\mathbf{i}_{\mathbf{t}-\mathbf{1}}$. The first term, $-\mathbf{n}_{\mathbf{t}-\mathbf{1}} \cdot \mathbf{q}_{\mathbf{t}}$, is the cost of the new ships it orders, while the second term, $-\mathbf{u}_{\mathbf{t}-\mathbf{1}} \cdot \mathbf{p}_{\mathbf{t}}$, is

\footnotetext{
${ }^{14}$ Other examples of recent productivity-enhancing technological advances include the adoption of Exhaust Gas Cleaning Systems (known as scrubbers), engines compatible with alternative fuels, battery technology, lighter materials, and geo-tracking and navigational technology. See Wang and Lutsey (2013) and Bouman et al. (2017) for more details.

${ }^{15}$ The aggregate rate of ship demolitions in our sample displays a high, statistically significant correlation of 0.8 with the global price of scrap steel.

${ }^{16}$ Stopford (2009) describes the significant environmental and regulatory costs associated with shipbreaking.

${ }^{17}$ We assume an arbitrary $\omega_{\mathbf{0}}$. The constraint on the investment set implies that $\mathbf{i}_{\mathbf{0}}+\mathbf{i}_{\mathbf{1}} \leq \mathbf{I}, \mathbf{n}_{\mathbf{0}}+\mathbf{n}_{\mathbf{1}} \leq \mathbf{N}$, and $\mathbf{u}_{\mathbf{0}}+\mathbf{u}_{\mathbf{1}} \leq \mathbf{U}$.
} 
the cost of the used ships it purchases in secondary markets. The third term, $\pi_{\mathbf{t}} \cdot\left(\omega_{\mathbf{t}}+\mathbf{i}_{\mathbf{t}-1}\right)$, is the operating cash flow the firm earns from its stock of ships, consisting of existing and newly invested ones.

If the firm disinvests in $t-1$, then its income is $\mathbf{s}_{\mathbf{t}-1} \cdot \mathbf{p}_{\mathbf{t}}+\mathbf{d e}_{\mathbf{t}-1} \cdot \mathbf{r}_{\mathbf{t}}+\pi_{\mathbf{t}} \cdot\left(\omega_{\mathbf{t}}-\mathbf{d}_{\mathbf{t}-1}\right)$ at $\mathrm{t}$. The first term, $\mathbf{s}_{\mathbf{t}-\mathbf{1}} \cdot \mathbf{p}_{\mathbf{t}}$, is the amount the firm receives from selling its ships in the secondary market. The second term, $\mathbf{d e}_{\mathbf{t}-1} \cdot \mathbf{r}_{\mathbf{t}}$, is the amount it receives from demolishing its ships. The third term, $\pi_{\mathbf{t}} \cdot\left(\omega_{\mathbf{t}}-\mathbf{d}_{\mathbf{t}-1}\right)$, is the cash flow the firm earns from its stock of ships, consisting of existing ships minus disinvested ones.

\subsection{Analysis}

We first analyze the firm's investment problem building on standard real-options arguments relating uncertainty and investment. We do so in order to frame the economic environment in which we advance our new results. The firm chooses its investment levels $\mathbf{i}_{\mathbf{0}}$ (invest now) and $\mathbf{i}_{\mathbf{1}}$ (invest later) based on Eq. (4). It prefers to invest now if the expected cash flow from doing so exceeds the expected cash flow from waiting to invest later, contingent on demand conditions evolving favorably. We state this condition via the following inequality:

$$
\underbrace{\mathbb{E}\left[\pi_{1}+\pi_{2}\right] \cdot \mathbf{i}_{0}-\mathbf{n}_{0} \cdot \mathbf{q}_{1}-\mathbf{u}_{0} \cdot \mathbf{p}_{1}}_{\text {Invest Now }} \geq \underbrace{\mathbb{E}\left[\max \left(\pi_{2} \cdot \mathbf{i}_{1}-\mathbf{n}_{1} \cdot \mathbf{q}_{2}-\mathbf{u}_{1} \cdot \mathbf{p}_{2}, 0\right)\right]}_{\text {Invest Later }} .
$$

The breakeven levels of investment, $\mathbf{i}_{\mathbf{0}}^{*}=\mathbf{n}_{\mathbf{0}}^{*}+\mathbf{u}_{\mathbf{0}}^{*}$ and $\mathbf{i}_{\mathbf{1}}^{*}=\mathbf{n}_{\mathbf{1}}^{*}+\mathbf{u}_{\mathbf{1}}^{*}$, are such that:

$$
\mathbb{E}\left[\pi_{1}+\pi_{2}\right] \cdot \mathbf{i}_{0}^{*}-\mathbf{n}_{0}^{*} \cdot \mathbf{q}_{1}-\mathbf{u}_{0}^{*} \cdot \mathbf{p}_{1}=\mathbb{E}\left[\max \left(\pi_{2} \cdot \mathbf{i}_{1}^{*}-\mathbf{n}_{1}^{*} \cdot \mathbf{q}_{2}-\mathbf{u}_{1}^{*} \cdot \mathbf{p}_{2}, 0\right)\right] .
$$

We first establish the existence of $\mathbf{i}_{0}^{*}$ and $\mathbf{i}_{1}^{*}$ in Lemma 1 . All proofs are in Appendix A.

Lemma 1. The optimal investment levels $\mathbf{i}_{0}^{*}$ and $\mathbf{i}_{1}^{*}$ are given by Eq. (5).

Analogously, the firm chooses its disinvestment levels $\mathbf{d}_{\mathbf{0}}$ (disinvest now) and $\mathbf{d}_{\mathbf{1}}$ (disinvest later) based on Eq. (6). It prefers to disinvest now if the expected cash flow from doing so exceeds the expected cash flow from disinvesting later only upon observing that demand conditions have evolved unfavorably. Formally:

$$
\underbrace{\mathbb{E}\left[-\pi_{1}-\pi_{2}\right] \cdot \mathbf{d}_{\mathbf{0}}+\mathbf{s}_{\mathbf{0}} \cdot \mathbf{p}_{\mathbf{1}}+\mathbf{d e}_{\mathbf{0}} \cdot \mathbf{r}_{1}}_{\text {Disinvest Now }} \geq \underbrace{\mathbb{E}\left[\max \left(-\pi_{2} \cdot \mathbf{d}_{1}+\mathbf{s}_{1} \cdot \mathbf{p}_{2}+\mathbf{d e}_{1} \cdot \mathbf{r}_{2}, 0\right)\right]}_{\text {Disinvest Later }} .
$$

The breakeven levels of disinvestment, $\mathbf{d}_{\mathbf{0}}^{*}=\mathbf{s}_{\mathbf{0}}^{*}+\mathbf{d} \mathbf{e}_{\mathbf{0}}^{*}$ and $\mathbf{d}_{\mathbf{1}}^{*}=\mathbf{s}_{\mathbf{1}}^{*}+\mathbf{d} \mathbf{e}_{\mathbf{1}}^{*}$, are such that:

$$
\mathbb{E}\left[-\pi_{1}-\pi_{2}\right] \cdot \mathbf{d}_{\mathbf{0}}^{*}+\mathbf{s}_{\mathbf{0}}^{*} \cdot \mathbf{p}_{\mathbf{1}}+\mathbf{d e}_{\mathbf{0}}^{*} \cdot \mathbf{r}_{\mathbf{1}}=\mathbb{E}\left[\max \left(-\pi_{2} \cdot \mathbf{d}_{1}^{*}+\mathbf{s}_{\mathbf{1}}^{*} \cdot \mathbf{p}_{2}+\mathbf{d e}_{\mathbf{1}}^{*} \cdot \mathbf{r}_{2}, 0\right)\right] .
$$

As with the case of investment, the existence of $\mathbf{d}_{\mathbf{0}}^{*}$ and $\mathbf{d}_{1}^{*}$ is established in Lemma 2.

Lemma 2. The optimal disinvestment levels $\mathbf{d}_{0}^{*}$ and $\mathbf{d}_{1}^{*}$ are given by Eq. (7). 
Explicitly writing the breakeven conditions in terms of $V_{t}$, and therefore, as a function of $x$ (the mean-preserving spread parameter), we can show that $D_{x} \mathbf{i}_{\mathbf{0}}^{*}<0$ and $D_{x} \mathbf{d}_{\mathbf{0}}^{*}<0$.

Proposition 1. Increased uncertainty leads to less investment and disinvestment. For $x^{\prime}>x$, namely when $H\left(., x^{\prime}\right)$ is obtained by a mean-preserving spread of $H(., x), \mathbf{i}_{\mathbf{0}}^{*}\left(x^{\prime}\right)<\mathbf{i}_{\mathbf{0}}^{*}(x)$ and $\mathbf{d}_{\mathbf{0}}^{*}\left(x^{\prime}\right)<\mathbf{d}_{\mathbf{0}}^{*}(x)$.

The economic intuition for Proposition 1 relies on the optionality inherent to the firm's investment and disinvestment decisions when they are costly to reverse. The option to delay investment (disinvestment) represents a call (put) option from the firm's perspective. In the case of investment, by waiting the firm can invest only if it observes that the cash flow from operating the ships it intends to purchase exceeds the price it must pay for them. By investing now, the firm foregoes this option. Likewise, in the case of disinvestment, by waiting the firm can disinvest only if it observes that the proceeds from disinvesting exceed the cash flows from continuing to operate these ships. By disinvesting now, the firm foregoes this option. The value of this call (put) option to "wait-and-see" increases in uncertainty. We next characterize the effect of uncertainty on various margins of the investment and disinvestment action space.

Proposition 2. The negative effect of uncertainty on investment is more pronounced for purchases of new ships relative to used ships, and the effect of uncertainty on disinvestment is more pronounced for demolition of ships than for ship sales; namely, $D_{x} \mathbf{n}_{\mathbf{0}}^{*}<D_{x} \mathbf{u}_{\mathbf{0}}^{*}$ and $D_{x} \mathbf{d e}_{\mathbf{0}}^{*}<D_{x} \mathbf{s}_{\mathbf{0}}^{*}$.

The option value of investment (disinvestment) decisions arises from the fact that these decisions are partially irreversible. Accordingly, the effect of uncertainty on investment in new ships and demolition is stronger than that on the purchase and sale of used ships, due to the additional fixed costs involved (represented by $F$ and $G$ ). Next, we show the moderating role of asset liquidity on the effects of uncertainty.

Proposition 3. The effect of uncertainty on investment and disinvestment is mitigated in more liquid markets (higher N); namely, $D_{x N} \mathbf{i}_{\mathbf{0}}^{*}>0$ and $D_{x_{N}} \mathbf{d}_{\mathbf{0}}^{*}>0$.

The intuition behind this result is that investment and disinvestment decisions are easier to reverse in more liquid secondary markets. The probability of successfully finding a trading counterparty is higher in more liquid markets. Accordingly, the option to "wait-and-see" is less valuable in more liquid markets, as investment (disinvestment) decisions taken now are less costly to reverse in the future, should shipping demand be lower (higher) than expected.

\subsection{Testable Implications}

Our model implies that there is a negative relation between uncertainty and both firm investment and disinvestment. We will take this more standard prediction to the data noting that the existing 
empirical literature has not investigated the impact of uncertainty on disinvestment, nor on capital composition - decisions that are critical for the replacement of outdated assets by assets that embed new technology. We state our first testable prediction.

Prediction 1. Shipping firms will reduce their investment and disinvestment in response to increases in uncertainty.

Our model also implies that because fixed costs are higher for new ship purchases and ship demolitions (relative to used ship purchases and sales), the negative effects of uncertainty should be more pronounced along these action margins. This leads to our second prediction, which is novel to the literature in illuminating the link between uncertainty and various dimensions of investment and disinvestment.

Prediction 2. Shipping firms will reduce their irreversible investment and disinvestment (new ship purchases and ship demolition) more than they will reduce their reversible investment and disinvestment (used ship purchases and sales) in response to increases in uncertainty.

Our analysis further implies that the negative relationship between uncertainty and investment and disinvestment is modulated by asset liquidity, as the incentive to "wait-and-see" before investing and disinvesting is reduced in thicker secondary asset markets. We state our third prediction.

Prediction 3. Shipping firms will reduce their investment and disinvestment in response to increases in uncertainty by a larger degree when the secondary ship market liquidity is lower.

Finally, because investing in more productive assets or disinvesting less productive assets is associated with a greater degree of irreversibility, our model implies that the effects of uncertainty increases will differ along the lines of asset productivity. This leads to our fourth prediction.

Prediction 4. Shipping firms will reduce their investment (disinvestment) in more (less) productive ships by a larger degree in response to increases in uncertainty.

We set out to test each of these empirical predictions in the remainder of our paper.

\section{Data and Empirical Methodology}

\subsection{Ship-Level Data}

We obtain near-universal data on shipping firms' ownership and transactions of ships over the 2006-2019 period from Clarksons Research. We use four databases compiled by Clarksons. The first 
is a panel dataset on ship ownership. This dataset allows us to observe characteristics of each ship, including unique ship identifiers (e.g., the International Maritime Organization, or IMO, number), the date the ship was built, the identity and country of its builder, its dead-weight tonnage (DWT), ${ }^{18}$ and engine characteristics such as speed (nautical miles per hour) and revolutions per minute (RPM). The dataset also contains point-in-time information on the identity of a ship's owning firm, allowing us to construct a firm-quarter panel of ship holdings. The Clarksons dataset covers 3,966 unique firms, both public and private, domiciled in 109 countries..$^{19}$ These firms own, on average, 7 ships in a given quarter, which are worth $\$ 412$ million (in average purchase price terms). The average aggregate value of the ship holdings across our sample firms in a given year is $\$ 378$ billion.

The second dataset provides information on new vessel orders and allows us to observe firms' investment in new ships. The third dataset contains records on secondary market ship transactions; i.e., purchases and sales of used ships. We observe the transaction date, ship identifiers, resale price, and buyer and seller identities, and calculate firms' investment in used ships and disinvestment of existing ships through sales. The final dataset contains information on ship demolition activity, including the demolition date, ship identifiers, owner identity, and scrap value.

Following the industry standard, we classify ships into two sectors, dry bulkers and tankers, and eight size-based subsectors (four within each sector). ${ }^{20}$ The four subsectors within dry bulkers are: Handysize (DWT less than 40,000), Handymax (DWT 40,000-60,000), Panamax (DWT 60,000110,000), and Capesize (DWT exceeding 110,000). The four subsectors within tankers are: Medium Range (DWT less than 45,000), Long Range 1 (DWT 45,000-80,000), Long Range 2 (DWT 80,000160,000), and Very Large Crude Carriers (or VLCC, DWT exceeding 160,000). Ships within each of these eight subsectors are operated for highly specialized purposes and routes due to physical size limitations and economic viability. Dry bulker ships, by design, hold dry cargo such as iron ore, coal, other minerals and grains. Tankers, on the other hand, hold liquid cargo, primarily crude oil and its refined derivatives. These sectors further divide into subsectors as ships of different sizes operate different routes and carry different subsets of dry or wet cargo. For instance, within tankers, the largest ships (VLCC) tend to exclusively carry crude oil, whereas the smaller ships carry a wider variety of refined products (e.g., propane, automobile fuel, and jet fuel). In addition, ships are limited in the routes they can navigate due to their size. For example, Panamax ships are so named because they are the largest bulkers that are able to traverse the Panama Canal. Capesize ships must navigate around the Cape of Good Hope as they are too large to transit through the Suez or Panama Canals. As a result, markets for shipping services and used ships are segmented between

\footnotetext{
${ }^{18} \mathrm{~A}$ ship's DWT specifies how much weight the ship can carry, including primarily cargo, but also fuel, crew, passengers, food, and water. DWT is expressed in long tons and is customarily used in the industry to define ship size.

${ }^{19}$ Ship-owning firms consist of primarily shipping firms - more than $93 \%$ of owning firms for whom we observe the SIC codes operate in SIC codes 44 (water transportation) or 47 (transportation services).

${ }^{20} \mathrm{We}$ omit containers from our analysis due to the high rate of chartering, as opposed to ownership, prevalent in that sector. Our study focuses on firms' owned ships and fleets, and we are unable to observe leasing or chartering activity.
} 


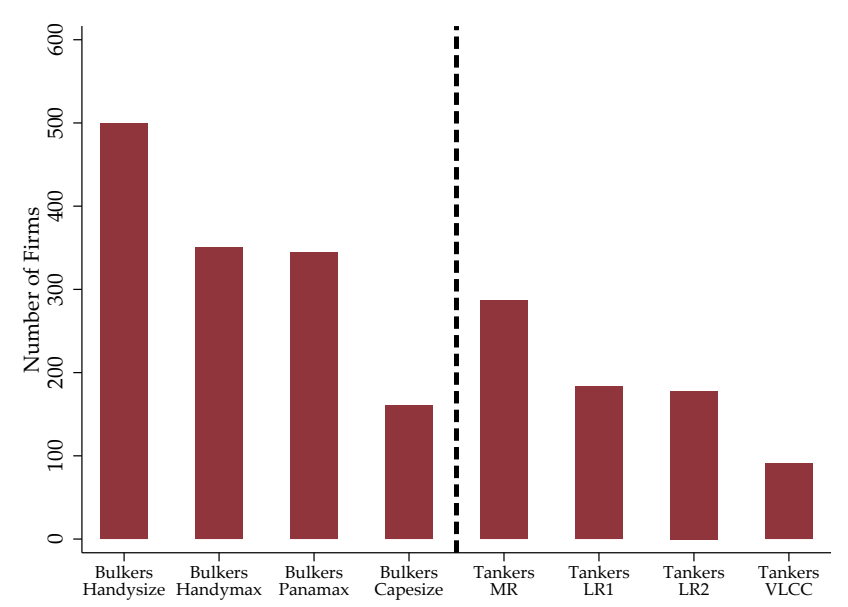

(A) Number of Firms per Subsector

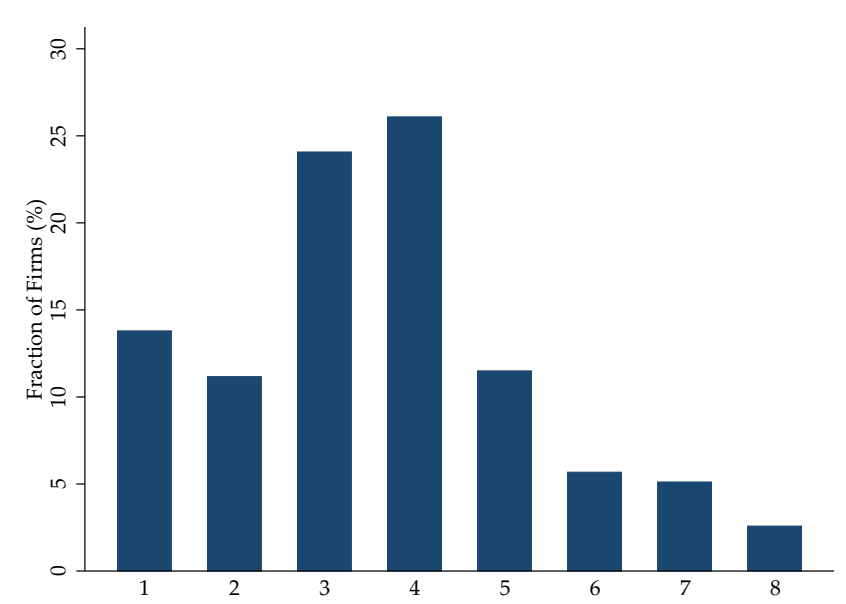

(B) Number of Subsectors per Firm

Figure 3. Shipping Firms' Operating Activities by Subsector. Panel A plots the number of firms operating ships in each of the 8 subsectors we analyze. Panel B plots the share of firms operating ships in one or more subsectors.

these subsectors. We define the unit of our analysis at the firm-subsector-quarter level. Our final panel of ship holdings consists of approximately 100,000 observations.

The aforementioned features of the shipping market lead to segmentation in the types of ships a firm operates. We show this by plotting our sample firms' ship ownership by subsector in Figure 3 . Panel A plots the number of firms operating in each subsector, with subsectors within the bulker or tanker sectors shown in ascending order of ship size. The panel indicates that there are a relatively large number of firms that operate smaller ships. Panel B plots the distribution of firms by the number of subsectors in which they operate ships. The vast majority of firms operate ships in one to four subsectors. Most shipping firms operate ships within just the bulker or tanker sector. Twenty four percent of firms operate ships across both of those two sectors.

\subsection{Variable Construction and Measurement}

\subsubsection{Ship Investment and Disinvestment}

We construct three measures of investment at the firm-subsector-quarter level. First, we compute the new ship investment rate as the number of new ships a given firm orders in a given subsector in a given quarter, scaled by the number of ships the firm owns in that same subsector in the previous quarter. ${ }^{21}$ We calculate the used ship investment rate in a similar fashion, by summing the number of used ships a given firm-subsector-quarter purchases in the secondary market, scaled by the

\footnotetext{
${ }^{21}$ Consider an example of the large shipping firm A.P. Moller - Maersk, which owned 13 Long Range 2 (LR2) tanker ships in the second quarter of 2006, and purchased two new LR2 tankers in the third quarter of 2006. The new ship investment rate for Maersk in the third quarter of 2006 for LR2 tankers was $15.4 \%(=2 / 13)$.
} 
number of ships the firm-subsector owns in the previous quarter. We calculate the total investment rate as the sum of the new and used ship investment rates in a given firm-subsector-quarter.

We construct measures of firm disinvestment in an analogous fashion. The first is the demolition rate, defined as the number of existing ships a given firm-subsector-quarter demolishes, scaled by the number of ships the firm-subsector owns in the previous quarter. Firms can also disinvest a ship through sales in the secondary market. We calculate the used ship sale rate as the number of existing ships a given firm-subsector-quarter sells, scaled by the number of ships the firm-subsector owns in the previous quarter. We calculate the total disinvestment rate as the sum of the demolition and used ship sale rates in a given firm-subsector-quarter. ${ }^{22}$

\subsubsection{Uncertainty in the Shipping Industry}

We construct an ex-ante measure of uncertainty in shipping, which we denote Uncertainty, at the subsector-quarter level. We do so using implied volatilities from publicly-traded options for shipping firms' stocks taken from OptionMetrics. Uncertainty is the quarterly average implied equity volatility from nearest-to-money American call options expiring at the end of the next quarter. The average is taken across all firms operating in a given subsector, weighted by the number of ships each firm operates in the subsector. ${ }^{23}$ In robustness tests, we employ the realized volatility of the subsectoral forward freight agreement price changes as an alternate proxy for uncertainty in the shipping sector, which we label Volatility $(\Delta$ Subsectoral BDI). We replicate our baseline results under various alternative option maturities in Appendix D.

\subsubsection{Secondary Ship Market Liquidity}

We construct three measures of liquidity in the secondary ship market capturing search frictions. The first (\# Ships) is the log total stock of ships in each subsector-quarter. This proxy, motivated by our model and Gavazza (2011), captures the thickness of the used ship market. The second measure (\# Firms) is the log total number of firms in each subsector-quarter. It captures the number of potential buyers in the secondary market (as in Benmelech (2009)). The third measure (\# Transactions) is the number of secondary market transactions completed in a given subsector-quarter divided by the lagged stock of ships in that subsector-quarter. This last measure captures ex post liquidity in the used ship market (see also Schlingemann et al. (2002)).

\footnotetext{
${ }^{22}$ In robustness checks, we construct similar investment and disinvestment measures by summing the dead-weight tonnage, instead of the number of ships, at the firm-subsector-quarter level (see Table 13). Our results are independent of our choice of the scaling factor used in constructing these measures.

${ }^{23}$ We also consider an alternative weighting that decomposes each firm's implied volatility across subsectors based on the share of its fleet belonging to the respective subsectors (see Appendix C).
} 


\subsubsection{Control Variables}

We control for a number of variables that are likely to influence shipping firms' demand for capital. First, we proxy for the expected shipping demand using a forward-looking measure of shipping rates at the subsector level. Specifically, $\triangle$ Subsectoral BDI is the quarterly return on the shipping rate indices derived from forward freight agreement prices for commonly-served routes in a given subsector. ${ }^{24}$ We obtain the forward rates quoted on the Baltic Exchange from Bloomberg. Second, Cash Flow is the quarterly income before extraordinary items plus depreciation and amortization divided by lagged total assets, averaged across all firms operating in a given subsector, weighted by the number of ships they operate in the subsector. To construct this variable, we manually match firms in the Clarksons data to public and private firms in Compustat and Orbis. We also construct controls for lagged fleet characteristics at the firm-subsector-quarter level. Specifically, we calculate the average log of age, DWT, and RPM, across all ships that a firm holds in a given subsector-quarter.

\subsubsection{Frictions in Secondary Ship Markets and Irreversibility}

We compute two measures of investment irreversibility to gauge how search frictions in the resale market for ships (captured by our liquidity measures) affect transaction prices (see also Gavazza (2011)). Using the notion that the degree of capital irreversibility is reflected in the difference between the purchase and resale prices of capital (cf. Arrow (1968)), we compute Price Premium as the resale price minus the purchase price divided by the purchase price. In addition, we compute Price Dispersion as the quarterly mean absolute deviation of resale prices divided by the mean resale price of all transactions in a given subsector.

We validate our secondary ship market liquidity metrics by verifying that they are negatively associated with the above irreversibility measures. Doing so is important for two reasons. First, building on the conceptual link between trading frictions and investment irreversibility, our analysis uses asset market liquidity as a proxy for irreversibility. Second, our model implies that the incentive to "wait-and-see" before investing or disinvesting under uncertainty is heightened when these decisions are costlier to reverse. For this validation analysis, we regress each of our two irreversibility measures, Price Premium and Price Dispersion, on each of our three liquidity measures, \# Ships, \# Firms, and \# Transactions, with a number of added controls. The results, reported in Appendix E. In each run, we find evidence consistent with the argument that investment and disinvestment decisions are indeed less costly to reverse when secondary markets are more liquid.

\footnotetext{
${ }^{24}$ Forward freight agreements (FFA) are derivatives that allow to lock in a price for a given freight shipping route at some future date. The Baltic Dry Index (BDI) is an example of a shipping index constructed from FFA prices that is widely used as a proxy for business prospects in the shipping industry.
} 


\subsection{Descriptive Statistics}

Table 1 presents descriptive statistics for our investment and disinvestment measures as well as other variables described above. The average total quarterly investment rate for our sample of shipping firms is around 1.4\%, whether calculated using number of ships acquired or their DWT. New ship orders account for approximately $82 \%$ of the average firm's total investment, used ship purchases account for the rest. Unlike standard data sources, our data also provide information on disinvestment. Firms in our sample have average quarterly total disinvestment rates of 1.3\%. About $51 \%$ of disinvestment occurs through ship sales in the secondary market, the rest is via demolition. Translating these rates into numbers of ships per firm-year implies that the average firm invests in 5.5 ships per year, out of which new ship orders account for 4.5. The average firm disinvests around 5.1 ships a year, out of which 2.5 ships are demolished. The annualized implied equity volatility, our base measure of uncertainty in a subsector, has a mean of $9 \%$ and standard deviation of $2.9 \%$.

\section{TABLE 1 ABOUT HERE.}

\subsection{Empirical Specification}

We use a model that relates firms' capital allocation decisions with uncertainty and asset liquidity to test the predictions outlined in Section 2.3. We do so controlling for other drivers of firm investment and disinvestment, including proxies for expected shipping demand and cash flows. Our base specification takes the form:

$$
\begin{aligned}
Y_{i, j, t}= & \beta_{1} \text { Uncertainty }_{j, t}+\beta_{2} \text { Liquidity }_{j, t}+\beta_{3} \text { Uncertainty }_{j, t} \times \text { Liquidity }_{j, t} \\
& +\theta \text { Controls }_{i, j, t}+F E s+\epsilon_{i, j, t}
\end{aligned}
$$

where $Y_{i, j, t}$ refers to the investment and disinvestment measures described in Section 3.2.1 for firm $i$, in subsector $j$, and year-quarter $t$. Uncertainty ${ }_{j, t}$ is subsectoral uncertainty measured by average implied equity volatility, and Liquidity $_{j, t}$ is one of the three subsectoral ship market liquidity measures (\# Ships, \# Firms, and \# Transactions). The vector Controls $_{i, j, t}$ contains proxies for the first moment of investment opportunities, $\Delta$ Subsectoral BDI and Cash Flow at the subsectorquarter level, as well as lagged fleet characteristics, including the average log age, log DWT, and log RPM in the firm-subsector-quarter. We estimate several variants of Eq. (8) controlling for unobservables at multiple levels by including fixed effects for: firm, subsector, (headquarter) country, year-quarter, country $\times$ year-quarter, and firm $\times$ subsector. Standard errors are double-clustered at the firm-subsector and year-quarter levels. ${ }^{25}$

\footnotetext{
${ }^{25}$ Our results are robust to clustering at the firm and year-quarter, as well as subsector and year-quarter levels.
} 


\section{Uncertainty, Investment, and Disinvestment}

\subsection{Total Investment, New Ship Orders, and Used Ship Purchase}

We estimate Eq. (8) first using total investment and then its disaggregated components (new ship orders and used ship purchases) as dependent variables. Table 2 reports the results.

\section{$\overline{\text { TABLE } 2 \text { ABOUT HERE. }}$}

In column (1) we estimate a standard investment equation. Expectedly, investment in ships is positively associated with $\Delta$ Subsectoral BDI and Cash Flow. However, only the former variable is statistically significant, suggesting that the industry-specific, forward-looking measure of shipping rates better captures first-moment expectations for shipping firms' investment opportunities. Importantly, this specification includes the subsector-level uncertainty measure, Uncertainty. In line with our model (Prediction 1), the coefficient estimate on Uncertainty shows that ship investment is negatively related to uncertainty in a given industry subsector. The estimates reported allow us to compare the effects of first- and second-moment expectations on investment. A one-standarddeviation increase in $\Delta$ Subsectoral BDI (0.249) is associated with a 0.12 -percentage-point increase in total investment rates $(0.249 \times 0.494=0.123)$, which represents $9 \%$ of the mean quarterly investment rate. By comparison, a one-standard-deviation increase in Uncertainty (2.893) is associated with a 0.20 -percentage-point decrease in total investment rates $(2.893 \times-0.069=-0.200)$, or $15 \%$ of the baseline investment rate. In economic terms, these estimates imply that a one-standard-deviation increase in uncertainty is associated with 0.83 fewer ships invested per year for the average firm. ${ }^{26}$

In column (2) we estimate the full specification in Eq. (8), including both Uncertainty and Liquidity, and their interaction. ${ }^{27}$ Using the number of ships in a subsector as a proxy for liquidity, we find that the negative relation between uncertainty and investment is significantly mitigated by secondary market liquidity. To gauge the economic magnitude of the modulating effect of liquidity, we calculate the marginal effects of uncertainty on investment at the $5^{\text {th }}$ and $95^{\text {th }}$ percentiles of resale market liquidity. When liquidity measured by the number of ships is at its $5^{\text {th }}$ percentile, a one-standard-deviation increase in Uncertainty decreases investment by up to $97 \%$ relative to baseline rates, or 5.3 fewer ships invested per year. At the other end of the spectrum, when asset liquidity is at its $95^{\text {th }}$ percentile, a one-standard-deviation increase in Uncertainty has a close to zero effect

\footnotetext{
${ }^{26}$ This economic magnitude is calculated by annualizing the mean quarterly investment rate per subsector and translating it across all subsectors, then multiplying it by the average number of ships owned by a firm across all subsectors. This calculation gives the average investment per firm-year of 5.5 ships. A 15\% decline in the number of ships invested, thus, amounts to 0.83 fewer ships invested.

${ }^{27}$ We note that the differences in magnitudes between the coefficients on Uncertainty in columns (1) and (2) is due to the addition of the interactive Liquidity term in column (2), which has a mean value of 7.5 (see Table 1), and whose effect on the dependent variable is inversely correlated with the main Uncertainty effect.
} 


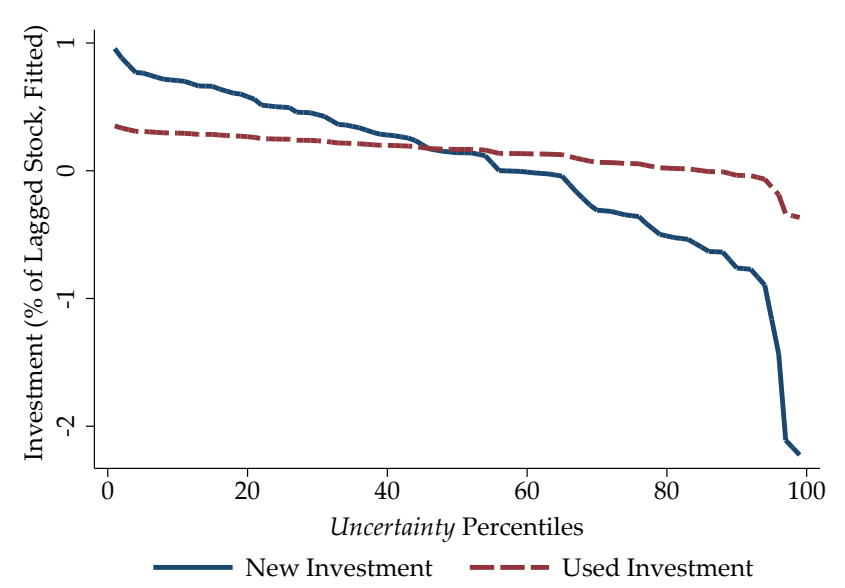

(A) Low-Liquidity

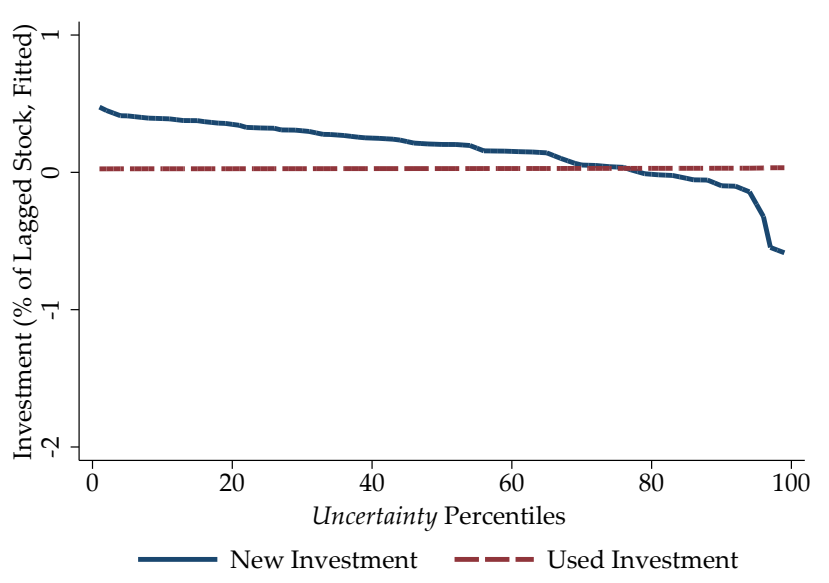

(B) High-Liquidity

Figure 4. Relationship between Uncertainty and Investment for Low- and High-Secondary Market Liquidity. Each panel depicts the fitted investment rate from the specification in Eq. (8) estimated at the $5^{\text {th }}$ ("Low") and $95^{\text {th }}$ ("High") percentiles of Liquidity measured as the log total number of ships in a given subsector-quarter.

on investment (investment rates reduce by only $2 \%$ of their mean).$^{28}$ These results verify our model prediction that heightened uncertainty increases firms' incentives to delay investment, particularly when investment decisions are costly to reverse due to low asset market liquidity (Prediction 3) ${ }^{29}$

Our real-options framework also predicts that the effect of uncertainty on investment should be particularly strong for the ordering new ships - as opposed to buying used ships - given sunk costs stemming from customization and time-to-build (Prediction 2). We test this prediction by estimating Eq. (8) with investment rates in new and used ships as separate dependent variables. The results are reported in columns (3) and (4) of Table 2. They show that the effect of uncertainty on total investment in columns (1) and (2) are driven almost entirely by new ship investments (see column (3)), rather than buying used ships (column (4)).

Figure 4 provides a graphical illustration of our findings. We plot the fitted investment rates, disaggregated across new and used ship purchases, against percentiles of Uncertainty at low $\left(5^{\text {th }}\right.$ percentile, Panel A) and high ( $95^{\text {th }}$ percentile, Panel B) levels of Liquidity. The figure shows that new ship orders (see blue solid line) respond more pronouncedly to variation in uncertainty than used ship purchases (red dashed line). A comparison of the two panels shows that the response is significantly stronger when asset market liquidity is low (Panel A). The figure also shows a non-linear effect of uncertainty on new investment: the effect is particularly strong at the highest levels of uncertainty.

\footnotetext{
${ }^{28}$ These magnitudes are calculated using the marginal effect of Uncertainty assuming liquidity measured by the log number of ships is at its $5^{\text {th }}$ and $95^{\text {th }}$ percentiles, 6.66 and 8.02 respectively. The marginal effects of Uncertainty at these percentiles are $-2.642+0.328 \times 6.66=-0.458$ and $-2.642+0.328 \times 8.02=-0.011$ respectively. Multiplying these marginal effects with the standard deviation of Uncertainty (2.893), we obtain $-0.458 \times 2.893=-1.32$ and $-0.011 \times 2.893=-0.03$. Finally, dividing by the average investment rate of $1.36 \%$, we get $-1.32 / 1.36=-97 \%$ and $-0.03 / 1.36=-2 \%$.

${ }^{29}$ Our inferences are robust to using alternative measures of liquidity based on the volume of secondary market transactions and the log number of firms in a given subsector-quarter (please see Appendix B).
} 


\subsection{Total Disinvestment, Demolition, and Used Ship Sales}

We next examine the effects of uncertainty on disinvestment; both total, as well as disaggregated into its components (demolition and sales). Our real-options model predicts that when disinvestment decisions are costly to reverse, uncertainty increases firms' incentive to delay disinvestment and that this effect is mitigated by asset market liquidity. The estimates in Table 3 confirm this prediction.

\section{TABLE 3 ABOUT HERE.}

The results in columns (1) and (2) indicate that uncertainty is negatively associated with disinvestment, consistent with Prediction 1 of the model. They also show that the first-moment proxies are generally negatively associated with disinvestment. Critically, and in accordance to our model, the negative uncertainty-disinvestment relation is mitigated by asset market liquidity, indicating that when disinvestment decisions are less costly to reverse, uncertainty has only a limited impact on disinvestment (Prediction 3). The associated economic magnitudes are large. First, estimates in column (1) indicate that a one-standard-deviation increase in sectoral uncertainty is associated with a $36 \%$ decline in disinvestment rates relative to the average disinvestment rate of $1.26 \%$. Second, when asset liquidity is at its $5^{\text {th }}$ percentile, a one-standard-deviation increase in uncertainty is associated with a $57 \%$ decline in disinvestment rates relative to the average (column (2)). In contrast, when liquidity is at its $95^{\text {th }}$ percentile, a one-standard-deviation increase in uncertainty is associated with a modest $4 \%$ decline from the baseline rate.

Our theoretical framework implies that the impact of uncertainty on disinvestment is particularly high for irreversible decisions such as ship demolition (Prediction 2). Irreversibility costs for demolition arise from the loss in value from disassembling the ship into components and regulatory costs due to the adverse environmental impact of ship breaking, among other reasons. We examine disinvestment in the form of demolition and sales separately in columns (3) and (4), and find the negative effect of uncertainty is far more pronounced for demolition: the magnitude of the effect on demolition is $64 \%$ of the total disinvestment effect, with sales making up the balance. These results are consistent with greater sunk costs making firms more cautious about demolishing relative to selling ships when uncertainty is high in the industry subsector.

The results in Tables 2 and 3 confirm a number of our model's predictions. They also provide early insight into an important result. Specifically, uncertainty bears a compositional effect on shipping firms' asset base: when uncertainty rises, firms invest less in new vessels (which embody new technology) and dispose less of ships intended for demolition (low quality technology). We study this effect in further depth in Section 5. 


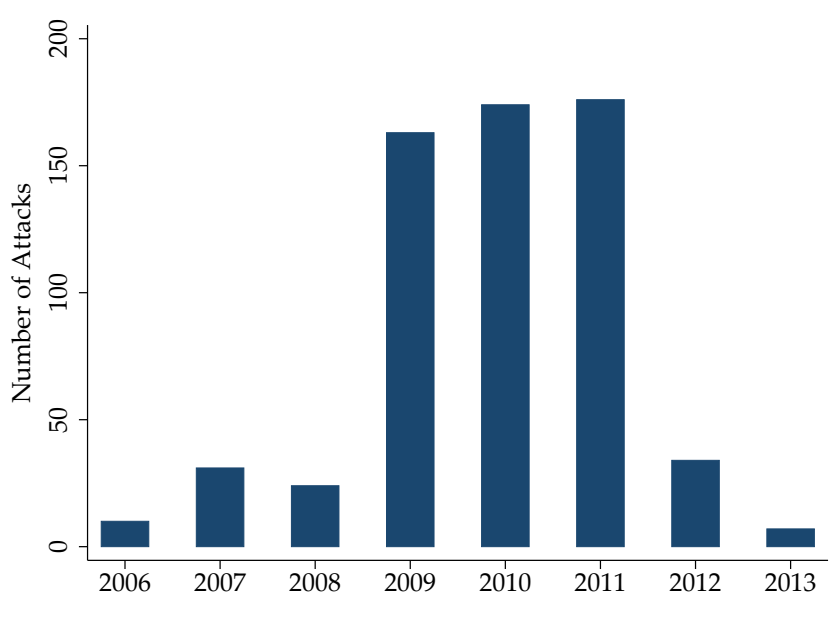

(A) Number of Attacks per Year

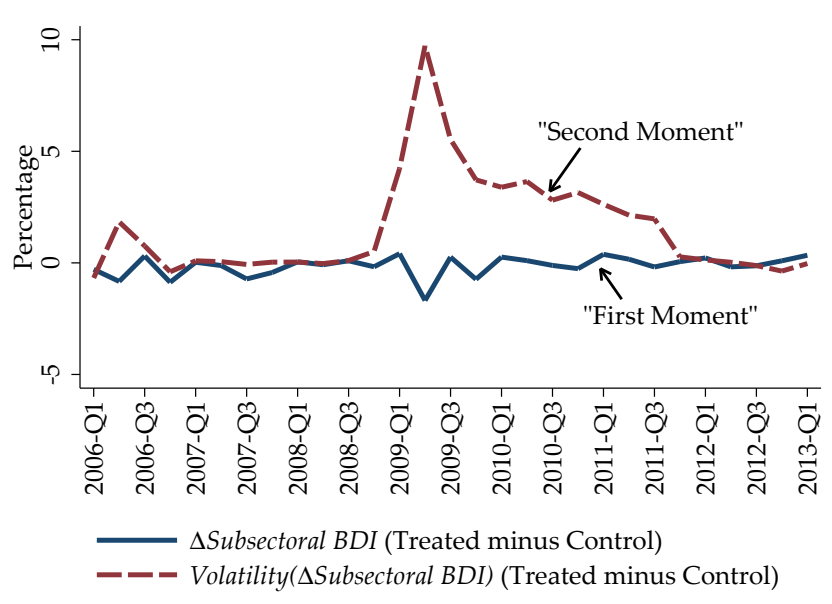

(B) $\triangle$ Subsectoral BDI Levels and Volatilities

Figure 5. Frequency of Somali Attacks, Shipping Demand Levels and Volatility. Panel A depicts the number of Somali pirate attacks per year based on statistics compiled by the International Maritime Bureau. Panel B shows the differences in the levels and volatilities of $\triangle$ Subsectoral BDI between treated and control subsectors. Treated subsectors consist of Panamax bulkers and LR2 tankers. Control subsectors consist of Capesize bulkers and VLCC tankers.

\subsection{A Quasi-Natural Experiment: The Somali Piracy Wave}

The evidence so far is consistent with shipping firms delaying their capital allocation decisions in the face of heightened uncertainty in their subsectors. In this section, we look for a more well-identified test strategy to support that assertion. We do so using the escalation of piracy off the coast of Somalia between 2009 and 2011 as a quasi-natural experiment that increases uncertainty in shipping. As we explain below, an important aspect of this geopolitical event is that the increase in piracy was sharp and affected a subset of vessel types based on a discontinuity generated by pre-determined size limitation on ships that are permitted to pass through the Suez Canal. Somalia is situated just south of the Gulf of Aden. Its territorial waters constitute a critical international shipping corridor, which ships entering and exiting the Suez Canal must pass through. The Somali civil war, and the poor economic and law-and-order situation that accompanied it, contributed to attacks by Somali pirates in recent decades.

We exploit the sudden increase in pirate attacks that occurred between 2009 and 2011 as a shock to uncertainty in shipping for two reasons. First, there was a clear period of heightened risk of pirate attacks, providing a discrete, identifiable shock to uncertainty in the industry. Panel A of Figure 5 shows that the number of attacks increased from 24 in 2008 to 163 in 2009, and remained at 174 and 176 in 2010 and 2011, respectively. The heightened risk of pirate attacks led to an increase in internationally-coordinated law enforcement activities in the area, which virtually ended the pirate attacks by $2012 .{ }^{30}$

\footnotetext{
${ }^{30}$ See The Economist, May 20, 2013, “What Happened to Somalia's Pirates?"
} 
Second, the increase in uncertainty affected some subsectors of ships, while leaving others largely unaffected, generating plausible "treated" and "control" groups of interest. To wit, the waters surrounding Somalia are traversed primarily by ships entering and exiting the Suez Canal, whose physical features limit the size of ships that can pass through it. Accordingly, the increase in uncertainty only affected ships that could pass through the Canal, whereas larger ships whose physical dimensions exceed the size limit were largely unaffected. Using this discontinuity, we define "treated subsectors" as those falling immediately below the size thresholds for using the Suez Canal (Panamax bulkers and LR2 tankers). The control group is defined as subsectors immediately above the size threshold for traversing the Canal (Capesize bulkers and VLCC tankers).

To verify that the escalation in Somali piracy represents a differential shock to uncertainty in shipping demand for the treated versus control subsectors, we examine changes in shipping rate volatility around the event period. Panel B of Figure 5 shows a marked increase in the difference in the volatility of $\triangle$ Subsectoral BDI for treated relative to control subsectors during the 2009-2011 period. We also plot the difference in the levels of $\Delta$ Subsectoral BDI between treated and control subsectors to ensure that the escalation in piracy threat did not embed a concurrent first-moment shock for treated subsectors. The level of $\Delta$ Subsectoral BDI is largely similar across the treated and control groups. The overall evidence is consistent with the escalation in piracy increasing the downside risk (e.g., costs from being attacked) as well as the potential upside from passing through successfully (e.g., due to a supply side contraction in an imperfectly competitive industry), acting as a mean-preserving spread.

We analyze the effect of the increase in uncertainty due to the rise in piracy by comparing the investment and disinvestment rates of firms operating ships in treated and control subsectors. In particular, for each treated firm-subsector, we assign a matched control firm-subsector as its nearest neighbor in terms of treatment propensity. We estimate the propensity score as a function of firmsubsector fleet characteristics, including the average log age, log DWT, and log RPM, in a subsectorquarter. Using the matched sample, we estimate the following difference-in-differences model:

$$
Y_{i, j, t}=\beta_{1} \text { Treat }_{j} \times \text { Piracy }_{t}+\theta \text { Controls }_{i, j, t}+F E s+\epsilon_{i, j, t},
$$

where $Y_{i, j, t}$ refers to the investment and disinvestment measures for firm $i$, in subsector $j$, and year-quarter $t$. Treat $_{j}$ is an indicator that is equal to one for the Panamax bulker and LR2 tanker subsectors, and zero for the Capesize bulker and VLCC tanker subsectors. Piracy is an indicator that is equal to one during 2009-2011, and zero for all other years from 2006 through 2013. The vector Controls $_{i, j, t}$ is defined as in Eq. (8). We include fixed effects for the firm's headquarter country-yearquarter as well as firm-subsector. ${ }^{31}$ Standard errors are clustered at the match level (cf. Abadie and Spiess (2020)). The coefficient of interest is $\beta_{1}$, which represents the difference in investment (or

\footnotetext{
${ }^{31}$ These fixed effects naturally subsume the main effects of Treat $_{j}$ and Piracy $_{t}$.
} 


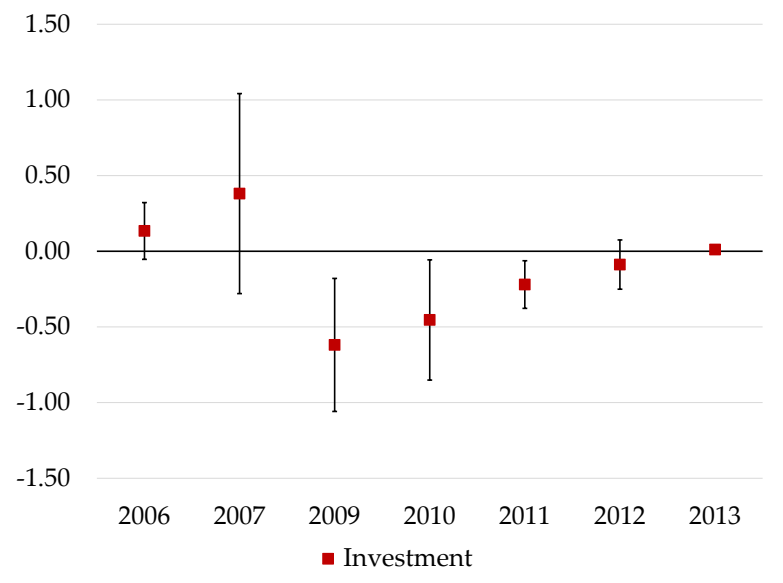

(A) Investment Dynamics

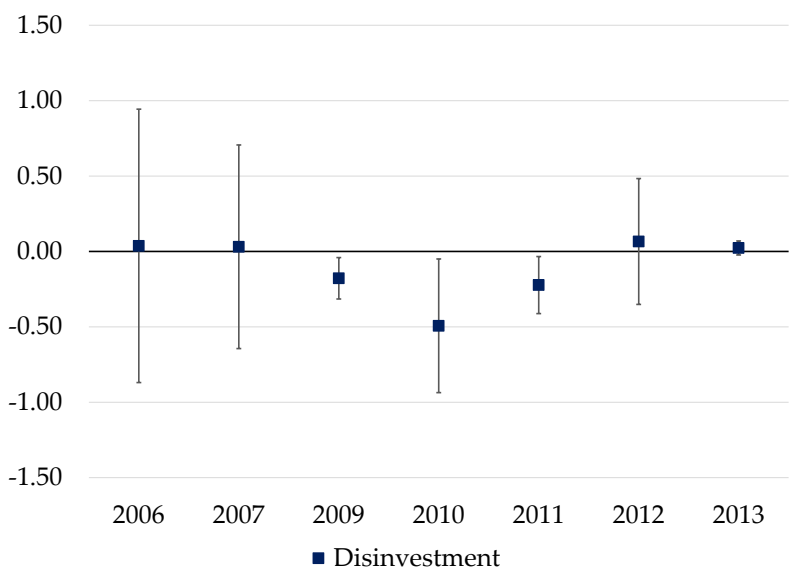

(B) Disinvestment Dynamics

Figure 6. Investment and Disinvestment Dynamics around the Escalation in Somali Piracy. This figure displays coefficient estimates and 95\% confidence bands for Treat ${ }_{j}$ interacted with yearly dummies estimated from a modified version of the specification in Eq. (9). The dependent variables are investment (Panel A) and disinvestment (Panel B). The year immediately prior to the event window (2008) is omitted as the baseline.

disinvestment) rates between affected and control firm-subsectors during the period of heightened uncertainty due to Somali piracy relative to all other years between 2006 and 2013.

Panel A of Table 4 reports the results from estimating Eq. (9). During the period of heightened risk of pirate attacks, treated firms cut both their investment and disinvestment in subsectors exposed to the risk, relative to the unaffected subsectors. The economic magnitude of the investment reduction is significant. In the three years of heightened uncertainty, the cut in quarterly investment rates implied by the estimate in column (1) is 1.30 percentage points, which represents $38 \%$ of the mean investment rate of $3.43 \%$ for treated firm-subsectors during the pre-event period (2006-2008). Likewise, treated firms cut their disinvestment rates by $18 \%$ of the comparable baseline disinvestment rate. The investment and disinvestment cuts are more pronounced among new ship purchases and ship demolition, where the degree of irreversibility is likely to be highest (as seen in Tables 2 and 3). Figure 6 shows the dynamic effects of the escalation in piracy on investment and disinvestment by plotting coefficient estimates corresponding to the year-by-year difference in outcomes between the treated and control groups. The figure further provides statistical evidence of parallel pre-trends in investment and disinvestment and illustrates their significant drops during the event window.

\section{$\overline{\text { TABLE } 4 \text { ABOUT HERE. }}$}

In Panel B of Table 4, we report second-stage estimates from an instrumental variables (IV) estimation of Eq. (8), in which we use Treat $_{j} \times$ Piracy $_{t}$ as an instrument for Uncertainty ${ }_{j, t}$. Doing so allows us to compare the magnitude of the effect of uncertainty on investment and disinvestment in the quasi-natural experiment with our baseline estimates. Comparing columns (1) and (4) of 
Panel B in Table 4 with column (1) of Tables 2 and 3, we find magnitudes in the IV specification on similar orders of magnitudes with the baseline estimates. Our quasi-natural experiment provides for a more causal-based claim that uncertainty dampens corporate capital allocation across both the investment and disinvestment margins.

\section{Uncertainty and Asset Productivity}

In this section, we test our model's prediction that firms' investment (disinvestment) in more (less) productive assets are particularly more affected by uncertainty (Prediction 4). The tests performed consider attributes that capture the productivity of each of the assets (vessels) a firm operates. The analysis provides insight into the impact of uncertainty on the productivity of firms' entire asset base (fleets) by examining its dual effects on the rate at which firms invest in more productive assets and dispose of less productive ones. These composition dynamics are studied in further detail in the next section.

We observe a number of individual ship characteristics that, based on industry standards, serve as proxies for asset productivity. Building on that information, we estimate a battery of hedonic pricing regressions in order to identify which ship attributes attract higher prices, reflecting greater productivity (see Appendix Table E.1). These in-ship-class attributes are: $D W T$ (larger ships carry a greater volume of goods per trip), RPM (ships with lower RPM are more fuel-efficient), and Age (new ships incorporate an array of technological advancements, ranging from safety to automation, to navigational and docking capabilities). We subsequently employ two approaches to gauge the productivity of individual ships firms invest in. First, we identify whether a given ship's specs are above or below its subsector-median numbers for two metrics: (1) $D W T$ and (2) $-1 \times R P M$. A ship is classified as "high-productivity" if it is above the median on at least one of those two parameters; "low-productivity" otherwise. Second, we look at the ship's Age. We consider this attribute separately because, as previously discussed, "age" captures a number of finer features associated with technology adoption in shipping. We then compute investment rates separately for high- and low-productivity ships based on these two classification schemes. We report results on investment in ships with differing levels of productivity in Table 5.

\section{$\overline{\text { TABLE } 5 \text { ABOUT HERE. }}$}

The estimates in Panel A of Table 5 show that uncertainty impacts investment in high-productivity ships, as captured by ship size ( $D W T)$ and engine efficiency ( $R P M)$, in the most negative manner; specifically, when these ships are new. In contrast, investments in new low-productivity ships and used ships in general are largely unaffected by uncertainty. These results are consistent with our model's prediction that firms delay their investment in high-productivity ships more when faced 


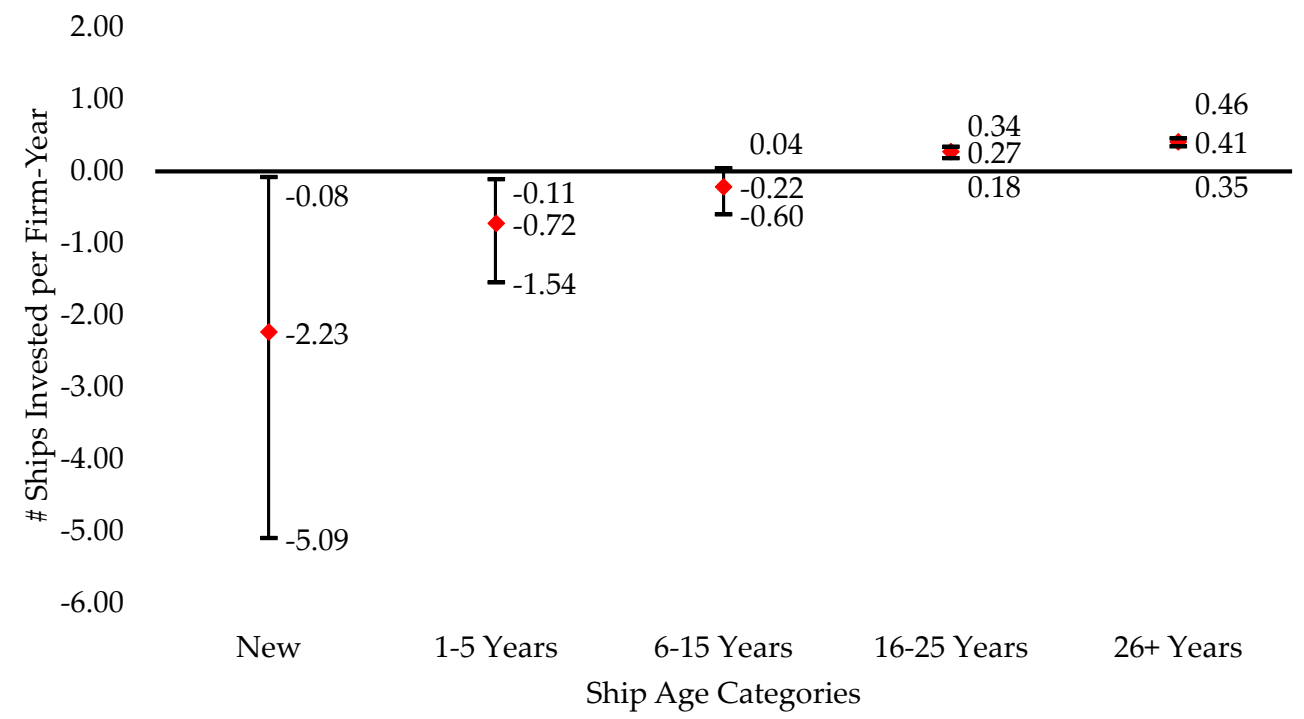

Figure 7. Effect of Uncertainty on Investment by Ship Age and Asset Market Liquidity. This figure shows the effects of a one-standard-deviation increase in uncertainty calculated at the $5^{\text {th }}, 50^{\text {th }}$, and $95^{\text {th }}$ percentiles of asset market liquidity (based on the log number of ships) on investment in various categories of ship ages. The marginal effects are translated into ships invested per firm-year by annualizing and multiplying the firm-susbsector-quarter estimates by the average number of ships held in each subsector and the number of subsectors per firm.

with higher uncertainty. They point to a noticeable slowdown in the rate at which firms upgrade their fleets during periods of heightened uncertainty by acquiring ships that are able to carry greater cargo and have more fuel-efficient engines.

We next drill down on the dimension of ship age. The estimates reported in Panel B of Table 5 show that the negative effect of uncertainty on investment becomes monotonically weaker as ship age increases. New ship orders and purchases of ships with ages less than 16 years are significantly negatively affected by increases in uncertainty, while purchases of older ships are not at all impacted. Simply put, when uncertainty is high, firms reduce investment in ships embodying the newest technologies the most. Acquisitions of old ships are utterly unaffected by uncertainty.

Figure 7 illustrates the effect of a one-standard-deviation increase in uncertainty at various points of the asset liquidity distribution and across ship age categories based on the estimates in Panel B of Table 5. It shows that uncertainty reduces investment in newly built ships and those with ages between one and five years the most. Importantly, this effect is aggravated by low asset market liquidity. Noticeably from the figure, the negative effect of uncertainty on investment wanes with older age, eventually becoming insignificant. Our results reveal the deleterious effect of uncertainty on the productivity of firms' asset base, which operates through an increased incentive to forgo investment in larger, more fuel-efficient ships, as well as newer ships containing the latest technological advances.

We conclude this section by examining whether uncertainty affects the rate at which firms disinvest ships (either through demolition or secondary market sales) according to asset-level pro- 
ductivity. For the purposes of these tests, we combine the two schemes used above and classify a ship as "high-productivity" if it satisfies at least two of the following three criteria in its subsectorquarter: (1) above median DWT, (2) below median RPM, and (3) below median age. We classify the rest as "low-productivity" ships. Table 6 reports the relevant results.

\section{TABLE 6 ABOUT HERE.}

Columns (1) and (3) ((2) and (4)) of Table 6 display estimates for demolition (sales) of highand low-productivity ships. The estimates in columns (3) and (4) show that the negative effect of uncertainty on disinvestment, and its interactive effect with asset liquidity, are driven by the demolition and sales of low-productivity ships. Our model would predict this exact relation if the costs of reversing demolition and sales of low-productivity ships are higher than those of high-productivity ships. Although we cannot directly test this conjecture, we find evidence that sunk costs are indeed comparatively higher for the demolition and sales of low-productivity ships. For demolished ships, we calculate an analogue to the price premium (see Table E.1) as the scrap value minus the most recent purchase price scaled by the purchase price. The higher this variable, the higher the percentage of the price paid that was recovered through demolition (and lower the deadweight loss). The average is $-67 \%$ ( $-42 \%$ ) for low- (high-) productivity ships. Similarly, the price premium conditional on sale is lower for low-productivity ships (around -5\%) than for high-productivity ships (22\%). It appears that firms incur a greater loss from demolishing or selling low- (versus high-) productivity ships. The sunk costs of demolishing low-productivity ships are likely higher due to their poorer conditions and environmental and regulatory restrictions on where and how they can be demolished (see Stopford (2009) for a detailed discussion).

\section{Uncertainty and Firm Asset Composition}

The firm-subsector level analyses conducted in the previous sections reveal considerable heterogeneity in firms' investment and disinvestment responses to uncertainty based on the vintage and productivity of assets. The differential responses at the individual asset level suggest that uncertainty may affect firms' overall asset base composition. In this section, we explicitly test how firms alter their asset portfolios under uncertainty. In the next section, we examine how capital markets value these uncertainty-induced changes in firm asset composition.

We first investigate whether firms alter the concentration of their asset holdings (fleets) in response to heightened uncertainty. Studying the effects of uncertainty on shipping firms' fleet concentration provides important context to our prior results. Notably, it allows us to disentangle whether the effects of uncertainty on firms' capital allocation decisions are driven by firms altering their intensive margin exposures to markets they already operate in or extensive margin exposures 
to new markets (cf. Williamson $(1975,1985)$ and Teece (1980)). Given fixed costs associated with a shipping firm operating fleets in a larger number of subsectors, decisions on the extensive margin (increasing exposure to new market subsectors) are more irreversible than intensive margin decisions. These costs arise from a variety of sources, including informational frictions, imperfect translation of technical and knowledge capital across subsectors, fleet coordination, as well as integrating asset specificity of ships designed to carry fixed sets of goods over pre-determined routes. In line with our theoretical framework featuring fixed costs, this logic implies that a firm's fleet concentration (in fewer ship subsectors) will increase in the face of increased uncertainty.

We measure a firm's fleet concentration by calculating the Herfindahl-Hirschman Index (HHI) of the number of ships a given firm-quarter operates across subsectors, and use it as the dependent variable in a variant of Eq. (8). The coefficient on uncertainty, therefore, captures the extent to which firms alter their asset composition when uncertainty increases by concentrating their fleets into a small number of market subsectors versus maintaining a diversified exposure to a larger number of subsectors. As a complementary measure, we also use the number of distinct market subsectors a shipping firm is exposed to (specifically, the logarithm of the number of subsectors measured at the firm-quarter level). Table 7 reports the results.

\section{$\overline{\text { TABLE } 7 \text { ABOUT HERE. }}$}

Across all columns in Panel A of Table 7, the coefficient on uncertainty is significantly positive and the coefficient on its interaction with liquidity is significantly negative, indicating that firms' holdings become more concentrated as uncertainty rises, particularly when asset liquidity is low. These results are consistent with fixed costs associated with operating ships across multiple market segments, which lead firms to concentrate their ship portfolios in subsectors with greater importance when uncertainty rises. Notably, low asset liquidity accentuates this effect as it makes ex-post reallocation more costly. These dynamics coincide with those under which firms pull back on their investment (and disinvestment) rates when measured at the individual ship level. The results in Panel B of Table 7 confirm that the increases in firm fleet concentration (HHI) is driven by firms reducing their exposures to diverse market subsectors in the face of heightened uncertainty. They are consistent with such extensive margin allocation decisions (that increase the number of subsectors a firm operates in) having greater irreversibility. Equivalently, they show that firms expand into new market subsectors during periods of lower uncertainty. When viewed together, these results confirm that shipping firms' individual asset-level allocation decisions in the face of heightened uncertainty do not "offset" each other, and instead have implications for their firm-level asset fleet composition. Uncertainty appears to affect the boundaries of the firm as shipping firms consolidate the number of market subsectors that they are exposed to during periods of heightened uncertainty. 
We next explore how the productivity metrics of the portfolio of ships a firm holds in its fleet change during periods of heightened uncertainty. These tests build upon the analysis presented in Section 5. In particular, we gauge whether the marginal asset allocation decisions along the lines of productivity that firms take in the face of uncertainty (Tables 5 and 6) translate into meaningful declines in the average productivity of the fleet of ships they retain. We do so by estimating our baseline specification in Eq. (8) at the firm level, using the logarithm of the average Age, DWT, and RPM of all ships a firm holds in a given quarter as the dependent variables. The results are reported in Table 8.

\section{TABLE 8 ABOUT HERE.}

The within-firm estimated coefficients point to a significant worsening in the average firmlevel productivity metrics when uncertainty increases, and particularly so when secondary ship markets are illiquid. Column (1) shows that the average Age of ships that firms hold in their fleets increases substantially when uncertainty is high. The economic magnitude of this effect is large: a one-standard-deviation increase in Uncertainty (2.90) is associated with an increase in average fleet age of $1.01 \log$ points or 2.74 years when liquidity is low (at its $5^{\text {th }}$ percentile of 6.66 ). ${ }^{32}$ This fleet aging represents an increase of $16 \%$ relative to the average fleet age of 17.69 years $\left(=e^{2.873}\right.$; see Table 1). Likewise, columns (2) and (3) show that firms hold relatively smaller ships (lower $D W T$ ) with less fuel-efficient engines (higher $R P M$ ) in the face of higher uncertainty. The results of this analysis imply that firms' asset portfolios experience a tangible degradation along the lines of ex-ante productivity attributes when uncertainty increases. Such uncertainty-induced asset compositional changes are likely to have implications for shipping firms' future performance, a notion we test explicitly in the subsequent section.

In our final set of tests, we aggregate our investment and disinvestment measures to the firmquarter level across all subsectors in which firms operate in a quarter. We do so to determine whether the previous micro-level findings on asset allocation within firm-subsector units ultimately translate into changes to a firm's overall fleet portfolio. Panel A (B) of Table 9 shows that the results from our firm-level analysis conform with the results we obtain at the firm-subsector level. In particular, comparing the estimates in columns (4) and (6) shows that firms as a whole predominantly cut back on new ship orders across subsectors when uncertainty increases, while used ship purchases are unaffected. Turning to Panel B of Table 9, the firm-level breakdown of the overall effect of uncertainty on disinvestment (column (2)) between demolition (column (4)) and secondary market sales (column (6)) closely resembles that reported in Table 3.

\section{TABLE 9 ABOUT HERE.}

\footnotetext{
${ }^{32}$ This magnitude is calculated by multiplying the marginal effect of Uncertainty when Liquidity $=6.66$ with the standard deviation of Uncertainty, i.e., $(0.382-6.66 \times 0.005) \times 2.893=1.009 \log$ points $\left(\right.$ or $e^{1.009}=2.742$ years $)$.
} 
Taken together, the results of this section show that when uncertainty is high, firms do not offset their investment and disinvestment cuts in certain subsectors (e.g., those with low liquidity) with increases in other subsectors. ${ }^{33}$ Rather, subsectoral capital misallocation decisions "add up" to the firm level, negatively affecting the productivity of shipping firms' overall fleet portfolios and their exposure to new markets. These results are new to the literature and carry aggregate-level implications. Notably, they point to a further deleterious effect of uncertainty: by increasing shipping firms' fleet concentration, reducing their exposures to new subsectors, and reducing their average fleet productivity, uncertainty may lead to diminished competition and innovation incentives commonly associated with healthy firm entry-exit dynamism (see, e.g., Foster et al. (2019)). In light of recent evidence of both rising uncertainty (Baker et al. (2014)) and declining business dynamism (Decker et al. (2016)), our results are the first to provide micro evidence for a potential connection between these two phenomena. They raise concerns that spells of high uncertainty could dampen economic growth and efficiency by hindering business dynamism (see also Akcigit and Ates (2019)).

\section{$7 \quad$ Uncertainty and Firm Value}

In our final analysis, we look at the equity values of shipping firms around finely-identified highuncertainty episodes. We do so using returns on U.S.-listed shipping firms. ${ }^{34}$ If firms curtail investment (disinvestment) in the most (least) productive assets when uncertainty is high, one might expect to see a negative valuation effect on those firms' equities as investors price in expectations of diminished future cash flows. On the other hand, if firms reallocate their ships across subsectors without changing their overall asset levels and composition, one would expect to see little change in expected cash flows and equity valuations. The analysis of this section deepens our understanding of the net effect of the uncertainty-induced changes to firms' asset allocation, composition, and productivity through the lens of capital market expectations regarding future firm performance.

We conduct this examination in the form of an event study. In particular, we identify events over the 2006-2019 period corresponding to the largest spikes in the daily counterpart to our shipping sector uncertainty measure. ${ }^{35}$ The test sample includes 76 shipping firms for which we are able to

\footnotetext{
${ }^{33}$ We repeat our main analysis in the subsample of "pure-play" firms that operate ships only in a single subsector. Such firms, by definition, do not substitute investment or disinvestment across subsectors. The results are similar to those observed for the full sample (please see Appendix Table F.1).

${ }^{34}$ This analysis is naturally limited to the subsample of shipping firms with publicly-traded stocks, of which firms with a U.S. listing comprise the vast majority ( $78 \%$ by market capitalization and $71 \%$ by fleet size).

${ }^{35}$ To identify these episodes, we first disaggregate Uncertainty (which is constructed at the subsector-quarter level) to the subsector-day level (using daily option implied volatilities from OptionMetrics). We then aggregate the subsector-day Uncertainty series to the daily level. We do so by taking the average of Uncertainty across all eight subsectors in a given day, weighted by the number of ships in each subsector. We then compute the day-on-day percentage change in Uncertainty and identify the dates in which the change was positive and greater than two standard deviations: (1) September 27, 2007; (2) May 2, 2008; (3) October 20, 2008; (4) October 23, 2011; (5) January 13, 2014; (6) January 25, 2016; (7) November
} 
obtain daily returns from CRSP for the one-month window beginning on each of the event dates. We calculate average annualized buy and hold abnormal returns (ABHAR) by compounding each stock's daily returns over the relevant event window, and subtracting the compounded daily returns of a characteristic-matched portfolio (based on size and book-to-market). We compute ABHARs across firms using both equal and value weights. Table 10 reports the results.

\section{$\overline{\text { TABLE } 10 \text { ABOUT HERE. }}$}

Our event study shows that firms operating in low-liquidity subsectors experience negative abnormal returns of 7-9\% during the month following high shipping sectoral uncertainty episodes. Firms operating in high-liquidity subsectors, on the other hand, observe insignificant abnormal returns. Combined with our results on firm-level capital allocation in Tables 7, 8, and 9, these results provide evidence that the changes in firms' capital allocation induced by high uncertainty and low asset market illiquidity are value-reducing.

\section{Robustness}

\subsection{Aggregate Uncertainty versus Sectoral Uncertainty}

We examine whether the effects of uncertainty that we document are driven by broad, macroeconomic uncertainty rather than shipping sector-specific uncertainty. This is important because macroeconomic uncertainty is often confounded with business-cycle movements (see Storesletten et al. (2004)). To this end, we augment our main specification in Eq. (8) with the following macroeconomic uncertainty measures: (1) the VIX index from the Chicago Board Options Exchange, (2) the Jurado et al. (2015) measure of macroeconomic uncertainty, (3) the Baker et al. (2016) economic policy uncertainty (EPU) index, and (4) the dispersion of GDP forecasts from the Federal Reserve Bank of Philadelphia's Survey of Professional Forecasters.

Table 11 reports results for investment and disinvestment rates. Across both columns, the only uncertainty measure that attracts statistically significant both main and interaction (with Liquidity) effects is our shipping sector-specific measure, Uncertainty. The estimates suggest that the source of uncertainty specific to shipping demand, as opposed to broader macroeconomic uncertainty, drives our results on shipping firms' investment and disinvestment policies.

\section{TABLE 11 ABOUT HERE.}

10, 2016; and (8) May 13, 2019. Reflecting the fact that our measure predominantly captures shipping industry-specific uncertainty, only two of these dates coincide with major macroeconomic volatility spikes: October 2008 saw the VIX index reach its peak during the Global Financial Crisis and the 2016 U.S. Presidential Election took place on November 8. Other two events coincide with market developments in the dry bulker sector: the Baltic Dry Index reached all-time highs in September 2007 and May 2008. The remaining dates relate to particular shipping routes: pirate attacks in Somali waters reached their apex in late 2011, while Gulf of Oman attacks resulted in tanker volatility spiking in the spring of 2019. 


\subsection{Financing Constraints}

We next investigate whether the negative relation between uncertainty and corporate asset allocation could be ascribed to concurrent increases in shipping firms' financing constraints. Prior work has shown that periods of higher uncertainty are associated with increased credit spreads, which may lead financially constrained firms to curtail investment (see, e.g., Gilchrist et al. (2014) and Alfaro et al. (2018)). We account for this channel in our analysis by including two widely available proxies for firms' financing constraints, together with their interactions with Uncertainty, as additional controls: (1) the size-age index as in Hadlock and Pierce (2010) and (2) an indicator for whether the firm is private.

\section{$\overline{\text { TABLE } 12 \text { ABOUT HERE. }}$}

Table 12 shows that our findings continue to hold when accounting for possible tightening of shipping firms' financing constraints. Columns (1) and (2) show that financing constraints are negatively related to investment, and that constrained firms cut their investment more when uncertainty increases. Notably, the interactive effect of uncertainty and liquidity remains significant in the presence of the interactive effect of uncertainty and the financing constraints proxies. Columns (3) and (4) show that financially constrained firms are more likely to disinvest, both unconditionally and when uncertainty increases. Once again, the interactive effect of uncertainty and liquidity on disinvestment remains significant. Our checks suggest that firms' financing constraints alone cannot explain the observed investment and disinvestment cuts attributed to changes in uncertainty.

\subsection{Investment and Disinvestment Tonnage}

Our main investment and disinvestment measures are calculated using numbers of ships. To address the possibility that these results may be disproportionately influenced by decisions involving small ships, we rerun our main tests using investment and disinvestment measures computed with dead-weight tonnage in place of the number of ships. Table 13 shows that our inferences continue to hold: high uncertainty is associated with both lower total investment and disinvestment, which is more pronounced when asset market liquidity is low.

$$
\underline{\text { TABLE } 13 \text { ABOUT HERE. }}
$$

\subsection{Lumpiness of Investment and Disinvestment}

We address potential estimation issues arising from the lumpiness of shipping firms' investment and disinvestment decisions in two ways. First, we re-estimate Eq. (8) at semi-annual and annual 
horizons, instead of the quarterly horizon used in our baseline tests. In addition to reducing investment (and disinvestment) lumpiness by aggregating the measures at a higher frequency, this test accounts for the possibility that measuring investment and disinvestment at a relatively high (quarterly) frequency may capture firms' delayed responses to past changes in uncertainty (rather than to contemporaneous variation). Panel A of Appendix Table G.1 confirms that the associations between uncertainty, liquidity, and capital allocation that we report in our base tests also hold at the longer horizons.

Second, we verify that our main results are not affected by statistical issues that may arise due to a large fraction of the dependent variable taking zeros. Specifically, we employ the investment and disinvestment rates (continuous variables) as dependent variables in zero-one inflated beta regressions, which explicitly allow for an inflated rate of zero and one values in the outcome variables (see also Ospina and Ferrari (2012) and Staub and Winkelmann (2013)). Columns (3) and (6) of Appendix Table G.1, Panel B show that the results using this specification are similar to the baseline results.

We also estimate linear probability and conditional logit models using indicator variables equal to one for firm-subsector-quarters in which the investment (disinvestment) rate is positive, and zero otherwise. Our results continue to hold in these specifications (see columns (1), (2), (4), and (5) of Appendix Table G.1, Panel B).

\subsection{Other Robustness Tests}

We conduct a number of other robustness tests, whose results are reported in appendices for brevity. In Appendix B, we verify that our results hold for alternative proxies for liquidity in the secondary shipping market. In Appendix C, we show that our inferences are robust to various alternative weighting schemes in the construction of the Uncertainty measure. In Appendix D, we examine the dynamics of the uncertainty-investment (-disinvestment) relations, as well as verify the robustness of our results to changing the maturity of the options considered in the calculation of our Uncertainty measure.

\section{Concluding Remarks}

Using near-universal data on shipping firms' capital allocation decisions across new orders, secondarymarket transactions, and demolition of ships, combined with sector-specific measures of uncertainty, we show that shipping firms delay both the purchases and disposal of ships in response to heightened uncertainty. Our findings are consistent with the augmented real-options model we propose. These dynamics are more pronounced for less liquid secondary ship markets and for new ship orders and demolition, relative to secondary market purchase and sales. New to the 
literature, we also show that investment (disinvestment) reductions are concentrated among more (less) productive ships.

Major recent geo-political developments, such as the escalation of trade tensions between U.S. and China and U.K.'s Brexit, have raised concerns on the effects of heightened economic uncertainty among managers and investors. The onset of the Covid-19 pandemic has only exacerbated those concerns. Our results uniquely suggest that such developments, indicative of heightened global uncertainty, may impose additional economic costs through their impact on the efficiency of firms' capital allocation decisions, particularly those that are costlier to reverse. Uncertainty appears to play an important role in decelerating "creative destruction" dynamics by impeding the adoption of novel technologies embodied in new capital, the disposal of obsolete technologies in old-vintage capital, and discouraging firm entry into new market segments. Critically, this dampened capital allocation at the firm-asset level could have an adverse effect on aggregate productivity and growth. While our work provides new insights into these dynamics, more research on this important topic is needed. 


\section{References}

Abadie, Alberto, and Jann Spiess, 2020, Robust Post-Matching Inference, Journal of the American Statistical Association 1-37.

Akcigit, Ufuk, and Sina Ates, 2019, What Happened to US Business Dynamism?, Technical report, National Bureau of Economic Research.

Alfaro, Ivan, Nicholas Bloom, and Xiaoji Lin, 2018, The Finance Uncertainty Multiplier, Technical report, National Bureau of Economic Research.

Arrow, Kenneth, 1968, Optimal Capital Policy with Irreversible Investment, in "Value, Capital and Growth, Essays in Honor of Sir John Hicks" (JN Wolfe, Ed.).

Baker, Scott, and Nicholas Bloom, 2013, Does Uncertainty Reduce Growth? Using Disasters as Natural Experiments, Technical report, National Bureau of Economic Research.

Baker, Scott, Nicholas Bloom, Brandice Canes-Wrone, Steven Davis, and Jonathan Rodden, 2014, Why Has US Policy Uncertainty Risen Since 1960?, American Economic Review 104, 56-60.

Baker, Scott, Nicholas Bloom, and Steven Davis, 2016, Measuring Economic Policy Uncertainty, The Quarterly Journal of Economics 131, 1593-1636.

Benhabib, Jess, and Aldo Rustichini, 1991, Vintage Capital, Investment, and Growth, Journal of Economic Theory 55, 323-339.

Benmelech, Efraim, 2009, Asset Salability and Debt Maturity: Evidence from Nineteenth-Century American Railroads, The Review of Financial Studies 22, 1545-1583.

Benmelech, Efraim, and Nittai Bergman, 2011, Vintage Capital and Creditor Protection, Journal of Financial Economics 99, 308-332.

Bloom, Nicholas, 2009, The Impact of Uncertainty Shocks, Econometrica 77, 623-685.

Bloom, Nicholas, Max Floetotto, Nir Jaimovich, Itay Saporta-Eksten, and Stephen Terry, 2018, Really Uncertain Business Cycles, Econometrica 86, 1031-1065.

Bouman, Evert, Elizabeth Lindstad, Agathe Rialland, and Anders Strømman, 2017, State-of-the-Art Technologies, Measures, and Potential for Reducing GHG Emissions from Shipping-A Review, Transportation Research Part D: Transport and Environment 52, 408-421.

Campello, Murillo, Gustavo Cortes, Fabricio d'Almeida, and Gaurav Kankanhalli, 2021, Exporting Uncertainty: The Impact of Brexit on Corporate America, Journal of Financial and Quantitative Analysis Forthcoming.

Decker, Ryan, John Haltiwanger, Ron Jarmin, and Javier Miranda, 2016, Declining Business Dynamism: What We Know and the Way Forward, American Economic Review 106, 203-07.

Foster, Lucia, Cheryl Grim, John Haltiwanger, and Zoltan Wolf, 2019, Innovation, Productivity Dispersion, and Productivity Growth, in Measuring and Accounting for Innovation in the 21st Century (University of Chicago Press).

Gavazza, Alessandro, 2011, The Role of Trading Frictions in Real Asset Markets, American Economic Review 101, 1106-43. 
Gilchrist, Simon, Jae Sim, and Egon Zakrajšek, 2014, Uncertainty, Financial Frictions, and Investment Dynamics, Technical report, National Bureau of Economic Research.

Gulen, Huseyin, and Mihai Ion, 2015, Policy Uncertainty and Corporate Investment, The Review of Financial Studies 29, 523-564.

Hackbarth, Dirk, and Timothy Johnson, 2015, Real Options and Risk Dynamics, The Review of Economic Studies 82, 1449-1482.

Hadlock, Charles, and Joshua Pierce, 2010, New Evidence on Measuring Financial Constraints: Moving Beyond the KZ Index, The Review of Financial Studies 23, 1909-1940.

Hsieh, Chang-Tai, 2001, Endogenous Growth and Obsolescence, Journal of Development Economics $66,153-171$.

Jens, Candace, 2017, Political Uncertainty and Investment: Causal Evidence from US Gubernatorial Elections, Journal of Financial Economics 124, 563-579.

Julio, Brandon, and Youngsuk Yook, 2012, Political Uncertainty and Corporate Investment Cycles, The Journal of Finance 67, 45-83.

Jurado, Kyle, Sydney Ludvigson, and Serena Ng, 2015, Measuring Uncertainty, American Economic Review 105, 1177-1216.

Kellogg, Ryan, 2014, The Effect of Uncertainty on Investment: Evidence from Texas Oil Drilling, American Economic Review 104, 1698-1734.

Kim, Hyunseob, and Howard Kung, 2017, The Asset Redeployability Channel: How Uncertainty Affects Corporate Investment, The Review of Financial Studies 30, 245-280.

Lee, Jaewoo, and Kwanho Shin, 2000, The Role of a Variable Input in the Relationship between Investment and Uncertainty, American Economic Review 90, 667-680.

Ma, Song, Justin Murfin, and Ryan Pratt, 2020, Young Firms, Old Capital, Cornell University Working Paper.

Ospina, Raydonal, and Silvia Ferrari, 2012, A General Class of Zero-or-one Inflated Beta Regression Models, Computational Statistics \& Data Analysis 56, 1609-1623.

Rampini, Adriano, 2019, Financing Durable Assets, American Economic Review 109, 664-701.

Schlingemann, Frederik, René Stulz, and Ralph Walkling, 2002, Divestitures and the Liquidity of the Market for Corporate Assets, Journal of Financial Economics 64, 117-144.

Solow, Robert, 1960, Investment and Technical Progress, Mathematical Methods in the Social Sciences $1,48-93$.

Staub, Kevin, and Rainer Winkelmann, 2013, Consistent Estimation of Zero-Inflated Count Models, Health Economics 22, 673-686.

Stopford, Martin, 2009, Maritime Economics $3^{\text {rd }}$ Edition (Routledge).

Storesletten, Kjetil, Chris Telmer, and Amir Yaron, 2004, Cyclical Dynamics in Idiosyncratic Labor Market Risk, Journal of Political Economy 112, 695-717.

Teece, David, 1980, Economies of Scope and the Scope of the Enterprise, Journal of Economic Behavior \& Organization 1, 223-247. 
Wang, Haifeng, and Nic Lutsey, 2013, Long-Term Potential for Increased Shipping Efficiency through the Adoption of Industry-Leading Practices, The International Council on Clean Transportation 65.

Williamson, Oliver, 1975, Markets and Hierarchies: Analysis and Antitrust Implications: A Study in the Economics of Internal Organization, University of Illinois at Urbana-Champaign's Academy for Entrepreneurial Leadership Historical Research Reference in Entrepreneurship .

Williamson, Oliver, 1985, The Economic Institutions of Capitalism (Free Press). 


\section{Table 1. Descriptive Statistics}

This table presents descriptive statistics for the main variables used in our empirical analyses over the 2006-2019 period. Dependent variables are indicated in normal-type font and independent variables are denoted in italics. The investment measures are calculated at the firm-subsector-quarter level by dividing the number (alternatively, dead-weight tons) of new, used, and the sum of new and used ships acquired by the lagged number (alternatively, dead-weight tons) of ships held, and are obtained from Clarksons Research data. The disinvestment measures are calculated at the firm-subsector-quarter level by dividing the number (alternatively, dead-weight tons) of ships demolished, sold, and the sum of ships demolished and sold by the lagged number (alternatively, dead-weight tons) of ships held, and are obtained from Clarksons Research data. Net investment, calculated at the firm-subsector-quarter level, is the total number (alternatively, dead-weight tons) of ships acquired minus the total number (alternatively, dead-weight tons) of ships disinvested divided by the lagged number (alternatively, dead-weight tons) of ships held, and is obtained from Clarksons Research data. Age is the average of the logarithm of the years since a ship was built, calculated across all ships in a given firm-subsector-quarter. $D W T$ is the average of the logarithm of dead-weight tons of a ship, calculated across all ships in a given firm-subsector-quarter. $R P M$ is the average of the logarithm of ship engine's revolutions per minute, calculated across all ships in a given firm-subsector-quarter. $\triangle$ Subsectoral $B D I$ is the quarterly percentage change in the sectoral indices derived from forward freight agreement prices for routes commonly served by ships in each subsector quoted on the Baltic Exchange, and is obtained from Bloomberg. Cash Flow is the quarterly income before extraordinary items plus depreciation and amortization divided by lagged total assets, averaged across all firms operating in a given subsector weighted by the number of ships they operate in the subsector, and is obtained from Compustat and Orbis. Uncertainty is the quarterly average of the annualized daily implied volatility of nearest-to-money American call options expiring at the end of the next quarter, averaged across all firms operating in a given subsector, weighted by the number of ships they operate in the subsector, and is obtained from OptionMetrics. The Liquidity measures are defined as the quarterly logarithm of the number of ships, number of transactions divided by the lagged number of ships, and logarithm of the number of firms in a given subsector. All variables are winsorized at the $1 \%$ and $99 \%$ levels. 


\begin{tabular}{|c|c|c|c|c|c|}
\hline Variable & $\mathrm{N}$ & Mean & SD & Median & IQR \\
\hline \multicolumn{6}{|c|}{ Investment Measures (Quarterly) } \\
\hline Investment (Ships)/Lagged Number of Ships (\%) & 99,928 & 1.360 & 9.712 & 0 & 0 \\
\hline Investment (DWT)/Lagged DWT of Ships (\%) & 99,928 & 1.378 & 9.988 & 0 & 0 \\
\hline Investment (New Ships)/Lagged Number of Ships (\%) & 99,928 & 1.115 & 9.317 & 0 & 0 \\
\hline Investment (New DWT)/Lagged DWT of Ships (\%) & 99,928 & 1.128 & 8.614 & 0 & 0 \\
\hline Investment (Used Ships)/Lagged Number of Ships (\%) & 99,928 & 0.245 & 2.534 & 0 & 0 \\
\hline Investment (Used DWT)/Lagged DWT of Ships (\%) & 99,928 & 0.250 & 2.540 & 0 & 0 \\
\hline \multicolumn{6}{|c|}{ Disinvestment Measures (Quarterly) } \\
\hline Disinvestment (Ships)/Lagged Number of Ships (\%) & 99,928 & 1.262 & 7.994 & 0 & 0 \\
\hline Disinvestment (DWT)/Lagged DWT of Ships (\%) & 99,928 & 1.257 & 8.004 & 0 & 0 \\
\hline Disinvestment (Ships Sold)/Lagged Number of Ships (\%) & 99,928 & 0.642 & 5.167 & 0 & 0 \\
\hline Disinvestment (DWT Sold)/Lagged DWT of Ships (\%) & 99,928 & 0.639 & 5.198 & 0 & 0 \\
\hline Disinvestment (Ships Demolished)/Lagged Number of Ships (\%) & 99,928 & 0.620 & 6.128 & 0 & 0 \\
\hline Disinvestment (DWT Demolished)/Lagged DWT of Ships (\%) & 99,928 & 0.618 & 5.218 & 0 & 0 \\
\hline \multicolumn{6}{|c|}{ Net Investment Measures (Quarterly) } \\
\hline Net Investment (Net Ships)/Lagged Number of Ships (\%) & 99,928 & 0.241 & 13.031 & 0 & 0 \\
\hline Net Investment (Net DWT)/Lagged DWT of Ships (\%) & 99,928 & 0.345 & 13.202 & 0 & 0 \\
\hline \multicolumn{6}{|c|}{ Firm Fleet Characteristics (Quarterly) } \\
\hline Age (Log \# Years) & 99,928 & 2.873 & 0.886 & 2.929 & 1.387 \\
\hline$D W T(\log )$ & 99,928 & 11.436 & 0.795 & 11.422 & 1.033 \\
\hline$R P M(\log )$ & 99,928 & 4.769 & 0.386 & 4.742 & 0.284 \\
\hline \multicolumn{6}{|c|}{ Control Variables (Quarterly) } \\
\hline$\triangle$ Subsectoral BDI & 99,928 & 0.002 & 0.249 & -0.001 & 0.281 \\
\hline Cash Flow & 99,928 & 0.011 & 0.025 & 0.011 & 0.017 \\
\hline Uncertainty (\%) & 99,928 & 9.039 & 2.893 & 8.234 & 3.628 \\
\hline Liquidity (Log \# Ships) & 99,928 & 7.486 & 0.407 & 7.436 & 0.566 \\
\hline Liquidity (\# Trans./Lagged Number of Ships) & 99,928 & 1.581 & 0.889 & 1.418 & 1.228 \\
\hline Liquidity (Log \# Firms) & 99,928 & 5.620 & 0.560 & 5.670 & 0.782 \\
\hline
\end{tabular}


Table 2. Uncertainty, Asset Liquidity, and Investment

This table reports output from Eq. (8). The dependent variable is the investment rate, both the total rate and disaggregated into its components. The investment rate is calculated at the firm-subsector-quarter level by dividing the number of ships acquired (total, new ships acquired, or used ships acquired) by the lagged number of ships held. $\triangle$ Subsectoral $B D I$ is the quarterly percentage change in the sectoral indices derived from forward freight agreement prices for routes commonly served by ships in each subsector quoted on the Baltic Exchange. Cash Flow is the quarterly income before extraordinary items plus depreciation and amortization divided by lagged total assets, averaged across all firms operating in a given subsector weighted by the number of ships they operate in the subsector. Uncertainty is the quarterly average of annualized daily implied volatility of nearest-to-money American call options expiring at the end of the next quarter, averaged across all firms operating in a given subsector, weighted by the number of ships they operate in the subsector. The Liquidity measure is defined as the quarterly logarithm of the number of ships in a given subsector. Firm fleet controls are the average Age, DWT, and RPM of ships held by the firm-subsector in the lagged quarter. Fixed effects for headquarter country, firm, subsector, and year-quarter are included as indicated. All regressions are estimated over the 2006-2019 period. $T$-statistics are reported in parentheses, computed using robust standard errors clustered by firm-subsector and year-quarter.

\begin{tabular}{lcccc}
\hline \hline & \multicolumn{4}{c}{ Investment (Ships Acquired) } \\
\cline { 2 - 5 } & Total & Total & New & Used \\
\cline { 2 - 5 } & $(1)$ & $(2)$ & $(3)$ & $(4)$ \\
\hline Subsectoral BDI & $0.494^{* * *}$ & $0.516^{* * *}$ & $0.459^{* * *}$ & 0.057 \\
Cash Flow & $(2.83)$ & $(2.79)$ & $(3.52)$ & $(1.55)$ \\
& 0.328 & 0.362 & 0.335 & 0.027 \\
Uncertainty & $(1.07)$ & $(1.16)$ & $(1.06)$ & $(1.49)$ \\
& $-0.069^{* *}$ & $-2.642^{* * *}$ & $-2.533^{* * *}$ & -0.108 \\
Liquidity & $(-2.44)$ & $(-3.12)$ & $(-3.13)$ & $(-0.99)$ \\
& & $-4.473^{* * *}$ & $-4.150^{* * *}$ & $-0.323^{* *}$ \\
Uncertainty $\times$ Liquidity & & $(-4.29)$ & $(-4.18)$ & $(-2.41)$ \\
& & $0.328^{* * *}$ & $0.315^{* * *}$ & 0.013 \\
& & $(3.34)$ & $(3.34)$ & $(0.99)$ \\
\hline Liquidity Measure & NA & \# Ships & \# Ships & $\#$ Ships \\
\hline Controls & & & & \\
Firm-Subsector Fleet & Yes & Yes & Yes & Yes \\
\hline Fixed Effects & & & & \\
Country $\times$ Year-Quarter & Yes & Yes & Yes & Yes \\
Firm & Yes & No & No & No \\
Subsector & Yes & No & No & No \\
Firm $\times$ Subsector & No & Yes & Yes & Yes \\
\hline Observations & 99,928 & 99,928 & 99,928 & 99,928 \\
R-squared & 0.039 & 0.043 & 0.040 & 0.030 \\
\hline \hline
\end{tabular}

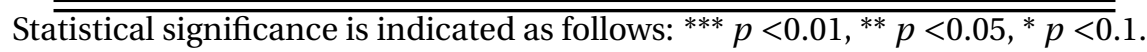


Table 3. Uncertainty, Asset Liquidity, and Disinvestment

This table reports output from Eq. (8). The dependent variable is the disinvestment rate, both the total rate and disaggregated into its components. The disinvestment rate is calculated at the firm-subsector-quarter level by dividing the number of ships disinvested (total, ships demolished, or ships sold) by the lagged number of ships held. $\Delta$ Subsectoral $B D I$ is the quarterly percentage change in the sectoral indices derived from forward freight agreement prices for routes commonly served by ships in each subsector quoted on the Baltic Exchange. Cash Flow is the quarterly income before extraordinary items plus depreciation and amortization divided by lagged total assets, averaged across all firms operating in a given subsector weighted by the number of ships they operate in the subsector. Uncertainty is the quarterly average of annualized daily implied volatility of nearest-to-money American call options expiring at the end of the next quarter, averaged across all firms operating in a given subsector, weighted by the number of ships they operate in the subsector. The Liquidity measures are defined as the quarterly logarithm of the number of ships, number of transactions divided by the lagged number of ships, and logarithm of the number of firms in a given subsector. Firm fleet controls are the average Age, $D W T$, and RPM of ships held by the firm-subsector in the lagged quarter. Fixed effects for headquarter country, firm, subsector, and year-quarter are included as indicated. All regressions are estimated over the 2006-2019 period. $T$-statistics are reported in parentheses, computed using robust standard errors clustered by firm-subsector and year-quarter.

\begin{tabular}{|c|c|c|c|c|}
\hline & \multicolumn{4}{|c|}{ Disinvestment (Ships Disinvested) } \\
\hline & Total & Total & Demolition & Sale \\
\hline & (1) & (2) & (3) & (4) \\
\hline$\Delta$ Subsectoral BDI & $\begin{array}{l}-0.220^{*} \\
(-1.92)\end{array}$ & $\begin{array}{l}-0.778 \\
(-1.36)\end{array}$ & $\begin{array}{l}-0.465 \\
(-1.42)\end{array}$ & $\begin{array}{l}-0.313 \\
(-0.86)\end{array}$ \\
\hline Cash Flow & $\begin{array}{l}-0.130 \\
(-0.19)\end{array}$ & $\begin{array}{l}-0.293 \\
(-0.56)\end{array}$ & $\begin{array}{l}-0.144 \\
(-0.85)\end{array}$ & $\begin{array}{l}-0.149 \\
(-1.48)\end{array}$ \\
\hline Uncertainty & $\begin{array}{c}-0.159 * * \\
(-2.04)\end{array}$ & $\begin{array}{c}-1.387^{* * *} \\
(-3.02)\end{array}$ & $\begin{array}{c}-0.893^{* * *} \\
(-3.24)\end{array}$ & $\begin{array}{l}-0.495^{*} \\
(-1.80)\end{array}$ \\
\hline Liquidity & & $\begin{array}{c}-1.173^{* *} \\
(-2.38)\end{array}$ & $\begin{array}{c}-0.850^{* * *} \\
(-2.93)\end{array}$ & $\begin{array}{l}-0.323 \\
(-1.21)\end{array}$ \\
\hline Uncertainty $\times$ Liquidity & & $\begin{array}{c}0.171^{* * *} \\
(3.18)\end{array}$ & $\begin{array}{c}0.117^{* * *} \\
(3.62)\end{array}$ & $\begin{array}{c}0.054^{*} \\
(1.83)\end{array}$ \\
\hline Liquidity Measure & NA & \# Ships & \# Ships & \# Ships \\
\hline $\begin{array}{l}\text { Controls } \\
\text { Firm-Subsector Fleet }\end{array}$ & Yes & Yes & Yes & Yes \\
\hline $\begin{array}{l}\text { Fixed Effects } \\
\text { Country } \times \text { Year-Quarter } \\
\text { Firm } \\
\text { Subsector } \\
\text { Firm } \times \text { Subsector }\end{array}$ & $\begin{array}{l}\text { Yes } \\
\text { Yes } \\
\text { Yes } \\
\text { No }\end{array}$ & $\begin{array}{l}\text { Yes } \\
\text { No } \\
\text { No } \\
\text { Yes }\end{array}$ & $\begin{array}{l}\text { Yes } \\
\text { No } \\
\text { No } \\
\text { Yes }\end{array}$ & $\begin{array}{l}\text { Yes } \\
\text { No } \\
\text { No } \\
\text { Yes }\end{array}$ \\
\hline $\begin{array}{l}\text { Observations } \\
\text { R-squared }\end{array}$ & $\begin{array}{c}99,928 \\
0.050\end{array}$ & $\begin{array}{c}99,928 \\
0.052\end{array}$ & $\begin{array}{c}99,928 \\
0.076\end{array}$ & $\begin{array}{c}99,928 \\
0.025\end{array}$ \\
\hline
\end{tabular}


Table 4. Uncertainty, Investment, and Disinvestment: A Quasi-Natural Experiment

This table reports output from Eq. (9) in a matched sample in Panel A. In Panel B, we report the second stage output from Eq. (8) estimated using instrumental variables. The dependent variable is the investment (disinvestment) rate. The investment rate is calculated at the firm-subsector-quarter level by dividing the number of ships acquired (disinvested) by the lagged number of ships held. Treat is an indicator that takes the value of 0 for the Capesize and VLCC subsectors and 1 for the Panamax and LR1 subsectors. Piracy is an indicator that takes the value of 1 for the years 2009-2011, and 0 for all other years. Subsector controls are $\Delta$ Subsectoral BDI and Cash Flow. $\Delta$ Subsectoral BDI is the quarterly percentage change in the sectoral indices derived from forward freight agreement prices for routes commonly served by ships in each subsector quoted on the Baltic Exchange. Cash Flow is the quarterly income before extraordinary items plus depreciation and amortization divided by lagged total assets, averaged across all firms operating in a given subsector weighted by the number of ships they operate in the subsector. Uncertainty is the quarterly average of annualized daily implied volatility of nearest-to-money American call options expiring at the end of the next quarter, averaged across all firms operating in a given subsector, weighted by the number of ships they operate in the subsector. Firm fleet controls are the average Age, $D W T$, and $R P M$ of ships held by the firm-subsector in the lagged quarter. Each treated firm-subsector is matched to 1 control firm-subsector (with replacement) which is its nearest neighbor in terms of treatment propensity. The propensity score is a function of the firm-subsector fleet controls. In Panel B, Uncertainty is instrumented by Treat $\times$ Piracy. Fixed effects for headquarter country, firm, subsector, and year-quarter are included as indicated. All regressions are estimated over the 2006-2013 period. $T$-statistics are reported in parentheses, computed using robust standard errors clustered by match in Panel A and by firm-subsector and year-quarter in Panel B.

\begin{tabular}{|c|c|c|c|c|c|c|}
\hline \multicolumn{7}{|c|}{ Panel A: Matched Sample Difference-in-Differences } \\
\hline & \multicolumn{3}{|c|}{ Investment (Ships Acquired) } & \multicolumn{2}{|c|}{$\begin{array}{l}\text { Disinvestment } \\
\text { vested) }\end{array}$} & \multirow{2}{*}{$\begin{array}{l}\text { Disin- } \\
\text { Sale }\end{array}$} \\
\hline & Total & New & Used & Total & Demolish & \\
\hline & (1) & $(2)$ & (3) & (4) & (5) & $(6)$ \\
\hline Treat $\times$ Piracy & $\begin{array}{c}-1.299^{* * *} \\
(-2.97)\end{array}$ & $\begin{array}{c}-1.197^{* * *} \\
(-3.41)\end{array}$ & $\begin{array}{l}-0.102 \\
(-0.89)\end{array}$ & $\begin{array}{c}-0.252^{* * *} \\
(-3.28)\end{array}$ & $\begin{array}{c}-0.166^{* * *} \\
(-3.44)\end{array}$ & $\begin{array}{l}-0.086 \\
(-1.17)\end{array}$ \\
\hline \multicolumn{7}{|l|}{ Controls } \\
\hline Subsector & Yes & Yes & Yes & Yes & Yes & Yes \\
\hline Firm-Subsector Fleet & Yes & Yes & Yes & Yes & Yes & Yes \\
\hline \multicolumn{7}{|l|}{ Fixed Effects } \\
\hline Country $\times$ Year-Quarter & Yes & Yes & Yes & Yes & Yes & Yes \\
\hline Firm $\times$ Subsector & Yes & Yes & Yes & Yes & Yes & Yes \\
\hline Observations & 14,651 & 14,651 & 14,651 & 14,651 & 14,651 & 14,651 \\
\hline R-squared & 0.045 & 0.055 & 0.043 & 0.066 & 0.085 & 0.053 \\
\hline
\end{tabular}

Statistical significance is indicated as follows: ${ }^{* * *} p<0.01,{ }^{* *} p<0.05,{ }^{*} p<0.1$. 


\begin{tabular}{|c|c|c|c|c|c|c|}
\hline \multicolumn{7}{|c|}{ Panel B: Instrumental Variables Regression (Second Stage) } \\
\hline & \multicolumn{3}{|c|}{ Investment (Ships Acquired) } & \multicolumn{3}{|c|}{ Disinvestment (Ships Disinvested) } \\
\hline & Total & New & Used & Total & Demolish & Sale \\
\hline & (1) & (2) & (3) & (4) & (5) & (6) \\
\hline Uncertainty & $\begin{array}{c}-0.187^{* * *} \\
(-2.80)\end{array}$ & $\begin{array}{c}-0.168^{* * *} \\
(-2.88)\end{array}$ & $\begin{array}{l}-0.019 \\
(-0.91)\end{array}$ & $\begin{array}{c}-0.038^{* *} \\
(-2.14)\end{array}$ & $\begin{array}{c}-0.025^{* *} \\
(-2.29)\end{array}$ & $\begin{array}{l}-0.013 \\
(-1.58)\end{array}$ \\
\hline $\begin{array}{l}\text { Controls } \\
\text { Subsector } \\
\text { Firm-Subsector Fleet }\end{array}$ & $\begin{array}{l}\text { Yes } \\
\text { Yes }\end{array}$ & $\begin{array}{l}\text { Yes } \\
\text { Yes }\end{array}$ & $\begin{array}{l}\text { Yes } \\
\text { Yes }\end{array}$ & $\begin{array}{l}\text { Yes } \\
\text { Yes }\end{array}$ & $\begin{array}{l}\text { Yes } \\
\text { Yes }\end{array}$ & $\begin{array}{l}\text { Yes } \\
\text { Yes }\end{array}$ \\
\hline $\begin{array}{l}\text { Fixed Effects } \\
\text { Country } \times \text { Year-Quarter } \\
\text { Firm } \times \text { Subsector }\end{array}$ & $\begin{array}{l}\text { Yes } \\
\text { Yes }\end{array}$ & $\begin{array}{l}\text { Yes } \\
\text { Yes }\end{array}$ & $\begin{array}{l}\text { Yes } \\
\text { Yes }\end{array}$ & $\begin{array}{l}\text { Yes } \\
\text { Yes }\end{array}$ & $\begin{array}{l}\text { Yes } \\
\text { Yes }\end{array}$ & $\begin{array}{l}\text { Yes } \\
\text { Yes }\end{array}$ \\
\hline $\begin{array}{l}\text { Observations } \\
\text { R-squared }\end{array}$ & $\begin{array}{c}14,651 \\
0.078\end{array}$ & $\begin{array}{c}14,651 \\
0.081\end{array}$ & $\begin{array}{c}14,651 \\
0.076\end{array}$ & $\begin{array}{c}14,651 \\
0.073\end{array}$ & $\begin{array}{c}14,651 \\
0.084\end{array}$ & $\begin{array}{c}14,651 \\
0.066\end{array}$ \\
\hline
\end{tabular}

Statistical significance is indicated as follows: ${ }^{* * *} p<0.01,{ }^{* *} p<0.05,{ }^{*} p<0.1$. 
Table 5. Uncertainty and Productivity - Investment

This table reports output from Eq. (8). The dependent variable is the investment rate conditioning on measures of productivity. The investment rate is calculated at the firm-subsector-quarter level by dividing the number of ships acquired (high- or low-productivity) by the lagged number of ships held. Panel A reports results on investment (new or used) conditioning on a ship's productivity. High-productivity ships are defined as a ship being above (below) median on at least one out of two characteristics: $D W T(R P M)$. Low-productivity ships are analogously defined. Panel B reports results on investment conditioning on a ship's Age at the time of investment. Subsector controls are $\Delta$ Subsectoral $B D I$ and Cash Flow. $\triangle$ Subsectoral BDI is the quarterly percentage change in the sectoral indices derived from forward freight agreement prices for routes commonly served by ships in each subsector quoted on the Baltic Exchange. Cash Flow is the quarterly income before extraordinary items plus depreciation and amortization divided by lagged total assets, averaged across all firms operating in a given subsector weighted by the number of ships they operate in the subsector. Uncertainty is the quarterly average of annualized daily implied volatility of nearest-to-money American call options expiring at the end of the next quarter, averaged across all firms operating in a given subsector, weighted by the number of ships they operate in the subsector. The Liquidity measure is the quarterly logarithm of the number of ships in a given subsector. Firm fleet controls are the average Age, DWT, and RPM of ships held by the firm-subsector in the lagged quarter. Fixed effects for headquarter country, firm, subsector, and year-quarter are included as indicated. All regressions are estimated over the 2006-2019 period. T-statistics are reported in parentheses, computed using robust standard errors clustered by firm-subsector and year-quarter.

\begin{tabular}{|c|c|c|c|c|}
\hline \multicolumn{5}{|c|}{ Panel A: Investment (Ships Acquired) by Productivity (DWT and RPM) } \\
\hline & \multicolumn{2}{|c|}{ New } & \multicolumn{2}{|c|}{ Used } \\
\hline & $\begin{array}{l}\text { High- } \\
\text { Productivity } \\
\text { (1) }\end{array}$ & $\begin{array}{c}\text { Low- } \\
\text { Productivity } \\
\text { (2) }\end{array}$ & $\begin{array}{l}\text { High- } \\
\text { Productivity } \\
\text { (3) }\end{array}$ & $\begin{array}{c}\text { Low- } \\
\text { Productivity } \\
\text { (4) }\end{array}$ \\
\hline Uncertainty & $\begin{array}{c}-1.944^{* * *} \\
(-3.85)\end{array}$ & $\begin{array}{l}-0.589 \\
(-0.85)\end{array}$ & $\begin{array}{l}-0.074 \\
(-0.97)\end{array}$ & $\begin{array}{l}-0.034 \\
(-0.63)\end{array}$ \\
\hline Liquidity & $\begin{array}{c}-3.484^{* * *} \\
(-2.92)\end{array}$ & $\begin{array}{l}-0.666 \\
(-0.48)\end{array}$ & $\begin{array}{l}-0.201^{*} \\
(-1.90)\end{array}$ & $\begin{array}{l}-0.122^{*} \\
(-1.69)\end{array}$ \\
\hline Uncertainty $\times$ Liquidity & $\begin{array}{c}0.220^{* * *} \\
(2.97)\end{array}$ & $\begin{array}{l}0.095 \\
(0.99)\end{array}$ & $\begin{array}{l}0.009 \\
(0.47)\end{array}$ & $\begin{array}{l}0.004 \\
(0.70)\end{array}$ \\
\hline Liquidity Measure & \# Ships & \# Ships & \# Ships & \# Ships \\
\hline $\begin{array}{l}\text { Controls } \\
\text { Subsector } \\
\text { Firm-Subsector Fleet }\end{array}$ & $\begin{array}{l}\text { Yes } \\
\text { Yes }\end{array}$ & $\begin{array}{l}\text { Yes } \\
\text { Yes }\end{array}$ & $\begin{array}{l}\text { Yes } \\
\text { Yes }\end{array}$ & $\begin{array}{l}\text { Yes } \\
\text { Yes }\end{array}$ \\
\hline $\begin{array}{l}\text { Fixed Effects } \\
\text { Country } \times \text { Year-Quarter } \\
\text { Firm } \times \text { Subsector }\end{array}$ & $\begin{array}{l}\text { Yes } \\
\text { Yes }\end{array}$ & $\begin{array}{l}\text { Yes } \\
\text { Yes }\end{array}$ & $\begin{array}{l}\text { Yes } \\
\text { Yes }\end{array}$ & $\begin{array}{l}\text { Yes } \\
\text { Yes }\end{array}$ \\
\hline $\begin{array}{l}\text { Observations } \\
\text { R-squared }\end{array}$ & $\begin{array}{c}99,928 \\
0.048\end{array}$ & $\begin{array}{c}99,928 \\
0.046\end{array}$ & $\begin{array}{c}99,928 \\
0.032\end{array}$ & $\begin{array}{c}99,928 \\
0.035\end{array}$ \\
\hline
\end{tabular}




\begin{tabular}{|c|c|c|c|c|c|}
\hline \multicolumn{6}{|c|}{ Panel B: Investment (Ships Acquired) by Age } \\
\hline & $\begin{array}{l}\text { New } \\
(1)\end{array}$ & $\begin{array}{c}1-5 \text { Years } \\
(2)\end{array}$ & $\begin{array}{c}\text { 6-15 Years } \\
\text { (3) }\end{array}$ & $\begin{array}{c}\text { 16-25 Years } \\
\text { (4) }\end{array}$ & $\begin{array}{c}26+\text { Years } \\
(5)\end{array}$ \\
\hline Uncertainty & $\begin{array}{c}-2.533^{* * *} \\
(-3.13)\end{array}$ & $\begin{array}{c}-0.731^{* *} \\
(-2.92)\end{array}$ & $\begin{array}{c}-0.301^{*} \\
(-1.79)\end{array}$ & $\begin{array}{l}-0.051 \\
(-0.63)\end{array}$ & $\begin{array}{l}-0.017 \\
(-1.04)\end{array}$ \\
\hline Liquidity & $\begin{array}{c}-4.150^{* * *} \\
(-4.18)\end{array}$ & $\begin{array}{c}-1.705^{* * *} \\
(-2.79)\end{array}$ & $\begin{array}{c}-0.594^{* *} \\
(-2.53)\end{array}$ & $\begin{array}{c}-0.025^{*} \\
(-1.88)\end{array}$ & $\begin{array}{l}-0.254^{*} \\
(-1.92)\end{array}$ \\
\hline Uncertainty $\times$ Liquidity & $\begin{array}{c}0.315^{* * *} \\
(3.34)\end{array}$ & $\begin{array}{c}0.089 * * * \\
(3.07)\end{array}$ & $\begin{array}{c}0.038^{* * *} \\
(3.18)\end{array}$ & $\begin{array}{l}0.010 \\
(1.22)\end{array}$ & $\begin{array}{l}0.007 \\
(1.39)\end{array}$ \\
\hline Liquidity Measure & \# Ships & \# Ships & \# Ships & \# Ships & \# Ships \\
\hline $\begin{array}{l}\text { Controls } \\
\text { Subsector }\end{array}$ & Yes & Yes & Yes & Yes & Yes \\
\hline Firm-Subsector Fleet & Yes & Yes & Yes & Yes & Yes \\
\hline Fixed Effects & & & & & \\
\hline Country $\times$ Year-Quarter & Yes & Yes & Yes & Yes & Yes \\
\hline Firm $\times$ Subsector & Yes & Yes & Yes & Yes & Yes \\
\hline Observations & 99,928 & 99,928 & 99,928 & 99,928 & 99,928 \\
\hline R-squared & 0.040 & 0.043 & 0.033 & 0.034 & 0.033 \\
\hline
\end{tabular}

Statistical significance is indicated as follows: ${ }^{* * *} p<0.01,{ }^{* *} p<0.05,{ }^{*} p<0.1$. 
Table 6. Uncertainty and Productivity - Disinvestment

This table reports output from Eq. (8). The dependent variable is the disinvestment rate conditioning on measures of productivity. The disinvestment rate is calculated at the firm-subsector-quarter level by dividing the number of ships disinvested (high- or low-productivity) by the lagged number of ships held. High-productivity ships are defined as a ship being above (below) median on two out of three characteristics: DWT (Age, RPM). Low-productivity ships are analogously defined. Subsector controls are $\triangle$ Subsectoral BDI and Cash Flow. $\triangle$ Subsectoral BDI is the quarterly percentage change in the sectoral indices derived from forward freight agreement prices for routes commonly served by ships in each subsector quoted on the Baltic Exchange. Cash Flow is the quarterly income before extraordinary items plus depreciation and amortization divided by lagged total assets, averaged across all firms operating in a given subsector weighted by the number of ships they operate in the subsector. Uncertainty is the quarterly average of annualized daily implied volatility of nearest-to-money American call options expiring at the end of the next quarter, averaged across all firms operating in a given subsector, weighted by the number of ships they operate in the subsector. The Liquidity measure is the quarterly logarithm of the number of ships in a given subsector. Firm fleet controls are the average Age, $D W T$, and $R P M$ of ships held by the firm-subsector in the lagged quarter. Fixed effects for headquarter country, firm, subsector, and year-quarter are included as indicated. All regressions are estimated over the 2006-2019 period. $T$-statistics are reported in parentheses, computed using robust standard errors clustered by firm-subsector and year-quarter.

\begin{tabular}{|c|c|c|c|c|}
\hline & \multicolumn{2}{|c|}{ High-Productivity Ships } & \multicolumn{2}{|c|}{ Low-Productivity Ships } \\
\hline & Demolition & Sale & Demolition & Sale \\
\hline & (1) & (2) & (3) & (4) \\
\hline Uncertainty & $\begin{array}{l}-0.105 \\
(-0.88)\end{array}$ & $\begin{array}{l}-0.054 \\
(-0.34)\end{array}$ & $\begin{array}{c}-0.788^{* * *} \\
(-2.99)\end{array}$ & $\begin{array}{c}-0.341^{* *} \\
(-2.23)\end{array}$ \\
\hline Liquidity & $\begin{array}{l}-0.152 \\
(-0.57)\end{array}$ & $\begin{array}{l}-0.095 \\
(-1.02)\end{array}$ & $\begin{array}{c}-0.698^{* * *} \\
(-3.44)\end{array}$ & $\begin{array}{l}-0.228 \\
(-1.17)\end{array}$ \\
\hline Uncertainty $\times$ Liquidity & $\begin{array}{l}0.025 \\
(0.83)\end{array}$ & $\begin{array}{l}0.011 \\
(0.46)\end{array}$ & $\begin{array}{c}0.102^{* * *} \\
(3.98)\end{array}$ & $\begin{array}{c}0.043^{* *} \\
(2.21)\end{array}$ \\
\hline Controls & & & & \\
\hline Subsector & Yes & Yes & Yes & Yes \\
\hline Firm-Subsector Fleet & Yes & Yes & Yes & Yes \\
\hline Fixed Effects & & & & \\
\hline Country $\times$ Year-Quarter & Yes & Yes & Yes & Yes \\
\hline Firm $\times$ Subsector & Yes & Yes & Yes & Yes \\
\hline Observations & 99,928 & 99,928 & 99,928 & 99,928 \\
\hline R-squared & 0.088 & 0.046 & 0.090 & 0.032 \\
\hline
\end{tabular}


Table 7. Uncertainty, Asset Liquidity, and Concentration of Firm Asset Holdings

This table reports output from a variant of Eq. (8) estimated at the firm-quarter level. The dependent variable in Panel A is the HHI of ship holdings. The HHI is calculated at the firm-quarter level based on the number of ships held by the firm across the subsectors it operates in. The dependent variable in Panel B is the number of subsectors (specifically, the natural logarithm of the number of distinct subsectors) a firm is exposed to, calculated at the firm-quarter level. Firm controls are Cash Flow and $\Delta$ Subsectoral BDI. Cash Flow is the quarterly income before extraordinary items plus depreciation and amortization divided by lagged total assets, averaged across all firms operating in a given subsector weighted by the number of ships they operate in the subsector, averaged across all subsectors that a firm operates in weighted by the number of ships it operates in the subsector. $\triangle$ Subsectoral $B D I$ is the quarterly percentage change in the sectoral indices derived from forward freight agreement prices for routes commonly served by ships in each subsector quoted on the Baltic Exchange, averaged across all subsectors that a firm operates in weighted by the number of ships it operates in the subsector. Uncertainty is the quarterly average of annualized daily implied volatility of nearest-to-money American call options expiring at the end of the next quarter, averaged across all firms operating in a given subsector, weighted by the number of ships they operate in the subsector, averaged across all subsectors that a firm operates in weighted by the number of ships it operates in the subsector. The Liquidity measures are defined as the quarterly logarithm of the number of ships, number of transactions divided by the lagged number of ships, and logarithm of the number of firms in a given subsector, averaged across all subsectors that a firm operates in weighted by the number of ships it operates in the subsector. Firm fleet controls are the average Age, DWT, and RPM of ships held by the firm in the lagged quarter. Fixed effects for headquarter country, firm, and year-quarter are included as indicated. All regressions are estimated over the 2006-2019 period. $T$-statistics are reported in parentheses, computed using robust standard errors clustered by firm and year-quarter.

\begin{tabular}{|c|c|c|c|c|}
\hline \multicolumn{5}{|c|}{ Panel A: HHI of Ship Holdings at the Firm-Level } \\
\hline & $(1)$ & $(2)$ & (3) & (4) \\
\hline Uncertainty & $\begin{array}{c}0.007^{* * *} \\
(3.64)\end{array}$ & $\begin{array}{c}0.241^{* * *} \\
(4.17)\end{array}$ & $\begin{array}{c}0.006^{* * *} \\
(3.99)\end{array}$ & $\begin{array}{c}0.166^{* * *} \\
(3.82)\end{array}$ \\
\hline Liquidity & & $\begin{array}{c}-0.281^{* * *} \\
(-6.14)\end{array}$ & $\begin{array}{l}-0.018 \\
(-1.17)\end{array}$ & $\begin{array}{c}-0.202^{* * *} \\
(-6.82)\end{array}$ \\
\hline Uncertainty $\times$ Liquidity & & $\begin{array}{c}-0.038^{* * *} \\
(-5.52)\end{array}$ & $\begin{array}{c}-0.003^{* * *} \\
(-3.16)\end{array}$ & $\begin{array}{c}-0.027^{* * *} \\
(-7.14)\end{array}$ \\
\hline Liquidity Measure & NA & \# Ships & \# Trans. & \# Firms \\
\hline \multicolumn{5}{|l|}{ Controls } \\
\hline Firm & Yes & Yes & Yes & Yes \\
\hline Firm Fleet & Yes & Yes & Yes & Yes \\
\hline \multicolumn{5}{|l|}{ Fixed Effects } \\
\hline Country×Year-Quarter & Yes & Yes & Yes & Yes \\
\hline Firm & Yes & Yes & Yes & Yes \\
\hline Observations & 42,206 & 42,206 & 42,206 & 42,206 \\
\hline R-squared & 0.788 & 0.690 & 0.690 & 0.690 \\
\hline
\end{tabular}




\begin{tabular}{|c|c|c|c|c|}
\hline \multicolumn{5}{|c|}{ Panel B: Number of Subsectors at the Firm-Level } \\
\hline & (1) & (2) & (3) & (4) \\
\hline Uncertainty & $\begin{array}{c}-0.006^{* * *} \\
(-7.39)\end{array}$ & $\begin{array}{c}-0.078^{* * *} \\
(-3.92)\end{array}$ & $\begin{array}{c}-0.008^{* * *} \\
(-4.84)\end{array}$ & $\begin{array}{c}-0.041^{* * *} \\
(-5.05)\end{array}$ \\
\hline Liquidity & & $\begin{array}{l}0.277 \\
(0.48)\end{array}$ & $\begin{array}{c}0.214^{* * *} \\
(14.33)\end{array}$ & $\begin{array}{l}0.213 \\
(1.61)\end{array}$ \\
\hline Uncertainty $\times$ Liquidity & & $\begin{array}{c}0.010^{* *} \\
(1.99)\end{array}$ & $\begin{array}{c}0.001^{* * *} \\
(3.86)\end{array}$ & $\begin{array}{c}0.007^{* * *} \\
(4.00)\end{array}$ \\
\hline Liquidity Measure & NA & \# Ships & \# Trans. & \# Firms \\
\hline \multicolumn{5}{|l|}{ Controls } \\
\hline Firm & Yes & Yes & Yes & Yes \\
\hline Firm Fleet & Yes & Yes & Yes & Yes \\
\hline \multicolumn{5}{|l|}{ Fixed Effects } \\
\hline Country×Year-Quarter & Yes & Yes & Yes & Yes \\
\hline Firm & Yes & Yes & Yes & Yes \\
\hline Observations & 42,206 & 42,206 & 42,206 & 42,206 \\
\hline R-squared & 0.835 & 0.838 & 0.838 & 0.838 \\
\hline
\end{tabular}


Table 8. Uncertainty, Asset Liquidity, and Productivity of Firm Asset Holdings

This table reports output from a variant of Eq. (8) estimated at the firm-quarter level. The dependent variables are the average Age, DWT, and RPM of ships held by a firm in a given quarter. Firm controls are Cash Flow and $\triangle$ Subsectoral BDI. Cash Flow is the quarterly income before extraordinary items plus depreciation and amortization divided by lagged total assets, averaged across all firms operating in a given subsector weighted by the number of ships they operate in the subsector, averaged across all subsectors that a firm operates in weighted by the number of ships it operates in the subsector. $\triangle$ Subsectoral $B D I$ is the quarterly percentage change in the sectoral indices derived from forward freight agreement prices for routes commonly served by ships in each subsector quoted on the Baltic Exchange, averaged across all subsectors that a firm operates in weighted by the number of ships it operates in the subsector. Uncertainty is the quarterly average of annualized daily implied volatility of nearest-to-money American call options expiring at the end of the next quarter, averaged across all firms operating in a given subsector, weighted by the number of ships they operate in the subsector, averaged across all subsectors that a firm operates in weighted by the number of ships it operates in the subsector. The Liquidity measure is defined as the quarterly logarithm of the number of ships held by all firms in a given subsector, averaged across all subsectors that a firm operates in weighted by the number of ships it operates in the subsector. Firm fleet controls are the average Age, DWT, and RPM of ships held by the firm in the lagged quarter. Fixed effects for headquarter country, firm, and year-quarter are included as indicated. All regressions are estimated over the 2006-2019 period. $T$-statistics are reported in parentheses, computed using robust standard errors clustered by firm and year-quarter.

\begin{tabular}{|c|c|c|c|}
\hline \multicolumn{4}{|c|}{ Productivity Characteristics at the Firm-Level } \\
\hline & Age & $D W T$ & $R P M$ \\
\hline & $(1)$ & $(2)$ & $(3)$ \\
\hline Uncertainty & $\begin{array}{c}0.382^{* * *} \\
(3.77)\end{array}$ & $\begin{array}{c}-0.044^{* *} \\
(2.23)\end{array}$ & $\begin{array}{c}0.047^{* * *} \\
(2.96)\end{array}$ \\
\hline Liquidity & $\begin{array}{c}0.405^{*} \\
(1.86)\end{array}$ & $\begin{array}{l}0.075 \\
(0.43)\end{array}$ & $\begin{array}{l}-0.036 \\
(-0.59)\end{array}$ \\
\hline Uncertainty $\times$ Liquidity & $\begin{array}{c}-0.005^{* *} \\
(-2.54)\end{array}$ & $\begin{array}{c}0.005^{* * *} \\
(3.20)\end{array}$ & $\begin{array}{c}-0.003^{* * *} \\
(-3.62)\end{array}$ \\
\hline Liquidity Measure & \# Ships & \# Ships & \# Ships \\
\hline \multicolumn{4}{|l|}{ Controls } \\
\hline Firm & Yes & Yes & Yes \\
\hline Firm Fleet & Yes & Yes & Yes \\
\hline \multicolumn{4}{|l|}{ Fixed Effects } \\
\hline Country $\times$ Year-Quarter & Yes & Yes & Yes \\
\hline Firm & Yes & Yes & Yes \\
\hline Observations & 42,206 & 42,206 & 42,206 \\
\hline R-squared & 0.756 & 0.740 & 0.696 \\
\hline
\end{tabular}

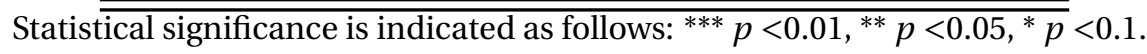


Table 9. Uncertainty, Asset Liquidity, and Asset Allocation at the Firm-Level

This table reports output from a variant of Eq. (8) estimated at the firm-quarter level. The dependent variables are the investment and disinvestment rates. The investment rate is calculated at the firm-quarter level by dividing the number of ships acquired (new, used, and total) by the lagged number of ships held. The disinvestment rate is calculated at the firm-quarter level by dividing the number of ships disinvested (demolished, sold, and total) by the lagged number of ships held. $\triangle$ Subsectoral $B D I$ is the quarterly percentage change in the sectoral indices derived from forward freight agreement prices for routes commonly served by ships in each subsector quoted on the Baltic Exchange, averaged across all subsectors that a firm operates in weighted by the number of ships it operates in the subsector. Cash Flow is the quarterly income before extraordinary items plus depreciation and amortization divided by lagged total assets, averaged across all firms operating in a given subsector weighted by the number of ships they operate in the subsector, averaged across all subsectors that a firm operates in weighted by the number of ships it operates in the subsector. Uncertainty is the quarterly average of annualized daily implied volatility of nearest-to-money American call options expiring at the end of the next quarter, averaged across all firms operating in a given subsector, weighted by the number of ships they operate in the subsector, averaged across all subsectors that a firm operates in weighted by the number of ships it operates in the subsector. The Liquidity measure is the quarterly logarithm of the number of ships in a given subsector, averaged across all subsectors that a firm operates in weighted by the number of ships it operates in the subsector. Firm fleet controls are the average Age, $D W T$, and $R P M$ of ships held by the firm in the lagged quarter. Fixed effects for headquarter country, firm, and year-quarter are included as indicated. All regressions are estimated over the 2006-2019 period. $T$-statistics are reported in parentheses, computed using robust standard errors clustered by firm and year-quarter.

\begin{tabular}{|c|c|c|c|c|c|c|}
\hline \multicolumn{7}{|c|}{ Panel A: Investment (Ships Acquired) at the Firm-Level } \\
\hline & \multicolumn{2}{|c|}{ Total } & \multicolumn{2}{|c|}{ New } & \multicolumn{2}{|c|}{ Used } \\
\hline & (1) & (2) & (3) & (4) & (5) & (6) \\
\hline$\Delta$ Subsectoral BDI & $\begin{array}{c}0.515^{* * *} \\
(3.55)\end{array}$ & $\begin{array}{c}0.614^{* * *} \\
(2.98)\end{array}$ & $\begin{array}{c}0.388^{* * *} \\
(3.07)\end{array}$ & $\begin{array}{c}0.501^{* * *} \\
(2.99)\end{array}$ & $\begin{array}{c}0.127^{* * *} \\
(3.02)\end{array}$ & $\begin{array}{l}0.113^{*} \\
(1.88)\end{array}$ \\
\hline Cash Flow & $\begin{array}{l}1.188^{*} \\
(1.66)\end{array}$ & $\begin{array}{c}1.047^{* *} \\
(2.12)\end{array}$ & $\begin{array}{c}0.913^{* *} \\
(2.38)\end{array}$ & $\begin{array}{c}0.864^{* *} \\
(2.65)\end{array}$ & $\begin{array}{c}0.275^{* *} \\
(2.24)\end{array}$ & $\begin{array}{c}0.183^{* *} \\
(2.47)\end{array}$ \\
\hline Uncertainty & $\begin{array}{c}-0.067^{* *} \\
(-2.64)\end{array}$ & $\begin{array}{c}-4.966^{* *} \\
(-2.41)\end{array}$ & $\begin{array}{c}-0.051^{* * *} \\
(-3.12)\end{array}$ & $\begin{array}{c}-4.110^{* * *} \\
(-2.89)\end{array}$ & $\begin{array}{l}-0.016 \\
(-1.08)\end{array}$ & $\begin{array}{l}-0.856 \\
(-0.72)\end{array}$ \\
\hline Liquidity & & $\begin{array}{l}-5.843 \\
(-1.53)\end{array}$ & & $\begin{array}{l}-3.615 \\
(-0.67)\end{array}$ & & $\begin{array}{c}-2.228^{*} \\
(-1.81)\end{array}$ \\
\hline Uncertainty $\times$ Liquidity & & $\begin{array}{c}0.814^{* *} \\
(2.36) \\
\end{array}$ & & $\begin{array}{c}0.686^{* *} \\
(2.44)\end{array}$ & & $\begin{array}{l}0.128 \\
(0.93) \\
\end{array}$ \\
\hline Liquidity Measure & NA & \# Ships & NA & \# Ships & NA & \# Ships \\
\hline $\begin{array}{l}\text { Controls } \\
\text { Firm Fleet }\end{array}$ & Yes & Yes & Yes & Yes & Yes & Yes \\
\hline Fixed Effects & & & & & & \\
\hline Country $\times$ Year-Quarter & Yes & Yes & Yes & Yes & Yes & Yes \\
\hline Firm & Yes & Yes & Yes & Yes & Yes & Yes \\
\hline Observations & 42,206 & 42,206 & 42,206 & 42,206 & 42,206 & 42,206 \\
\hline R-squared & 0.071 & 0.070 & 0.069 & 0.070 & 0.038 & 0.037 \\
\hline
\end{tabular}




\begin{tabular}{|c|c|c|c|c|c|c|}
\hline \multicolumn{7}{|c|}{ Panel B: Disinvestment (Ships Disinvested) at the Firm-Level } \\
\hline & \multicolumn{2}{|c|}{ Total } & \multicolumn{2}{|c|}{ Demolition } & \multicolumn{2}{|c|}{ Sale } \\
\hline & (1) & (2) & (3) & (4) & (5) & (6) \\
\hline$\triangle$ Subsectoral BDI & $\begin{array}{c}-0.288^{* * *} \\
(-3.73)\end{array}$ & $\begin{array}{c}-0.199 * * * \\
(-3.44)\end{array}$ & $\begin{array}{c}-0.212^{* * *} \\
(-5.89)\end{array}$ & $\begin{array}{c}-0.126^{* *} \\
(-2.24)\end{array}$ & $\begin{array}{c}-0.076^{* *} \\
(-2.49)\end{array}$ & $\begin{array}{c}-0.073^{*} \\
(-1.82)\end{array}$ \\
\hline Cash Flow & $\begin{array}{c}-0.486^{*} \\
(-1.81)\end{array}$ & $\begin{array}{c}-0.327^{*} \\
(-1.70)\end{array}$ & $\begin{array}{l}-0.244 \\
(-1.14)\end{array}$ & $\begin{array}{l}-0.201 \\
(-1.09)\end{array}$ & $\begin{array}{l}-0.242 \\
(-1.49)\end{array}$ & $\begin{array}{l}-0.126 \\
(-1.17)\end{array}$ \\
\hline Uncertainty & $\begin{array}{c}-0.051^{* * *} \\
(-3.13)\end{array}$ & $\begin{array}{c}-6.482^{* * *} \\
(-2.98)\end{array}$ & $\begin{array}{c}-0.026^{* * *} \\
(-3.99)\end{array}$ & $\begin{array}{c}-3.378^{* * *} \\
(-3.41)\end{array}$ & $\begin{array}{l}-0.025^{*} \\
(-1.78)\end{array}$ & $\begin{array}{c}-3.104^{* *} \\
(-2.17)\end{array}$ \\
\hline Liquidity & & $\begin{array}{c}-5.712^{* * *} \\
(-3.68)\end{array}$ & & $\begin{array}{c}-3.126^{* * *} \\
(-4.19)\end{array}$ & & $\begin{array}{c}-2.586^{*} \\
(-1.73)\end{array}$ \\
\hline Uncertainty $\times$ Liquidity & & $\begin{array}{c}0.882^{* * *} \\
(3.32)\end{array}$ & & $\begin{array}{c}0.498^{* * *} \\
(3.91)\end{array}$ & & $\begin{array}{l}0.384^{*} \\
(1.83)\end{array}$ \\
\hline Liquidity Measure & NA & \# Ships & NA & \# Ships & NA & \# Ships \\
\hline $\begin{array}{l}\text { Controls } \\
\text { Firm Fleet }\end{array}$ & Yes & Yes & Yes & Yes & Yes & Yes \\
\hline $\begin{array}{l}\text { Fixed Effects } \\
\text { Country } \times \text { Year-Quarter } \\
\text { Firm }\end{array}$ & $\begin{array}{l}\text { Yes } \\
\text { Yes }\end{array}$ & $\begin{array}{l}\text { Yes } \\
\text { Yes }\end{array}$ & $\begin{array}{l}\text { Yes } \\
\text { Yes }\end{array}$ & $\begin{array}{l}\text { Yes } \\
\text { Yes }\end{array}$ & $\begin{array}{l}\text { Yes } \\
\text { Yes }\end{array}$ & $\begin{array}{l}\text { Yes } \\
\text { Yes }\end{array}$ \\
\hline $\begin{array}{l}\text { Observations } \\
\text { R-squared }\end{array}$ & $\begin{array}{l}42,206 \\
0.052\end{array}$ & $\begin{array}{l}42,206 \\
0.055\end{array}$ & $\begin{array}{l}42,206 \\
0.059\end{array}$ & $\begin{array}{c}42,206 \\
0.060\end{array}$ & $\begin{array}{c}42,206 \\
0.035\end{array}$ & $\begin{array}{l}42,206 \\
0.035\end{array}$ \\
\hline
\end{tabular}

Statistical significance is indicated as follows: ${ }^{* * *} p<0.01,{ }^{* *} p<0.05,{ }^{*} p<0.1$. 
Table 10. Asset Liquidity and Event-Study of High Uncertainty Episodes

This table reports event-study results. The events correspond to the eight highest spikes in our shipping industry uncertainty measure, Uncertainty, aggregated across subsectors. These spikes represent eight dates on which the percentage change in the series represented a two standard deviation or more movement. The sample for this analysis consists of 76 shipping firms for which we are able to obtain valid daily returns for the one-month event window beginning on each of these dates. In each window, we calculate the average annualized buy and hold abnormal returns (ABHAR) by compounding each stock's daily returns over the one month after the event, and subtracting the compounded daily returns of a benchmark characteristic-matched portfolio. We weight across firms using both equal and value weights. Low-Liquidity Firms are firms who, in the quarter of the event, operate the majority of their ships in the four subsectors with lowest number of ships. High-Liquidity Firms are firms which, in the quarter of the event, operate the majority of their ships in the four subsectors with the highest number of ships.

\begin{tabular}{lcccc}
\hline \hline & All Firms & $\begin{array}{c}\text { Low-Liquidity } \\
\text { Firms }\end{array}$ & $\begin{array}{c}\text { High-Liquidity } \\
\text { Firms }\end{array}$ & $\begin{array}{c}\text { Difference } \\
\text { (Low - High) }\end{array}$ \\
\cline { 2 - 5 } & $(1)$ & $(2)$ & $(3)$ & $(4)$ \\
\hline EW ABHAR (0,+1 Month) & $-3.18 \%$ & $-8.62 \% * *$ & $1.81 \%$ & $-10.43^{* *}$ \\
& $(-1.41)$ & $(-2.47)$ & $(1.54)$ & $(-2.27)$ \\
VW ABHAR (0,+1 Month) & $-2.44 \%$ & $-7.26 \%^{* *}$ & $2.93 \%$ & $-10.19^{* *}$ \\
& $(-1.37)$ & $(-2.58)$ & $(1.22)$ & $(-2.18)$ \\
\hline Observations & 76 & 35 & 41 & \\
\hline \hline
\end{tabular}

Statistical significance is indicated as follows: ${ }^{* * *} p<0.01,{ }^{* *} p<0.05,{ }^{*} p<0.1$. 
Table 11. Aggregate versus Sectoral Uncertainty and Investment and Disinvestment

This table reports output from Eq. (8). The dependent variables are the investment and disinvestment rates. The investment (disinvestment) rate is calculated at the firm-subsector-quarter level by dividing the number of ships acquired (disinvested) by the lagged number of ships held. VIX is the quarterly Volatility Index from the CBOE. JLN Uncertainty is the quarterly uncertainty index from Jurado et al. (2015). EPU is the quarterly US Economic Policy Uncertainty Index from Baker et al. (2016). GDP Dispersion is the quarterly GDP forecast dispersion from the Survey of Professional Forecasters compiled by the Federal Reserve Bank of Philadelphia. Uncertainty is the quarterly average of annualized daily implied volatility of nearest-to-money American call options expiring at the end of the next quarter, averaged across all firms operating in a given subsector, weighted by the number of ships they operate in the subsector. Subsector controls consist of $\Delta$ Subsectoral BDI and Cash Flow. See Table 2 for definitions of these variables. The Liquidity measure is the quarterly logarithm of the number of ships in a given subsector. Firm fleet controls are the average Age, DWT, and RPM of ships held by the firm-subsector in the lagged quarter. Fixed effects for firm and subsector are included as indicated. All regressions are estimated over the 2006-2019 period. $T$-statistics are reported in parentheses, computed using robust standard errors clustered by firm-subsector and year-quarter.

\begin{tabular}{lcc}
\hline \hline & Investment & Disinvestment \\
\cline { 2 - 3 } & $(1)$ & $(2)$ \\
\hline Liquidity & $-3.623^{* * *}$ & $-0.967^{* *}$ \\
& $(-3.90)$ & $(-1.96)$ \\
VIX & -0.015 & -0.010 \\
& $(-0.51)$ & $(-0.96)$ \\
VIX $\times$ Liquidity & 0.125 & 0.054 \\
JLN Uncertainty & $(1.12)$ & $(1.34)$ \\
& -0.006 & $-0.289^{*}$ \\
JLN Uncertainty $\times$ Liquidity & $(-0.01)$ & $(-1.84)$ \\
& 0.159 & 0.731 \\
EPU & $(0.55)$ & $(0.43)$ \\
& -0.015 & -0.001 \\
EPU $\times$ Liquidity & $(-0.94)$ & $(-0.18)$ \\
GDP Dispersion & 0.037 & 0.000 \\
GDP Dispersion $\times$ Liquidity & $(0.09)$ & $(0.66)$ \\
& -0.093 & -1.453 \\
Uncertainty & $(-0.40)$ & $(-0.04)$ \\
& 0.000 & 0.053 \\
Uncertainty $\times$ Liquidity & $(0.67)$ & $(0.40)$ \\
& $-3.319^{* * *}$ & $-1.905^{* * *}$ \\
\hline Liquidity Measure & $(-3.37)$ & $(-3.01)$ \\
\hline Controls & $0.416^{* * *}$ & $0.252^{* * *}$ \\
Subsector & $(3.68)$ & $(3.19)$ \\
Firm-Subsector Fleet & $\#$ Ships & $\#$ Ships \\
\hline Fixed Effects & & Yes \\
Firm $\times$ Subsector & Yes & Yes \\
\hline Observations & Yes & 99,928 \\
R-squared & & 0.155 \\
\hline \hline
\end{tabular}

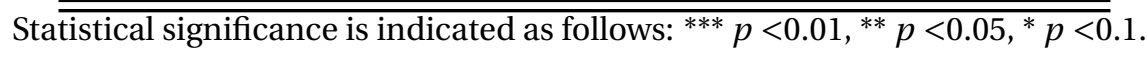


Table 12. Investment and Disinvestment Controlling for Financing Constraints

This table reports output from Eq. (8). The dependent variable is the investment (disinvestment) rate. The investment (disinvstment) rate is calculated at the firm-subsector-quarter level by dividing the number of ships acquired (disinvested) by the lagged number of ships held. Subsector controls consist of $\Delta$ Subsectoral BDI and Cash Flow. $\triangle$ Subsectoral $B D I$ is the quarterly percentage change in the sectoral indices derived from forward freight agreement prices for routes commonly served by ships in each subsector quoted on the Baltic Exchange. Cash Flow is the quarterly income before extraordinary items plus depreciation and amortization divided by lagged total assets, averaged across all firms operating in a given subsector weighted by the number of ships they operate in the subsector. Uncertainty is the quarterly average of annualized daily implied volatility of nearest-to-money American call options expiring at the end of the next quarter, averaged across all firms operating in a given subsector, weighted by the number of ships they operate in the subsector. The Liquidity measure is defined as the quarterly logarithm of the number of ships in a given subsector. FC is either the size-age index calculated as in Hadlock and Pierce (2010) or an indicator variable for whether a given firm is private. Firm fleet controls are the average Age, DWT, and RPM of ships held by the firm-subsector in the lagged quarter. Fixed effects for headquarter country, firm, subsector, and year-quarter are included as indicated. All regressions are estimated over the 2006-2019 period. $T$-statistics are reported in parentheses, computed using robust standard errors clustered by firm-subsector and year-quarter.

\begin{tabular}{|c|c|c|c|c|}
\hline & \multicolumn{2}{|c|}{ Investment } & \multicolumn{2}{|c|}{ Disinvestment } \\
\hline & (1) & (2) & (3) & (4) \\
\hline Uncertainty & $\begin{array}{c}-1.327^{* * *} \\
(-3.87)\end{array}$ & $\begin{array}{c}-1.199 * * * \\
(-3.36)\end{array}$ & $\begin{array}{c}-1.122^{* * *} \\
(-3.41)\end{array}$ & $\begin{array}{l}-0.718^{* *} \\
(-2.89)\end{array}$ \\
\hline Liquidity & $\begin{array}{c}-3.470^{* * *} \\
(-3.94)\end{array}$ & $\begin{array}{c}-3.447^{* * *} \\
(-4.12)\end{array}$ & $\begin{array}{c}-0.990^{* *} \\
(-2.07)\end{array}$ & $\begin{array}{c}-0.630^{*} \\
(-1.84)\end{array}$ \\
\hline Uncertainty $\times$ Liquidity & $\begin{array}{c}0.382^{* * *} \\
(3.08)\end{array}$ & $\begin{array}{c}0.325^{* * *} \\
(2.95)\end{array}$ & $\begin{array}{c}0.121^{* * *} \\
(3.53)\end{array}$ & $\begin{array}{c}0.126^{* * *} \\
(2.89)\end{array}$ \\
\hline$F C$ & $\begin{array}{c}-0.288^{*} \\
(-1.82)\end{array}$ & $\begin{array}{c}-1.114^{* *} \\
(-2.37)\end{array}$ & $\begin{array}{c}0.475^{*} \\
(1.77)\end{array}$ & $\begin{array}{l}1.236 \\
(0.63)\end{array}$ \\
\hline Uncertainty $\times F C$ & $\begin{array}{c}-0.221^{*} \\
(-1.85)\end{array}$ & $\begin{array}{c}-0.099^{*} \\
(-1.89) \\
\end{array}$ & $\begin{array}{l}0.024 \\
(0.78) \\
\end{array}$ & $\begin{array}{l}0.080 \\
(1.07) \\
\end{array}$ \\
\hline Liquidity Measure & \# Ships & \# Ships & \# Ships & \# Ships \\
\hline$F C$ Measure & Size-Age & Private & Size-Age & Private \\
\hline $\begin{array}{l}\text { Controls } \\
\text { Subsector } \\
\text { Firm-Subsector Fleet }\end{array}$ & $\begin{array}{l}\text { Yes } \\
\text { Yes }\end{array}$ & $\begin{array}{l}\text { Yes } \\
\text { Yes }\end{array}$ & $\begin{array}{l}\text { Yes } \\
\text { Yes }\end{array}$ & $\begin{array}{l}\text { Yes } \\
\text { Yes }\end{array}$ \\
\hline $\begin{array}{l}\text { Fixed Effects } \\
\text { Country } \times \text { Year-Quarter } \\
\text { Firm } \times \text { Subsector }\end{array}$ & $\begin{array}{l}\text { Yes } \\
\text { Yes }\end{array}$ & $\begin{array}{l}\text { Yes } \\
\text { No }\end{array}$ & $\begin{array}{l}\text { Yes } \\
\text { Yes }\end{array}$ & $\begin{array}{l}\text { Yes } \\
\text { No }\end{array}$ \\
\hline $\begin{array}{l}\text { Observations } \\
\text { R-squared }\end{array}$ & $\begin{array}{c}99,928 \\
0.049\end{array}$ & $\begin{array}{c}99,928 \\
0.049\end{array}$ & $\begin{array}{c}99,928 \\
0.045\end{array}$ & $\begin{array}{c}99,928 \\
0.045\end{array}$ \\
\hline
\end{tabular}


Table 13. Uncertainty, Asset Liquidity, and Investment and Disinvestment Tonnage

This table reports output from Eq. (8). The dependent variable are the investment and disinvestment rates. The investment (disinvestment) rate is calculated at the firm-subsector-quarter level by dividing the DWT of ships acquired (disinvested) by the lagged DWT of ships held. Subsector controls consist of $\Delta$ Subsectoral BDI and Cash Flow. $\Delta$ Subsectoral $B D I$ is the quarterly percentage change in the sectoral indices derived from forward freight agreement prices for routes commonly served by ships in each subsector quoted on the Baltic Exchange. Cash Flow is the quarterly income before extraordinary items plus depreciation and amortization divided by lagged total assets, averaged across all firms operating in a given subsector weighted by the number of ships they operate in the subsector. Uncertainty is the quarterly average of annualized daily implied volatility of nearest-to-money American call options expiring at the end of the next quarter, averaged across all firms operating in a given subsector, weighted by the number of ships they operate in the subsector. The Liquidity measure is the quarterly logarithm of the number of ships in a given subsector. Firm fleet controls are the average Age, DWT, and RPM of ships held by the firm-subsector in the lagged quarter. Fixed effects for headquarter country, firm, subsector, and year-quarter are included as indicated. All regressions are estimated over the 2006-2019 period. $T$-statistics are reported in parentheses, computed using robust standard errors clustered by firm-subsector and year-quarter.

\begin{tabular}{|c|c|c|c|c|}
\hline & \multicolumn{2}{|c|}{ DWT Invested } & \multicolumn{2}{|c|}{ DWT Disinvested } \\
\hline & (1) & (2) & (3) & (4) \\
\hline Uncertainty & $\begin{array}{c}-0.068^{* *} \\
(-2.24)\end{array}$ & $\begin{array}{c}-2.215^{* * *} \\
(-3.76)\end{array}$ & $\begin{array}{c}-0.199 * * \\
(-2.31)\end{array}$ & $\begin{array}{c}-1.367^{* * *} \\
(-3.27)\end{array}$ \\
\hline Liquidity & & $\begin{array}{c}-3.579^{* * *} \\
(-3.62)\end{array}$ & & $\begin{array}{c}-1.126^{* *} \\
(-2.46)\end{array}$ \\
\hline Uncertainty $\times$ Liquidity & & $\begin{array}{c}0.288^{* * *} \\
(3.54)\end{array}$ & & $\begin{array}{c}0.194^{* * *} \\
(3.19)\end{array}$ \\
\hline Liquidity Measure & NA & \# Ships & NA & \# Ships \\
\hline Controls & & & & \\
\hline Subsector & Yes & Yes & Yes & Yes \\
\hline Firm-Subsector Fleet & Yes & Yes & Yes & Yes \\
\hline Fixed Effects & & & & \\
\hline Country×Year-Quarter & Yes & Yes & Yes & Yes \\
\hline Firm & Yes & No & Yes & No \\
\hline Subsector & Yes & No & Yes & No \\
\hline Firm $\times$ Subsector & No & Yes & No & Yes \\
\hline Observations & 99,928 & 99,928 & 99,928 & 99,928 \\
\hline R-squared & 0.054 & 0.060 & 0.050 & 0.048 \\
\hline
\end{tabular}




\section{Appendix A Proofs}

\section{A.1 Proof of Lemma 1}

Proof. Let us take a representative element of the investment vector in Eq. (5) and define a function

$$
H\left(i_{0}^{*}, i_{1}^{*}\right)=\mathbb{E}\left[\pi_{1}+\pi_{2}\right] i_{0}^{*}-n_{0}^{*} q_{1}-u_{0}^{*} p_{1}-\mathbb{E}\left[\max \left(\pi_{2} i_{1}^{*}-n_{1}^{*} q_{2}-u_{1}^{*} p_{2}, 0\right)\right] .
$$

We can rewrite the function $H(\cdot)$ purely in terms of $i_{0}^{*}$ given that the constraint $i_{0}^{*}+i_{1}^{*} \leq I$ will bind for some $I$.

$$
H\left(i_{0}^{*}\right)=\mathbb{E}\left[\pi_{1}+\pi_{2}\right] i_{0}^{*}-n_{0}^{*} q_{1}-u_{0}^{*} p_{1}-\mathbb{E}\left[\max \left(\pi_{2}\left(I-i_{0}^{*}\right)-\left(N-n_{0}^{*}\right) q_{2}-\left(U-u_{0}^{*}\right) p_{2}, 0\right)\right] .
$$

To guarantee the existence of $i_{0}^{*}$ (and, equivalently, $i_{1}^{*}$ ) as characterized by Eq. (5), it suffices to show that $H\left(i_{0}^{*}\right)=0$ for some $i_{0}^{*} \in[0, I]$. Since $H(\cdot)$ is a sum of continuous functions, it is itself continuous. Since $\pi_{1}>0$ and $\pi_{2}>0$, it follows that:

$$
H(0)=-\mathbb{E}\left[\pi_{2} I-N q_{2}-U p_{2}\right]<0 .
$$

Finally, for $I \rightarrow \infty$, we have that:

$$
\begin{aligned}
\lim _{I \rightarrow \infty} H(I) & =\lim _{I \rightarrow \infty}\left(\mathbb{E}\left[\pi_{1}+\pi_{2}\right] I-N q_{1}-U p_{1}\right)+\lim _{N \rightarrow \infty}\left(\mathbb{E}\left[\max \left(\pi_{2}(I-I)-(N-N) q_{2}-(U-U) p_{2}, 0\right)\right]\right) \\
& =\infty-0=\infty .
\end{aligned}
$$

Thus, there must exist an $\bar{I} \in \mathbb{R}$ such that, for $I>\bar{I}, H(\bar{I})>0$. Putting these conditions together with the continuity of $H(\cdot)$ over $[0, I]$, the Intermediate Value Theorem guarantees that there exists an $i_{0}^{*} \in[0, I]$ and $i_{1}^{*} \in[0, I]$ such that $H\left(i_{0}^{*}, i_{1}^{*}\right)=0$.

\section{A.2 Proof of Lemma 2}

Proof. Symmetric to the case of investment.

\section{A.3 Proof of Proposition 1}

Proof. Let us, once again, consider a representative element of the investment vector in Eq. (5) and define

$$
H\left(i_{0}^{*} ; r\right)=\mathbb{E}\left[\pi_{1}+\pi_{2}\right] i_{0}^{*}-n_{0}^{*} q_{1}-u_{0}^{*} p_{1}-\mathbb{E}\left[\max \left(\pi_{2}\left(I-i_{0}^{*}\right)-\left(N-n_{0}^{*}\right) q_{2}-\left(U-u_{0}^{*}\right) p_{2}, 0\right) ; r\right] .
$$

By the Implicit Function Theorem,

$$
\frac{d i_{0}^{*}}{d r}=-\frac{\partial H / \partial i_{0}^{*}}{\partial H / \partial r}
$$

Considering first the derivative of $H$ with respect to $i_{0}^{*}$, we have:

$$
\begin{aligned}
\frac{\partial H\left(i_{0}^{*} ; r\right)}{\partial i_{0}^{*}} & =\mathbb{E}\left[\pi_{1}+\pi_{2}\right]-q_{1}-p_{1}-\frac{\partial}{\partial i_{0}^{*}} \mathbb{E}\left[\max \left(\pi_{2}\left(I-i_{0}^{*}\right)-\left(N-n_{0}^{*}\right) q_{2}-\left(U-u_{0}^{*}\right) p_{2}, 0\right) ; r\right] \\
& =\mathbb{E}\left[\pi_{1}+\pi_{2}\right]-q_{1}-p_{1}-\mathbb{E}\left[\frac{\partial}{\partial i_{0}^{*}} \max \left(\pi_{2}\left(I-i_{0}^{*}\right)-\left(N-n_{0}^{*}\right) q_{2}-\left(U-u_{0}^{*}\right) p_{2}, 0\right) ; r\right] \\
& =\mathbb{E}\left[\pi_{1}+\pi_{2}\right]-q_{1}-p_{1}-\mathbb{E}\left[-\max \left(\pi_{2}-\left(q_{2}+p_{2}\right), 0\right) ; r\right] \\
& <0 .
\end{aligned}
$$

Next, considering the derivative of $H$ with respect to $r$, we have:

$$
\frac{\partial H\left(i_{0}^{*} ; r\right)}{\partial r}=-\frac{\partial}{\partial r} \mathbb{E}\left[\max \left(\pi_{2}\left(I-i_{0}^{*}\right)-\left(N-n_{0}^{*}\right) q_{2}-\left(U-u_{0}^{*}\right) p_{2}, 0\right) ; r\right] .
$$


Because $G\left(\cdot, r^{\prime}\right)$ is a MPS of $G(\cdot, r)$, for any convex function $J(\cdot)$,

$$
\begin{aligned}
\mathbb{E}\left[J\left(\pi_{2}\right) ; r^{\prime}\right] & =\int J\left(\pi_{2}\right) d G\left(\pi_{2}, r^{\prime}\right) \\
& \geq \int J\left(\pi_{2}\right) d G\left(\pi_{2}, r\right) \\
& =\mathbb{E}\left[J\left(\pi_{2}\right) ; r\right] .
\end{aligned}
$$

Since $\max \left(\pi_{2}\left(I-i_{0}^{*}\right)-\left(N-n_{0}^{*}\right) q_{2}-\left(U-u_{0}^{*}\right) p_{2}, 0\right)$ is convex in $\pi_{2}$, it follows that:

$\mathbb{E}\left[\max \left(\pi_{2}\left(I-i_{0}^{*}\right)-\left(N-n_{0}^{*}\right) q_{2}-\left(U-u_{0}^{*}\right) p_{2}, 0\right) ; r^{\prime}\right] \geq \mathbb{E}\left[\max \left(\pi_{2}\left(I-i_{0}^{*}\right)-\left(N-n_{0}^{*}\right) q_{2}-\left(U-u_{0}^{*}\right) p_{2}, 0\right) ; r\right] \forall r^{\prime}>r$.

This implies

$$
\frac{\partial}{\partial r} \mathbb{E}\left[\max \left(\pi_{2}\left(I-i_{0}^{*}\right)-\left(N-n_{0}^{*}\right) q_{2}-\left(U-u_{0}^{*}\right) p_{2}, 0\right) ; r\right] \geq 0
$$

Thus,

$$
\begin{aligned}
\frac{\partial H\left(i_{0}^{*} ; r\right)}{\partial r} & =-\frac{\partial}{\partial r} \mathbb{E}\left[\max \left(\pi_{2}\left(I-i_{0}^{*}\right)-\left(N-n_{0}^{*}\right) q_{2}-\left(U-u_{0}^{*}\right) p_{2}, 0\right) ; r\right] \\
& \leq 0 .
\end{aligned}
$$

Putting these conditions together, we have:

$$
\frac{d i_{0}^{*}}{d r}=-\frac{\partial H / \partial i_{0}^{*}}{\partial H / \partial r}<0
$$

The disinvestment case is symmetric.

\section{A.4 Proof of Propositions 2 and 3}

Proof. Considering, once again, a representative element of the investment vector in in Eq. (5), we must show that:

$$
\frac{d n_{0}^{*}}{d r}<\frac{d u_{0}^{*}}{d r}
$$

Using the Implicit Function Theorem, this is equivalent to showing:

$$
-\frac{\partial H / \partial n_{0}^{*}}{\partial H / \partial r}<-\frac{\partial H / \partial u_{0}^{*}}{\partial H / \partial r}
$$

or, since $\frac{\partial H}{\partial r} \leq 0$, we must show that:

$$
\frac{\partial H}{\partial n_{0}^{*}}<\frac{\partial H}{\partial u_{0}^{*}}
$$

Simplifying the above, it is clear that:

$$
\frac{\partial H}{\partial n_{0}^{*}}<\frac{\partial H}{\partial u_{0}^{*}} \Leftrightarrow F+\widetilde{\gamma}_{i t}^{\alpha_{i}}>\lambda_{i}\left(N_{i t}\right) \times \text { Seller }_{i t}+\gamma_{i t}^{\alpha_{i}} .
$$

Simplifying further, and noting that $\widetilde{\gamma}_{i t}^{\alpha_{i}}=\left(\widetilde{\delta}_{i} \gamma_{i t}\right)^{\alpha_{i}}$ with $\widetilde{\delta}_{i}>1$ and $\alpha_{i}>0$, we have:

$$
F-\lambda_{i}\left(N_{i t}\right) \times \text { Seller }_{i t}>\gamma_{i t}^{\alpha_{i}}-\left(\widetilde{\delta}_{i} \gamma_{i t}\right)^{\alpha_{i}},
$$

since $F>0, N>0$, Seller $_{i t}=-1$. The disinvestment case is symmetric. It immediately follows that the cross-partial derivatives $\frac{\partial^{2} i_{0}^{*}}{\partial r \partial N}$ and $\frac{\partial^{2} d_{0}^{*}}{\partial r \partial N}$ are positive as $\lambda(\cdot)$ is differentiable for $N>0$ and $\lambda^{\prime}(\cdot)>0$. 


\section{Appendix B Alternative Liquidity Measures}

Table A.1. Uncertainty, Alternative Measures of Asset Liquidity, and Investment and Disinvestment

This table reports output from Eq. (8). The dependent variable is the investment (disinvestment) rate. The investment (disinvestment) rate is calculated at the firm-subsector-quarter level by dividing the number of ships acquired (disinvested) by the lagged number of ships held. $\triangle$ Subsectoral $B D I$ is the quarterly percentage change in the sectoral indices derived from forward freight agreement prices for routes commonly served by ships in each subsector quoted on the Baltic Exchange. Cash Flow is the quarterly income before extraordinary items plus depreciation and amortization divided by lagged total assets, averaged across all firms operating in a given subsector weighted by the number of ships they operate in the subsector. Uncertainty is the quarterly average of annualized daily implied volatility of nearest-to-money American call options expiring at the end of the next quarter, averaged across all firms operating in a given subsector, weighted by the number of ships they operate in the subsector. The alternative Liquidity measures are defined as the quarterly number of transactions divided by the lagged number of ships, and the logarithm of the number of firms, in a given subsector. Firm fleet controls are the average Age, DWT, and RPM of ships held by the firm-subsector in the lagged quarter. Fixed effects for headquarter country, firm, subsector, and year-quarter are included as indicated. All regressions are estimated over the 2006-2019 period. $T$-statistics are reported in parentheses, computed using robust standard errors clustered by firm-subsector and year-quarter.

\begin{tabular}{|c|c|c|c|c|}
\hline & \multicolumn{2}{|c|}{ Investment } & \multicolumn{2}{|c|}{ Disinvestment } \\
\hline & (1) & (2) & (3) & (4) \\
\hline$\Delta$ Subsectoral BDI & $\begin{array}{c}0.597^{* * *} \\
(3.82)\end{array}$ & $\begin{array}{c}0.582^{* * *} \\
(4.14)\end{array}$ & $\begin{array}{l}-0.212^{*} \\
(-1.94)\end{array}$ & $\begin{array}{l}-0.183 \\
(-0.74)\end{array}$ \\
\hline Cash Flow & $\begin{array}{l}0.218 \\
(1.11)\end{array}$ & $\begin{array}{l}0.223 \\
(0.95)\end{array}$ & $\begin{array}{l}-0.087 \\
(-0.79)\end{array}$ & $\begin{array}{l}-0.204 \\
(-0.52)\end{array}$ \\
\hline Uncertainty & $\begin{array}{c}-0.028^{* * *} \\
(-3.32)\end{array}$ & $\begin{array}{c}-1.433^{* * *} \\
(-3.84)\end{array}$ & $\begin{array}{c}-0.137^{* * *} \\
(-2.86)\end{array}$ & $\begin{array}{c}-0.618^{* *} \\
(-2.72)\end{array}$ \\
\hline Liquidity & $\begin{array}{c}-0.318^{* * *} \\
(-2.88)\end{array}$ & $\begin{array}{c}-3.476^{* * *} \\
(-3.91)\end{array}$ & $\begin{array}{c}-0.212^{*} \\
(-1.69)\end{array}$ & $\begin{array}{c}-0.618^{*} \\
(-1.78)\end{array}$ \\
\hline Uncertainty $\times$ Liquidity & $\begin{array}{c}0.028^{* * *} \\
(3.46)\end{array}$ & $\begin{array}{c}0.265^{* * *} \\
(4.01)\end{array}$ & $\begin{array}{l}0.005^{* *} \\
(2.43)\end{array}$ & $\begin{array}{c}0.118^{* * *} \\
(3.18)\end{array}$ \\
\hline Liquidity Measure & \# Trans. & \# Firms & \# Trans. & \# Firms \\
\hline $\begin{array}{l}\text { Controls } \\
\text { Firm-Subsector Fleet }\end{array}$ & Yes & Yes & Yes & Yes \\
\hline $\begin{array}{l}\text { Fixed Effects } \\
\text { Country } \times \text { Year-Quarter } \\
\text { Firm } \times \text { Subsector }\end{array}$ & $\begin{array}{l}\text { Yes } \\
\text { Yes }\end{array}$ & $\begin{array}{l}\text { Yes } \\
\text { Yes }\end{array}$ & $\begin{array}{l}\text { Yes } \\
\text { Yes }\end{array}$ & $\begin{array}{l}\text { Yes } \\
\text { Yes }\end{array}$ \\
\hline $\begin{array}{l}\text { Observations } \\
\text { R-squared }\end{array}$ & $\begin{array}{c}99,928 \\
0.048\end{array}$ & $\begin{array}{c}99,928 \\
0.048\end{array}$ & $\begin{array}{c}99,928 \\
0.048\end{array}$ & $\begin{array}{c}99,928 \\
0.048\end{array}$ \\
\hline
\end{tabular}




\section{Appendix C Decomposed Uncertainty}

Our baseline measure of uncertainty in a shipping subsector is obtained by averaging option-implied equity volatilities of firms operating in that subsector, weighted by the number of ships in that subsector each firm operates. Implicitly, this measure allows for the contribution of each firm's uncertainty to the subsectoral uncertainty to be proportional to its market share in that subsector. We test whether our results are robust to an alternative weighting scheme that decomposes each firm's implied volatility across subsectors based on the share of its fleet belonging to the respective subsectors. Specifically, in each quarter, we select eight (i.e., number of subsectors in our sample) or more firms in ascending order by the size of the total fleet. This gives a system of eight or more equations in which each firm's loading on each subsector's implied volatility (eight unknowns) is the fraction of that firm's fleet in that subsector. From this equation system, we solve for each subsector's implied volatility in that period. The results from estimating our baseline specification using this alternative decomposed uncertainty measure are reported in Table C.1. The coefficient estimates are similar in both statistical significance and economic magnitude to those reported in Tables 2 and 3, suggesting that our results are not an artifact of the scheme used in allocating firms' implied volatilities across subsectors.

Table C.1. Decomposed Uncertainty and Investment and Disinvestment

This table reports output from Eq. (8). The dependent variable is the investment (disinvestment) rate. The investment rate is calculated at the firm-subsector-quarter level by dividing the number of ships acquired (disinvested) by the lagged number of ships held. Uncertainty is an alternative implied volatility measure that decomposes each firm's implied volatility across subsectors based on the share of its fleet belonging to the respective subsectors. Subsector controls consist of $\Delta$ Subsectoral BDI and Cash Flow. See Table 2 for definitions of these variables. The Liquidity measure is the quarterly logarithm of the number of ships in a given subsector. Firm fleet controls are the average Age, DWT, and $R P M$ of ships held by the firm-subsector in the lagged quarter. Fixed effects for headquarter country, firm, subsector, and year-quarter are included as indicated. All regressions are estimated over the 2006-2019 period. $T$-statistics are reported in parentheses, computed using robust standard errors clustered by firm-subsector and year-quarter.

\begin{tabular}{|c|c|c|c|c|c|c|}
\hline & \multicolumn{3}{|c|}{ Investment (Ships Acquired) } & \multicolumn{3}{|c|}{ Disinvestment (Ships Disinvested) } \\
\hline & Total & New & Used & Total & Demolish & Sale \\
\hline & (1) & (2) & (3) & (4) & (5) & (6) \\
\hline Uncertainty & $\begin{array}{c}-1.688^{* *} \\
(-2.66)\end{array}$ & $\begin{array}{c}-1.512^{* * *} \\
(-3.18)\end{array}$ & $\begin{array}{l}-0.176 \\
(-0.61)\end{array}$ & $\begin{array}{c}-1.118^{* * *} \\
(-3.97)\end{array}$ & $\begin{array}{c}-0.693^{* * *} \\
(-5.07)\end{array}$ & $\begin{array}{l}-0.425 \\
(-1.19)\end{array}$ \\
\hline Liquidity & $\begin{array}{c}-3.289^{* * *} \\
(-3.99)\end{array}$ & $\begin{array}{c}-2.814^{* * *} \\
(-4.15)\end{array}$ & $\begin{array}{l}-0.475 \\
(-1.34)\end{array}$ & $\begin{array}{c}-0.873^{* *} \\
(-2.55)\end{array}$ & $\begin{array}{c}-0.615^{* * *} \\
(-3.83)\end{array}$ & $\begin{array}{l}-0.258 \\
(-0.94)\end{array}$ \\
\hline Uncertainty $\times$ Liquidity & $\begin{array}{c}0.254^{* * *} \\
(3.28)\end{array}$ & $\begin{array}{c}0.212^{* * *} \\
(3.31)\end{array}$ & $\begin{array}{l}0.042 \\
(0.97)\end{array}$ & $\begin{array}{c}0.183^{* * *} \\
(4.12)\end{array}$ & $\begin{array}{c}0.102^{* * *} \\
(5.66)\end{array}$ & $\begin{array}{l}0.081^{*} \\
(1.91)\end{array}$ \\
\hline Liquidity Measure & \# Ships & \# Ships & \# Ships & \# Ships & \# Ships & \# Ships \\
\hline $\begin{array}{l}\text { Controls } \\
\text { Subsector } \\
\text { Firm-Subsector Fleet }\end{array}$ & $\begin{array}{l}\text { Yes } \\
\text { Yes }\end{array}$ & $\begin{array}{l}\text { Yes } \\
\text { Yes }\end{array}$ & $\begin{array}{l}\text { Yes } \\
\text { Yes }\end{array}$ & $\begin{array}{l}\text { Yes } \\
\text { Yes }\end{array}$ & $\begin{array}{l}\text { Yes } \\
\text { Yes }\end{array}$ & $\begin{array}{l}\text { Yes } \\
\text { Yes }\end{array}$ \\
\hline $\begin{array}{l}\text { Fixed Effects } \\
\text { Country } \times \text { Year-Quarter } \\
\text { Firm } \times \text { Subsector }\end{array}$ & $\begin{array}{l}\text { Yes } \\
\text { Yes }\end{array}$ & $\begin{array}{l}\text { Yes } \\
\text { Yes }\end{array}$ & $\begin{array}{l}\text { Yes } \\
\text { Yes }\end{array}$ & $\begin{array}{l}\text { Yes } \\
\text { Yes }\end{array}$ & $\begin{array}{l}\text { Yes } \\
\text { Yes }\end{array}$ & $\begin{array}{l}\text { Yes } \\
\text { Yes }\end{array}$ \\
\hline $\begin{array}{l}\text { Observations } \\
\text { R-squared }\end{array}$ & $\begin{array}{c}99,928 \\
0.065\end{array}$ & $\begin{array}{c}99,928 \\
0.065\end{array}$ & $\begin{array}{c}99,928 \\
0.051\end{array}$ & $\begin{array}{c}99,928 \\
0.055\end{array}$ & $\begin{array}{c}99,928 \\
0.056\end{array}$ & $\begin{array}{c}99,928 \\
0.049\end{array}$ \\
\hline
\end{tabular}

Statistical significance is indicated as follows: ${ }^{* * *} p<0.01,{ }^{* *} p<0.05,{ }^{*} p<0.1$. 


\section{Appendix D Dynamics of Uncertainty Effects on Capital Alloca- tion}

Recent theoretical work on firm responses to uncertainty shocks shows that the delaying effect of uncertainty on firm investment displays a "drop-and-rebound" pattern (e.g., Bloom (2009)). We empirically examine the dynamic effect of uncertainty on shipping firms' asset allocation decisions by estimating Eq. (8) with leads of the investment and disinvestment rates as the dependent variables. Table D.1 reports the estimation results.

\section{TABLE D.1 ABOUT HERE.}

Columns (1) through (4) of Panel A (B) present the relationship between uncertainty and investment (disinvestment) measured one through six quarters ahead. They show that the drop in investment (disinvestment) lasts for up to three quarters ahead, with the magnitude declining over time. By the fourth quarter, there is no significant relation between uncertainty and investment or disinvestment, suggesting capital allocation returns to its baseline level about a year after a change in uncertainty. These results are consistent with delaying effects of uncertainty as dynamic models predict.

Relatedly, we examine the robustness of our results to varying the maturity of the options considered in computing the implied volatilities underlying our Uncertainty measure. The results, presented in Figure D.1, suggest that our conclusions are similar regardless of the underlying option maturity. This lack of variation is to be expected for two reasons. First, implied volatility captures market expectations of the volatility of the entire stream of future cash flows, and not only for the maturity period of the option being considered. Second, in our context, implied volatility is highly persistent across horizons. This finding is reassuring for the validity of our results in suggesting that the effects we document are not reactions to short-term uncertainty fluctuations.

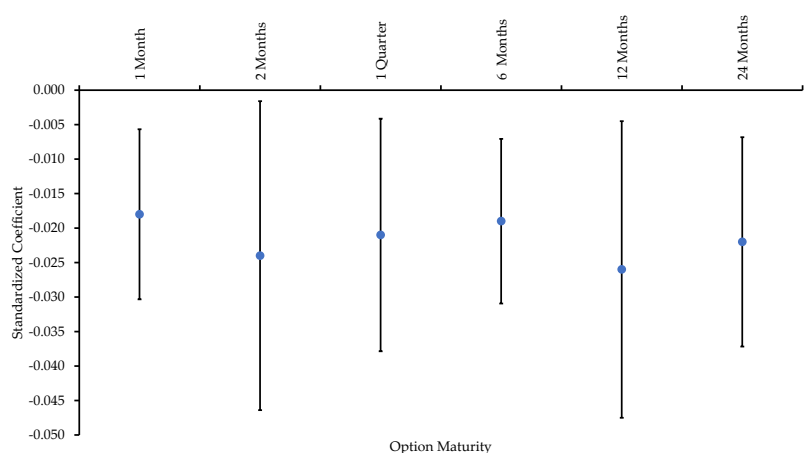

(A) Investment

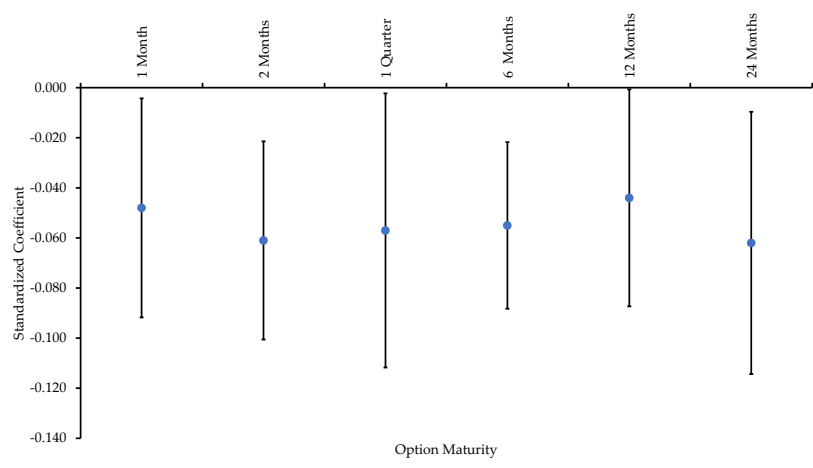

(B) Disinvestment

Figure D.1. Effect of Uncertainty on Investment and Disinvestment by Option Maturity. This figure displays standardized coefficient estimates and 95\% confidence bands for Uncertainty estimated from the specification in Eq. (8). We report standardized coefficients (the baseline regression coefficient multiplied by the ratio of the standard deviations of the independent and dependent variable) so as to compare the magnitude of the effects across the different option maturities. The dependent variables are investment (Panel A) and disinvestment (Panel B). Each point represents the coefficient corresponding to a particular maturity of options used in computing Uncertainty, with "1 Quarter" corresponding to the baseline effects reported in column (1) of Tables 2 and 3. 
Table D.1. Dynamics of Uncertainty, Asset Liquidity, and Investment and Disinvestment

This table reports output from a variant of Eq. (8) which uses the leads of the investment and disinvestment rates as the dependent variables. The investment (disinvestment) rate is calculated at the firm-subsector-quarter level by dividing the number of ships acquired (disinvested) by the lagged number of ships held. Subsector controls are $\Delta$ Subsectoral BDI and Cash Flow. $\Delta$ Subsectoral BDI is the quarterly percentage change in the sectoral indices derived from forward freight agreement prices for routes commonly served by ships in each subsector quoted on the Baltic Exchange. Cash Flow is the quarterly income before extraordinary items plus depreciation and amortization divided by lagged total assets, averaged across all firms operating in a given subsector weighted by the number of ships they operate in the subsector. Uncertainty is the quarterly average of annualized daily implied volatility of nearest-to-money American call options expiring at the end of the next quarter, averaged across all firms operating in a given subsector, weighted by the number of ships they operate in the subsector. The Liquidity measure is the quarterly logarithm of the number of ships in a given subsector. Firm fleet controls are the average Age, DWT, and RPM of ships held by the firm-subsector in the lagged quarter. Fixed effects for headquarter country, firm, subsector, and year-quarter are included as indicated. All regressions are estimated over the 2006-2019 period. $T$-statistics are reported in parentheses, computed using robust standard errors clustered by firm-subsector and year-quarter.

\begin{tabular}{|c|c|c|c|c|c|c|}
\hline \multicolumn{7}{|c|}{ Panel A: Leads of Investment } \\
\hline \multirow{3}{*}{ Lead: } & \multicolumn{6}{|c|}{ Investment (Ships Acquired) } \\
\hline & $t+1$ & $t+2$ & $t+3$ & $t+4$ & $t+5$ & $t+6$ \\
\hline & (1) & (2) & (3) & (4) & (5) & (6) \\
\hline Uncertainty & $\begin{array}{c}-1.817^{* * *} \\
(-2.82)\end{array}$ & $\begin{array}{c}-1.141^{* *} \\
(-2.62)\end{array}$ & $\begin{array}{c}-0.799 * \\
(-1.89)\end{array}$ & $\begin{array}{l}-0.469 \\
(-1.15)\end{array}$ & $\begin{array}{l}-0.162 \\
(-0.73)\end{array}$ & $\begin{array}{l}-0.006 \\
(-0.34)\end{array}$ \\
\hline Liquidity & $\begin{array}{c}-3.404^{* * *} \\
(-3.92)\end{array}$ & $\begin{array}{c}-2.605^{* * *} \\
(-4.01)\end{array}$ & $\begin{array}{c}-1.931^{* * *} \\
(-2.88)\end{array}$ & $\begin{array}{c}-1.771^{* *} \\
(-2.14)\end{array}$ & $\begin{array}{l}-0.889 \\
(-1.46)\end{array}$ & $\begin{array}{l}-0.732 \\
(-1.56)\end{array}$ \\
\hline Uncertainty $\times$ Liquidity & $\begin{array}{c}0.220^{* * *} \\
(2.84)\end{array}$ & $\begin{array}{c}0.141^{* *} \\
(2.67)\end{array}$ & $\begin{array}{l}0.117^{*} \\
(1.89)\end{array}$ & $\begin{array}{l}0.071 \\
(1.18)\end{array}$ & $\begin{array}{l}0.064 \\
(0.86)\end{array}$ & $\begin{array}{l}-0.019 \\
(-0.35)\end{array}$ \\
\hline Liquidity Measure & \# Ships & \# Ships & \# Ships & \# Ships & \# Ships & \# Ships \\
\hline $\begin{array}{l}\text { Controls } \\
\text { Subsector }\end{array}$ & & V & Y & V & Y & Yeo \\
\hline Firm-Subsector Fleet & Yes & Yes & Yes & Yes & Yes & Yes \\
\hline Fixed Effects & & & & & & \\
\hline Country $\times$ Year-Quarter & Yes & Yes & Yes & Yes & Yes & Yes \\
\hline Firm $\times$ Subsector & Yes & Yes & Yes & Yes & Yes & Yes \\
\hline Observations & 99,928 & 95,007 & 90,264 & 85,794 & 81,475 & 77,377 \\
\hline R-squared & 0.036 & 0.032 & 0.034 & 0.034 & 0.027 & 0.029 \\
\hline
\end{tabular}

Statistical significance is indicated as follows: ${ }^{* * *} p<0.01,{ }^{* *} p<0.05,{ }^{*} p<0.1$. 


\begin{tabular}{|c|c|c|c|c|c|c|}
\hline \multicolumn{7}{|c|}{ Panel B: Leads of Disinvestment } \\
\hline \multirow{3}{*}{ Lead: } & \multicolumn{6}{|c|}{ Disinvestment (Ships Disinvested) } \\
\hline & $t+1$ & $t+2$ & $t+3$ & $t+4$ & $t+5$ & $t+6$ \\
\hline & (1) & (2) & (3) & (4) & (5) & (6) \\
\hline Uncertainty & $\begin{array}{c}-1.037^{* * *} \\
(-3.78)\end{array}$ & $\begin{array}{c}-0.785^{* *} \\
(-2.66)\end{array}$ & $\begin{array}{c}-0.771^{* *} \\
(-2.28)\end{array}$ & $\begin{array}{l}-0.517 \\
(-1.12)\end{array}$ & $\begin{array}{l}-0.479 \\
(-0.46)\end{array}$ & $\begin{array}{l}-0.296 \\
(-0.70)\end{array}$ \\
\hline Liquidity & $\begin{array}{c}-0.780^{* *} \\
(-2.34)\end{array}$ & $\begin{array}{l}-0.363 \\
(-1.00)\end{array}$ & $\begin{array}{l}-0.243 \\
(-0.58)\end{array}$ & $\begin{array}{l}-0.134 \\
(-0.25)\end{array}$ & $\begin{array}{l}0.114 \\
(0.27)\end{array}$ & $\begin{array}{l}0.345 \\
(0.92)\end{array}$ \\
\hline Uncertainty $\times$ Liquidity & $\begin{array}{c}0.134^{* * *} \\
(3.68)\end{array}$ & $\begin{array}{c}0.088^{* *} \\
(2.38)\end{array}$ & $\begin{array}{l}0.087^{*} \\
(1.91)\end{array}$ & $\begin{array}{l}0.055 \\
(0.94)\end{array}$ & $\begin{array}{l}0.059 \\
(1.26)\end{array}$ & $\begin{array}{l}0.018 \\
(0.34)\end{array}$ \\
\hline Liquidity Measure & \# Ships & \# Ships & \# Ships & \# Ships & \# Ships & \# Ships \\
\hline Controls & & & & & & \\
\hline $\begin{array}{l}\text { Subsector } \\
\text { Firm-Subsector Fleet }\end{array}$ & $\begin{array}{l}\text { Yes } \\
\text { Yes }\end{array}$ & $\begin{array}{l}\text { Yes } \\
\text { Yes }\end{array}$ & $\begin{array}{l}\text { Yes } \\
\text { Yes }\end{array}$ & $\begin{array}{l}\text { Yes } \\
\text { Yes }\end{array}$ & $\begin{array}{l}\text { Yes } \\
\text { Yes }\end{array}$ & $\begin{array}{l}\text { Yes } \\
\text { Yes }\end{array}$ \\
\hline Fixed Effects & & & & & & \\
\hline Country $\times$ Year-Quarter & Yes & Yes & Yes & Yes & Yes & Yes \\
\hline Firm $\times$ Subsector & Yes & Yes & Yes & Yes & Yes & Yes \\
\hline Observations & 99,928 & 95,007 & 90,264 & 85,794 & 81,475 & 77,377 \\
\hline R-squared & 0.056 & 0.063 & 0.068 & 0.060 & 0.058 & 0.057 \\
\hline
\end{tabular}




\section{Appendix E Asset Liquidity and Irreversibility}

We verify that secondary market liquidity is associated with a higher liquidation value relative to the purchase price ("price premium"), an inverse measure of irreversibility. We estimate secondary market transaction-level regressions of the form:

$$
\text { Price Premium }_{i, j, t}=\beta_{1} \text { Liquidity }_{j, t}+\theta \text { Controls }_{i, j, t}+F E s+\epsilon_{i, j, t} \text {, }
$$

where Price Premium $_{i, j, t}$ is an (inverse) measure of irreversibility, defined as the resale price minus the purchase price divided by the purchase price for transaction $i$ involving a ship in subsector $j$ in year-quarter $t .^{36}$ Liquidity $_{j, t}$ refers to one of the three subsectoral ship market liquidity measures,

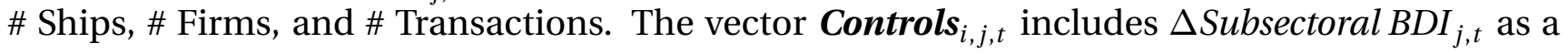
subsector-quarter-level proxy for changes in expected shipping demand, and ship-level characteristics that affect their secondary market pricing. These include the log of the ship's age, DWT, RPM, as well as indicator variables for whether the ship was built in Korea, Japan, or China. ${ }^{37}$ We estimate Eq. (E.1) with both subsector and year-quarter fixed effects. Standard errors are double-clustered at the subsector and year-quarter levels. Table E.1 reports the results.

\section{TABLE E.1 ABOUT HERE.}

The estimates for Liquidity in columns (1) through (6) show that greater secondary market liquidity is associated with higher resale relative to purchase prices and lower price dispersion across all three liquidity measures. The economic magnitude of these relations is large. Estimates in column (1) suggest that a one-standard-deviation increase in liquidity measured by the log number of ships in the subsector-quarter $(0.41)$ is associated with an 10.7 -percentage point $(=0.41 \times 26.12)$ increase in resale price premium. Likewise, the estimated coefficient on Liquidity in column (2) indicates that a one-standard-deviation increase in the transaction-based liquidity measure $(0.89)$ is associated with a 5.9 -percentage point $(=0.89 \times 6.58)$ increase in resale price premia.

The positive relationship between liquidity and price premia suggests that investment decisions are less costly to reverse when secondary markets are more liquid. This finding provides an important support for our model by showing that the incentive to forego investment and disinvestment in the face of heightened uncertainty is particularly acute when secondary market liquidity is low. ${ }^{38}$ The negative relationship between liquidity and price dispersion (columns (4) through (6)) suggests that liquidity mitigates search frictions, leading to a more "stable" match quality between buyers and sellers (Gavazza (2011)).

Table E.1 also sheds light on general pricing determinants in the secondary ship market. The estimates in column (1), for instance, show that resale price premia are strongly related to shipping demand, evident from the positive and significant coefficient on $\Delta$ Subsectoral BDI. Younger and larger ships, and those with lower-RPM engines attract significantly higher resale prices relative

\footnotetext{
${ }^{36}$ As an alternate measure of irreversibility, we also consider Price Dispersion $_{j, t}$, defined as the quarterly mean absolute deviation of resale prices divided by the mean resale price of all transactions involving ships in subsector $j$ in year-quarter $t$.

${ }^{37}$ These three shipbuilding nations account for 95\% of new ship deliveries in our sample. We do not include engine speed as a control due to collinearity with RPM. Engines in larger ships have both lower RPM and lower speed.

${ }^{38}$ The results in Table E.1 provide empirical support for our modeling of the price processes in Eq. (1) and (2). Note that one can subtract Eq. (2) from Eq. (1) and scale by Eq. (2) to obtain an analogue to the resale price premium. By differentiating the resulting expression with respect to $N$ and $\gamma$, one can show that the resale price premium is positively related to both liquidity and productivity for $N>0$.
} 
to their purchase prices. To the extent that ship prices reflect their productivity, the estimates in columns (1) through (3) indicate that ships with lower age, higher DWT, and lower RPM engines tend to be more productive. We exploit these ex ante proxies for ship productivity in our analyses examining investment and disinvestment measures conditional on productivity. 


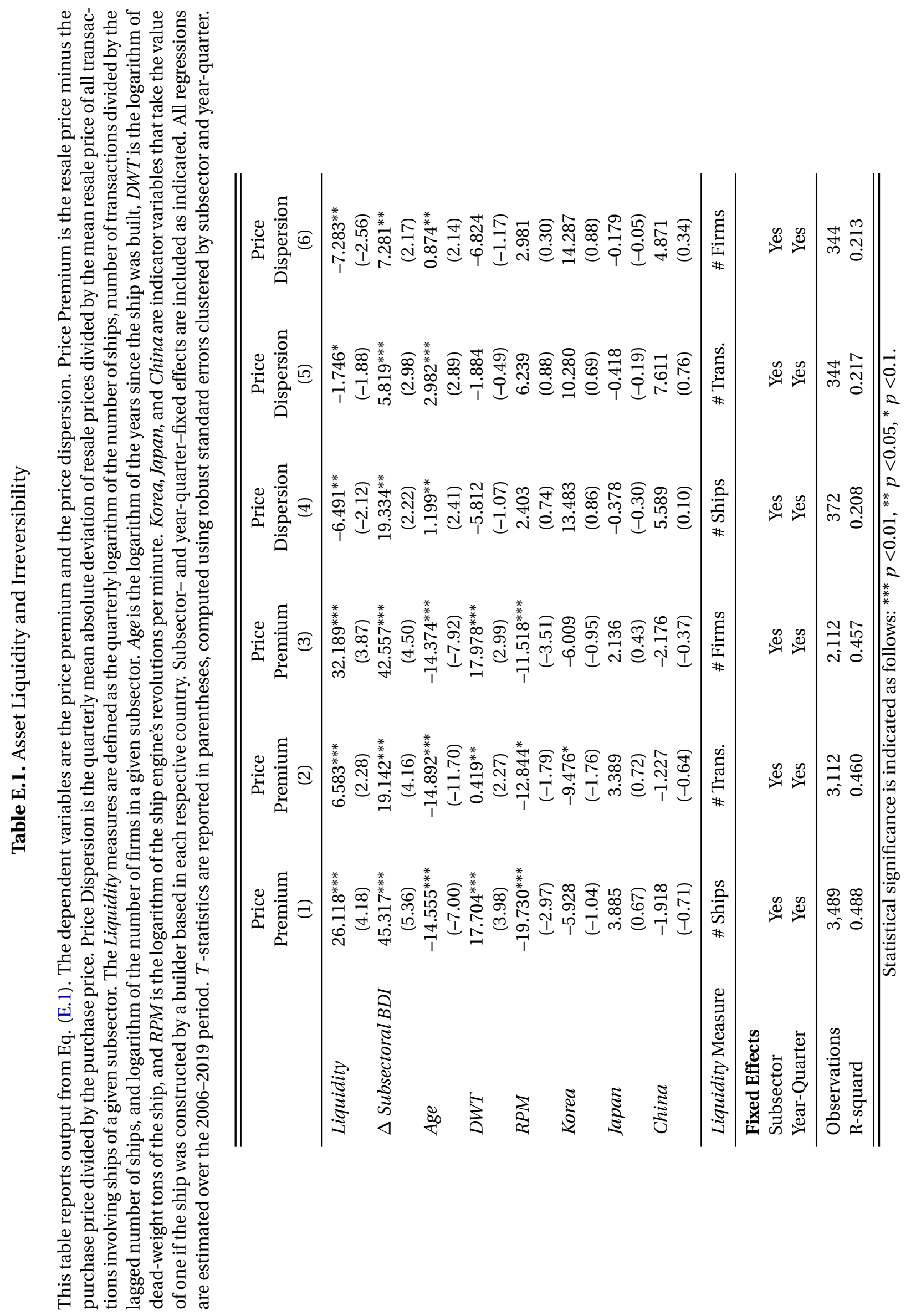




\section{Appendix F Pure-Play Firms}

Table F.1. Uncertainty, Asset Liquidity, and Investment and Disinvestment for Pure-Play Firms

This table reports output from Eq. (8) estimated on the sample of firms operating in only a single subsector over the sample period ("pure-play" firms). The dependent variables are the investment and disinvestment rates. The investment (disinvestment) rate is calculated at the firm-quarter level by dividing the number of ships acquired (disinvested) by the lagged number of ships held. Subsector controls are $\Delta$ Subsectoral BDI and Cash Flow. $\Delta$ Subsectoral BDI is the quarterly percentage change in the sectoral indices derived from forward freight agreement prices for routes commonly served by ships in each subsector quoted on the Baltic Exchange. Cash Flow is the quarterly income before extraordinary items plus depreciation and amortization divided by lagged total assets, averaged across all firms operating in a given subsector weighted by the number of ships they operate in the subsector. Uncertainty is the quarterly average of annualized daily implied volatility of nearest-to-money American call options expiring at the end of the next quarter, averaged across all firms operating in a given subsector, weighted by the number of ships they operate in the subsector. The Liquidity measure is the quarterly logarithm of the number of ships in a given subsector. Firm fleet controls are the average $A g e, D W T$, and $R P M$ of ships held by the firm-subsector in the lagged quarter. Fixed effects for headquarter country, firm, and year-quarter are included as indicated. All regressions are estimated over the 2006-2019 period. $T$-statistics are reported in parentheses, computed using robust standard errors clustered by firm and year-quarter.

\begin{tabular}{lccc}
\hline \hline \multicolumn{4}{c}{ Panel A: Investment (Ships Acquired) } \\
\hline & Investment & New & Used \\
\cline { 2 - 4 } & $(1)$ & $(2)$ & $(3)$ \\
\hline Uncertainty & $-0.887^{* * *}$ & $-0.712^{* * *}$ & -0.175 \\
& $(-2.81)$ & $(-3.14)$ & $(-1.02)$ \\
Liquidity & $-2.018^{* * *}$ & $-1.558^{* *}$ & -0.460 \\
& $(-2.97)$ & $(-2.08)$ & $(-1.44)$ \\
Uncertainty $\times$ Liquidity & $0.079^{* *}$ & $0.065^{* *}$ & 0.014 \\
& $(2.25)$ & $(2.78)$ & $(0.16)$ \\
\hline Liquidity Measure & \# Ships & \# Ships & \# Ships \\
\hline Controls & & & \\
Subsector & Yes & Yes & Yes \\
Firm Fleet & Yes & Yes & Yes \\
\hline Fixed Effects & \multicolumn{3}{|}{} \\
Country $\times$ Year-Quarter & Yes & Yes & Yes \\
Firm & Yes & Yes & Yes \\
\hline Observations & 14,497 & 14,497 & 14,497 \\
R-squared & 0.050 & 0.048 & 0.042 \\
\hline \hline 年 & &
\end{tabular}




\begin{tabular}{lccc}
\hline \multicolumn{4}{c}{ Panel B: Disinvestment (Ships Disinvested) } \\
\hline & Disinvestment & Demolition & Sale \\
\cline { 2 - 4 } & $(1)$ & $(2)$ & $(3)$ \\
\hline Uncertainty & $-1.982^{* * *}$ & $-1.217^{* * *}$ & -0.567 \\
Liquidity & $(-3.88)$ & $(-2.91)$ & $(-0.77)$ \\
& $-2.930^{* * *}$ & $-1.485^{* *}$ & $-1.667^{* *}$ \\
Uncertainty $\times$ Liquidity & $(-3.09)$ & $(-2.18)$ & $(-2.47)$ \\
& $0.319^{* * *}$ & $0.179^{* * *}$ & $0.082^{*}$ \\
\hline Liquidity Measure & $(3.24)$ & $(2.97)$ & $(1.84)$ \\
\hline Controls & $\#$ Ships & $\#$ Ships & $\#$ Ships \\
Subsector & & & \\
Firm Fleet & Yes & Yes & Yes \\
\hline Fixed Effects & Yes & Yes & Yes \\
Country $\times$ Year-Quarter & Yes & Yes & Yes \\
Firm & Yes & Yes & Yes \\
\hline Observations & 14,497 & 14,497 & 14,497 \\
R-squared & 0.059 & 0.088 & 0.051 \\
\hline \hline Stical significance is indicated as follows: ${ }^{* * *} p<0.01,^{* *} p<0.05,{ }^{*} p<0.1$. \\
\end{tabular}




\section{Appendix G Lumpiness of Investment and Disinvestment}

This Appendix presents results from estimating alternative specifications and on alternative samples to the baseline model. Panel A provides results estimated using the investment and disinvestment measures calculated at the semi-annual and annual horizons as the dependent variables. Panel B presents results from estimating a zero-one inflated beta regression model. This method is appropriate for dependent variables which are proportions, and therefore tend to be bounded and have a mass of probability at zero, one, or both. In such cases, linear models may be inappropriate as the effect of explanatory variables might be non-linear and the variance tends to decrease when the mean gets closer to either the zero or one boundary. The zero-one inflated beta regression consists of three components. First, it fits the range of the dependent variable lying between zero and one (non-inclusive) to a beta distribution where the mean is a function of explanatory variables. It further allows zeros and one values of the dependent variable to be explained by two distinct (but potentially correlated) processes. Specifically, it fits separate logit regressions for the zero and one values of the dependent variable. The model is jointly estimated via maximum likelihood. See Ospina and Ferrari (2012) for more details. In our implementation, we use the same set of explanatory variables across all three processes, and values of the dependent variable lying above one are capped at one. For brevity, we report coefficient estimates solely from the first process; i.e., the beta distribution for values of the dependent variable between zero and one. 
Table G.1. Robustness Tests to Address Lumpiness of Investment and Disinvestment

This table reports output from variants of Eq. (8). Panel A reports output from semi-annual and annualized versions of Eq. (8). The dependent variable is the investment (disinvestment) rate. The investment (disinvestment) rate is calculated at the firm-subsector-semi-annual or firm-subsector-annual level by dividing the number of ships acquired (disinvested) by the lagged number of ships held. The independent variables are similarly computed at the semi-annual or annual levels. Panel B reports results from estimation procedures accounting for zero investment and disinvestment rates. Columns (1) and (4) report results from a linear probability model (LPM) which takes the form of Eq. (8), where the dependent variable is an indicator which takes the value of 1 if the investment (disinvestment) rate in a firm-subsectorquarter is positive, and 0 otherwise. Columns (2) and (5) report estimates from a conditional logit model, using the same dependent variables as in Columns (1) and (4). Columns (3) and (6) report estimates from a zero-one inflated beta (ZOIB) model where the dependent variable is investment (disinvestment) rate, bounded below at zero and bounded above at one. Subsector controls consist of $\Delta$ Subsectoral BDI and Cash Flow. $\Delta$ Subsectoral BDI is the quarterly percentage change in the sectoral indices derived from forward freight agreement prices for routes commonly served by ships in each subsector quoted on the Baltic Exchange. Cash Flow is the quarterly income before extraordinary items plus depreciation and amortization divided by lagged total assets, averaged across all firms operating in a given subsector weighted by the number of ships they operate in the subsector. Uncertainty is the quarterly average of annualized daily implied volatility of nearest-to-money American call options expiring at the end of the next quarter, averaged across all firms operating in a given subsector, weighted by the number of ships they operate in the subsector. The Liquidity measure is the quarterly logarithm of the number of ships in a given subsector. Firm fleet controls are the average Age, DWT, and RPM of ships held by the firm-subsector in the lagged quarter. Fixed effects for headquarter country, firm, subsector, and year-quarter are included as indicated. We opt for a reduced set of fixed effects when estimating the conditional logit model and ZOIB model as the estimation routines for these models do not converge under the full set of baseline fixed effects (due to the incidental parameters problem). All regressions are estimated over the 2006-2019 period. $T$-statistics are reported in parentheses, computed using robust standard errors clustered by firm-subsector and year-quarter.

\begin{tabular}{|c|c|c|c|c|}
\hline \multicolumn{5}{|c|}{ Panel A: Investment and Disinvestment Measured at Longer Horizons } \\
\hline & \multicolumn{2}{|c|}{ Investment } & \multicolumn{2}{|c|}{ Disinvestment } \\
\hline & Semi-Annual & Annual & Semi-Annual & Annual \\
\hline & (1) & (2) & (3) & (4) \\
\hline Uncertainty & $\begin{array}{c}-3.788^{* *} \\
(-2.67)\end{array}$ & $\begin{array}{c}-9.291^{* * *} \\
(-3.22)\end{array}$ & $\begin{array}{c}-2.387^{* * *} \\
(-4.59)\end{array}$ & $\begin{array}{c}-6.429^{* * *} \\
(-2.74)\end{array}$ \\
\hline Liquidity & $\begin{array}{c}-6.884^{* * *} \\
(-3.34)\end{array}$ & $\begin{array}{c}-14.539^{* * *} \\
(-4.79)\end{array}$ & $\begin{array}{c}-1.187^{* * *} \\
(-3.88)\end{array}$ & $\begin{array}{c}-5.782^{* *} \\
(-2.50)\end{array}$ \\
\hline Uncertainty $\times$ Liquidity & $\begin{array}{c}0.480^{* * *} \\
(3.55)\end{array}$ & $\begin{array}{c}1.277^{* * *} \\
(3.71)\end{array}$ & $\begin{array}{c}0.319^{* * *} \\
(3.24)\end{array}$ & $\begin{array}{c}0.752^{* * *} \\
(3.95)\end{array}$ \\
\hline Liquidity Measure & \# Ships & \# Ships & \# Ships & \# Ships \\
\hline Controls & & & & \\
\hline Subsector & Yes & Yes & Yes & Yes \\
\hline Firm-Subsector Fleet & Yes & Yes & Yes & Yes \\
\hline Fixed Effects & & & & \\
\hline Country×Time & Yes & Yes & Yes & Yes \\
\hline Firm $\times$ Subsector & Yes & Yes & Yes & Yes \\
\hline Observations & 52,684 & 27,780 & 52,684 & 27,780 \\
\hline R-squared & 0.058 & 0.059 & 0.060 & 0.077 \\
\hline
\end{tabular}

Statistical significance is indicated as follows: ${ }^{* * *} p<0.01,{ }^{* *} p<0.05,{ }^{*} p<0.1$. 


\begin{tabular}{|c|c|c|c|c|c|c|}
\hline \multicolumn{7}{|c|}{ Panel B: Accounting for Zero Investment and Disinvestment } \\
\hline & \multicolumn{3}{|c|}{ Investment } & \multicolumn{3}{|c|}{ Disinvestment } \\
\hline & LPM & Logit & ZOIB & LPM & Logit & ZOIB \\
\hline & (1) & (2) & (3) & (4) & (5) & (6) \\
\hline Uncertainty & $\begin{array}{c}-0.044^{* * *} \\
(-4.89)\end{array}$ & $\begin{array}{c}-0.781^{* * *} \\
(-3.77)\end{array}$ & $\begin{array}{c}-0.217^{* *} \\
(-2.19)\end{array}$ & $\begin{array}{c}-0.049^{* * *} \\
(-3.17)\end{array}$ & $\begin{array}{c}-0.241^{* *} \\
(-2.26)\end{array}$ & $\begin{array}{c}-0.220^{* *} \\
(-2.46)\end{array}$ \\
\hline Liquidity & $\begin{array}{c}-0.091^{* * *} \\
(-4.55)\end{array}$ & $\begin{array}{c}-1.174^{* * *} \\
(-3.62)\end{array}$ & $\begin{array}{c}-0.188^{*} \\
(-1.89)\end{array}$ & $\begin{array}{l}-0.004 \\
(-0.56)\end{array}$ & $\begin{array}{c}-0.683^{* *} \\
(-2.41)\end{array}$ & $\begin{array}{l}0.122 \\
(0.93)\end{array}$ \\
\hline Uncertainty $\times$ Liquidity & $\begin{array}{c}0.004^{* * *} \\
(5.26)\end{array}$ & $\begin{array}{c}0.187^{* * *} \\
(4.47)\end{array}$ & $\begin{array}{l}0.043^{*} \\
(1.70)\end{array}$ & $\begin{array}{c}0.014^{* * *} \\
(3.88)\end{array}$ & $\begin{array}{c}0.075^{* *} \\
(2.95)\end{array}$ & $\begin{array}{l}0.018^{*} \\
(1.68)\end{array}$ \\
\hline Liquidity Measure & \# Ships & \# Ships & \# Ships & \# Ships & \# Ships & \# Ships \\
\hline $\begin{array}{l}\text { Controls } \\
\text { Subsector } \\
\text { Firm-Subsector Fleet }\end{array}$ & $\begin{array}{l}\text { Yes } \\
\text { Yes }\end{array}$ & $\begin{array}{l}\text { Yes } \\
\text { Yes }\end{array}$ & $\begin{array}{l}\text { Yes } \\
\text { Yes }\end{array}$ & $\begin{array}{l}\text { Yes } \\
\text { Yes }\end{array}$ & $\begin{array}{l}\text { Yes } \\
\text { Yes }\end{array}$ & $\begin{array}{l}\text { Yes } \\
\text { Yes }\end{array}$ \\
\hline $\begin{array}{l}\text { Fixed Effects } \\
\text { Country } \times \text { Year-Quarter } \\
\text { Firm } \times \text { Subsector } \\
\text { Subsector } \\
\text { Year-Quarter }\end{array}$ & $\begin{array}{l}\text { Yes } \\
\text { Yes } \\
\text { No } \\
\text { No }\end{array}$ & $\begin{array}{l}\text { No } \\
\text { No } \\
\text { Yes } \\
\text { Yes }\end{array}$ & $\begin{array}{l}\text { No } \\
\text { No } \\
\text { Yes } \\
\text { Yes }\end{array}$ & $\begin{array}{l}\text { Yes } \\
\text { Yes } \\
\text { No } \\
\text { No }\end{array}$ & $\begin{array}{l}\text { No } \\
\text { No } \\
\text { Yes } \\
\text { Yes }\end{array}$ & $\begin{array}{l}\text { No } \\
\text { No } \\
\text { Yes } \\
\text { Yes }\end{array}$ \\
\hline $\begin{array}{l}\text { Observations } \\
\text { R-squared } \\
\text { Pseudo R-squared }\end{array}$ & $\begin{array}{c}99,928 \\
0.091 \\
\text { NA }\end{array}$ & $\begin{array}{c}48,693 \\
\text { NA } \\
0.147\end{array}$ & $\begin{array}{l}82,606 \\
\text { NA } \\
0.119\end{array}$ & $\begin{array}{c}99,928 \\
0.057 \\
\text { NA }\end{array}$ & $\begin{array}{l}55,998 \\
\text { NA } \\
0.078\end{array}$ & $\begin{array}{l}82,606 \\
\text { NA } \\
0.061\end{array}$ \\
\hline
\end{tabular}

Statistical significance is indicated as follows: ${ }^{* * *} p<0.01,{ }^{* *} p<0.05,{ }^{*} p<0.1$. 